Linköping Studies in Pedagogic Practices No. 34 Linköping Studies in Education and Social Sciences No. 15

Skrifter utgivna av Svenska barnboksinstitutet nr 144

\title{
Framing Education
}

Doing Comics Literacy in the Classroom

\author{
Lars Wallner
}

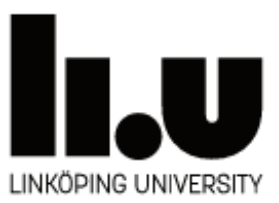

Department of Social and Welfare Studies 
Lars Wallner

Framing Education: Doing Comics Literacy in the Classroom

(C) Lars Wallner

Cover illustration: Lars Wallner

On the cover: Linnéa Frejd, Milo Gottfridsson, Iris Stolpe

Printed by: LiU-Tryck, 2017

"Speak of the Bubble: constructing comic book bubbles as literary devices in a primary classroom" is reprinted from Journal of Graphic Novels and Comics with kind permission from Taylor \& Francis.

ISBN: 978-91-7685-419-8

ISSN: 1653-0101 (Linköping Studies in Pedagogic Practices)

ISSN: 0347-5387 (Skrifter utgivna av Svenska barnboksinstitutet)

Distributed by:

Department of Social and Welfare Studies

Linköping University

SE-581 83 Linköping 
Till mormor 



\section{Acknowledgements}

I have more or less always read comics, starting with the Swedish Bamse and Pellefant when I was around four or five, followed by a ten-year run of Donald Duck that my parents helped me read, understand, and enjoy. As a teen I moved on to handed-down $X$ Men, Batman (or Läderlappen, as he was known in Sweden), The Phantom, Superman, and many more, as did many kids my age. However, it was not until my mid-twenties that I actually discovered and started collecting graphic novels, and really understanding the value that they had in telling stories and encapsulating the reader. I am not the most dedicated comic reader among my friends (Joakim Wahlström constantly bests me in that area), but I do enjoy a good comic and a cup of tea.

During my time as a pre-service teacher I was afforded the chance to try using graphic novels in one of my high-school classes due to a supportive mentor at the school, and an encouraging and open-minded tutor at Linköping University (thank you, Thomas Svensk). This experience showed me that not only do teachers have an immense amount of literature available to them that approaches fiction and storytelling in different ways from that of traditional classroom texts, but also that when you hand graphic novels and comics to students, their reactions can be very positive, and the ensuing reading and discussion follows suit.

In the writing of this dissertation, I have encountered many different kinds of comics, graphic novels, web-comics, comic strips, doodles, cartoons and sketches that have inspired and motivated me, as well as so many talented and dedicated artists, scholars, writers, teachers, colleagues, friends, and family members who have supported and pushed me when needed. Much of this dissertation could not have come about without your help.

A special thank you goes to the anonymous teachers and students of Bangalla Secondary School and Duckburg Primary School, who gave me the opportunity to study the everyday work of their classrooms. Without your inspiring work, this dissertation would have had nothing to stand on.

Throughout the past five years, I have had two supervisors, Katarina Eriksson Barajas and Eva Reimers, who've infused in me 
the three pillars of academia: literacy, coffee and conversation. As supervisors, you complete each other, and have given me different perspectives to work with, and freedom to do so. For this, I am very grateful.

Good work also requires good colleagues, and I have had the best possible: Anders Albinsson, Anita Andersson, Mats Bevemyr, Daniel Björklund, Polly Björk-Willén, Linnea Bodén, Ulrika Bodén, Eva Bolander, Mats Brusman, Thomas Dahl, Magnus Dahlstedt, Sara Dalgren, Katarina Elfström Pettersson, Helene Elvstrand, Anna Ericson, Johanna Frejd, Martin Harling, RizwanU1 Huq, Linda Häll, Ingrid Karlsson, Anna Martín-Bylund, Elinor Månsson, Jörgen Nissen, Birgitta Plymoth, Tünde Puskas, Ayaz Razmjooei, Josefine Rostedt, Susanne Severinsson, Linnéa Stenliden, Kirsten Stoewer, and Lina Söderman Lago, and, of course, the administrative, technical and library staff that support us on a daily basis!

Thank you to the SiS-group at Campus Valla for sharing your work and helping me take my first stumbling steps into analysing social interaction: Alia Amir, Mathias Broth, Asta Cekaite, Leelo Keevallik, Mina Kheirkhah, Ali Reza Majlesi, and Maziar Yazdan Panah, and many more.

During my visit to Loughborough University in 2015, I was honoured to have the assistance of the DARG seminar group: Carly Butler, Mirko Demasi, Ann Doehring, Paul Drew, Shani Ellen, Joe Ford, Christian Greiffenhagen, Alexa Hepburn, Emily Hofstetter, Bogdana Huma, Jonathan Potter, Liz Stokoe, and the one and only Derek Edwards.

A special thanks to Jonas Lidheimer (Egmont) and Jane af Sandeberg (Skolvärlden), who enabled me to reach further than I could have done on my own, and allowed me to find teachers and pupils interested in my study.

Many, many people have read and contributed to this text throughout the years, but some have made a more significant impact during key moments: Jakob Cromdal, Mathias Martinsson, Helen Melander, Nigel Musk, Anna Nordenstam, Christina OlinScheller, Maria Simonsson, Michael Tholander, Åsa Warnqvist, Sally Wiggins, and Judith Rinker Öhman and Karen Williams. 
I am deeply indebted to Karin Stolpe, who has been my informal supervisor, right-hand woman, accomplice, training partner, coffee dealer and bollplank for the last five years. Without you, this dissertation probably never could have happened.

A big thank you to all my friends and my family: Mom, who has always been my moral support and guidance, Dad, who imparted me with a love of work making me capable of handling academia, and Leyla, Hugo and Tindra, for your love and support.

Last but not least, to my wonderful wife. I am immensely grateful to have a partner who provides me with a sober perspective on academia and academic writing. You push and encourage me and remind me why I do the work I do, when I need it, and take me down a notch and hold me back when I get ahead of myself.

Norrköping, September 2017

Lars Wallner 



\section{Contents}

1. INTRODUCTION

A SHORT HISTORY OF COMICS 3

COMICS IN THE SWEDISH CURRICULUM

PURPOSE AND AIMS

SIGNIFICANCE

STRUCTURE OF THE TEXT $\quad 10$

2. STUDYING TALK-AS-SOCIAL-ACTION IN THE CLASSROOM 13

A SOCIALlY CONSTRUCTED STUDY 13

DIFFERENT ASPECTS OF SOCIAL INTERACTION 15

$\begin{array}{ll}\text { Discursive Psychology } & 17\end{array}$

Social Interaction and Classroom Studies $\quad 19$

CONCLUDING REMARKS $\quad 22$

3. COMICS, LITERACY, AND COMICS LITERACY 23

WHAT ARE COMICS? 24

Comics Terms 27

The Page, Panel and Gutter - the Visual Structure of Comics 27

Comics in Relation to Picture Books 29

A ViSUAL LITERATURE 34

WHAT IS LITERACY? $\quad 36$

Literacy as Socially Constructed Practice $\quad 37$

Literacy as Ideology $\quad 38$

Literacy Practices and Literacy Events $\quad 40$

One Literacy among Many 40

NEW LITERACY STUDIES AND NEW LITERACIES 41

NEW LITERACIES AND COMICS IN THE CLASSROOM 43

Comics Literacy 45

CONCLUDING REMARKS $\quad 46$

4. EARLIER RESEARCH ON COMICS IN EDUCATION 49

COMICS IN EDUCATION $\quad 49$

Using Comics for Literacy $\quad 52$ 
5. METHODOLOGY AND RESEARCH DESIGN 61

NATURALLY OCCURRING LITERACY INTERACTION IN SCHOOL 61

FINDING A FIELD OF STUDY $\quad 62$

DATA - RECORDING, HANDLING AND STORING 65

Video Observations $\quad 66$

The Field Study $\quad 67$

Data Material 68

Grade 3 - Duckburg Primary School 69

Grade 8 - Bangalla Secondary School $\quad 70$

$\begin{array}{ll}\text { A Note on Materials } & 71\end{array}$

Data Considerations $\quad 72$

Ethical Considerations $\quad 73$

CONCLUDING REMARKS $\quad 75$

6. REPRESENTING THE DATA $\quad \mathbf{7 7}$

TRANSCRIBING VERBAL AND NON-VERBAL INTERACTION 77

Graphic Transcripts $\quad 79$

Translation $\quad 82$

CONCLUDING REMARKS $\quad 83$

7. ANALYSING THE DATA 85

ANALYSING ClASSROOM TALK WITH DisCURSIVE PSYCHOLOGY 85

COLLECTIONS OF DATA $\quad 88$

CONCLUDING REMARKS $\quad 90$

8. SUMMARY OF PAPERS

PAPER I: KID FRIENDLY? 91

Construction of Comics Literacy in the Classroom 91

PAPER II: GUTTER TALK 93

Co-constructing Narratives Using Comics in the Classroom 93

PAPER III: SPEAK OF THE BUBBLE 95

Constructing Comic Book Bubbles as Literary Devices in a

Primary School Classroom. 95

9. CONCLUDING DISCUSSION 97

COMICS LiTERACY IN THE CLASSROOM $\quad 97$

$\begin{array}{ll}\text { What Signifies Comics Literacy } & 97\end{array}$ 
Doing Comics Literacy in the Classroom 101

Teachers' Work with Comics Literacy 105

FUTURE STUDIES 107

FINAL THOUGHTS 109

10. SVENSK SAMMANFATTNING

BAKGRUND 111

SYFTE OCH FRÅGESTÄLLNINGAR 112

TEORETISKA PERSPEKTIV 113

Social interaktion och diskursiv psykologi i klassrummet 113

Vad är en serie? 114

Serien som visuell literacy $\quad 115$

Vad är literacy? 116

New Literacy Studies och new literacies $\quad 117$

Comics Literacy - serie-literacy 119

FORSKNING OM SERIER I SKOLA 119

Serier för literacy $\quad 121$

METOD, DATAINSAMLING OCH DELTAGARE 122

RESULTAT 123

DISKUSSION 123

Serie-literacy i klassrummet $\quad 124$

Framtida studier $\quad 128$

$\begin{array}{ll}\text { Avslutningsvis } & 129\end{array}$

\section{REFERENCES}

PUBLICATIONS INCLUDED IN THE THESIS

APPENDICES 1-6 



\section{Introduction}

The latter half of the twentieth century experienced an alteration in the definition of literacy. [---] From road signs to mechanical use instructions, imagery aided words, and at times even supplanted them. Indeed, visual literacy has entered the panoply of skills required for communication. Comics are at the center of this phenomenon.

(Eisner, 2008b, p. xv)

In the past thirty years, comics ${ }^{1}$ have seen a rise in cultural literary status (Saguisag, 2017). Meanwhile, they have received broader public recognition, while keeping a steady base of dedicated fans who purchase, read, and collect comics, as well as engaging with other readers on- and offline (see Pustz, 2017). Comics creators and artists such as Stan Lee (Captain America, Iron Man, Spider-man, and more) and Bob Kane (Batman), or Swedes such as Liv Strömquist (Einsteins fru) and Nanna Johansson (Välkommen till din psykos) have become more familiar names among the public. In the case of Lee and Kane, their creations have reached a wider audience through major motion pictures, video games and television shows, while Strömquist and Johansson have been more active through social media, often using their art to inspire political debate. With these new media - films, video games, television and the Internet - comics narratives reach more prospective readers now than ever before (see, e.g., Pustz, 2017).

\footnotetext{
${ }^{1}$ I will continuously use the term comics here, to represent all forms of comic books, comic strips and graphic novels being discussed, although the empirical materials used are in the form of comic books and comic strips. In this, I follow Douglas Wolk (2007), himself aligning with "people who actually make them [comics]" (61).
} 
During the manga boom of 2002-2010, publishing of Japanese and Korean comics in Sweden flourished with an increase in published titles of over $400 \%$ between 2002 and 2006 (Warnqvist, 2012). Even though the manga craze quickly died down and comics have been in a steady decline since 2008, they now seem to have been revitalized, with an increase in publications of $50 \%$ between 2014 and 2015. Spearheading this has been a dramatic increase in published comics aimed specifically at younger children (ages 6-9) (The Swedish Institute for Children's Books, 2016).

The format of comics has also undergone a change throughout the past century. The traditional newspaper comic strip, such as Peanuts or Calvin and Hobbes, still consists of two to four panels, each with its own content, purpose or message, and characters interacting. However, today's comics are often published as colourful, glossy issues collected as trade paperback or hardcover graphic novels; autobiographical novels are created as graphic novels, and webcomics are plentiful and varied.

This dissertation is about reading and writing in school, classroom talk, and comics. Most people who attend school read a book or two during that time. In any given context, cultural ideology structures the norms of literacy and literature, but one cannot view these structures as deterministically binding for the individuals therein. This means that the literature lists of any school are bound to change over time, as what is considered to be literature changes. This dissertation engages with the field of New Literacy Studies (NLS) (Gee, 1992; Street, Pahl, \& Rowsell, 2011) which deals with "social, cultural, political, economic, and psychological processes" (Bloome, Katz, Hong, May-Woods, \& Wilson, 2003, p. 385). Literature and literacy are not seen as a given set of practices; rather literacy is seen as something socially and contextually constructed. With this view, the dissertation aims to investigate the locally situated literacy practices of pupils and teachers, and their methods and ways of doing classroom interaction with comics.

The research paradigm of NLS separated itself from previous research around literacy in the 1980s and 1990s through a shift in perspective from viewing literacy as an individual cognitive skill, to seeing it as a sociocultural activity (Street, 1993). Furthermore, 
the added perspectives of the so-called new literacies and multimodality opened the door for images, gestures, and other nontext print and media to be explored as forms of literacy (Jewitt, 2008; Street et al., 2011). This, in turn, has paved the way for researchers interested in comics as a form of literature, and opens up new perspectives and pathways for investigating comics and their use for literacy practices.

\section{A Short History of Comics}

There is a great deal of work on the history of comics as both an art form and a literary form. I will not go into it all here ${ }^{2}$, but mainly give the reader a short introduction to comics' history, so as to create context.

When comic art was born is highly debated, and presumably impossible to know exactly. Some credit Rodolphe Töpffer (17991846) as the first comics artist, whereas comic books as we know them today saw the light of day in the 1920s and 1930s (Duncan, Smith, \& Levitz, 2015). Superhero comics and Disney animal comics made up the majority of sales during the 1940s (Duncan et al., 2015), and at that time the overwhelming majority of children read comics (Sones, 1944). However, after the Second World War, a debate arose, primarily in the United States, although it came to spread to other countries as well. This debate took up, among other things, the immorality of comics and their depictions of superheroes, which were viewed by some as extensions of fascism and as glorifying violence (Tilley, 2012). This was by no means a new phenomenon. Comics had been criticized for a few decades before this (Sabin, 2001), but as publishers widened their range of publications to include horror and crime, in an effort to reach a wider (older) audience, reactions came from the public that comics

\footnotetext{
${ }^{2}$ For those interested in learning more, I recommend Gene Yang's website Comics in Education (http://geneyang.com/comicsedu/), Roger Sabin's (2001) Comics, Comix \& Graphic Novels: A History of Comic Art, and Part 1 of Frank Bramlett, Roy T. Cook, and Aaron Meskin's (2017) The Routledge Companion to Comics, wherein you will find concise histories of the development of comics in different countries.
} 
were inappropriate reading materials for children (Groensteen, 2007, 2009; Tilley, 2012; see also Sabin, 2001).

The US anti-comics movement waged a crusade against the comic book industry, similar to that against the film industry (see Thrasher, 1949). This culminated in psychiatrist Fredric Wertham's Seduction of the Innocent (1954), where comics were accused of promoting juvenile delinquency, something that did not pass without criticism (Thrasher, 1949; see also Tilley, 2012). Although Wertham may not have intended it, this would eventually lead to the introduction in the US of the Comics Code Authority that same year, an agreement between publishers meant to act as an assurance for concerned parents that comic books did not contain any harmful elements (Beaty, 2004; Duncan et al., 2015; Miodrag, 2017). This resulted in many shops that sold comics losing business, and comic writers became severely limited in what they could write about.

Despite a severe blow to both publishing and readership during the 1960s and 1970s, some publishers adapted to the demands of parent groups and became more commercial and family-friendly, while others took the route towards alternative art and comics (see C. Hatfield, 2005; Sabin, 2001), and the comic book again began receiving literary and educational attention. Charles Hatfield writes that the 1960s were a quiet time for comics scholarship, while the 1970s saw a new interest in comics as material for reluctant or disabled readers (2006). Thierry Groensteen (2009) claims that the educational and cultural turning point for comics was the publishing of Antoine Roux's La bande dessinnée peut être educative in 1970.

In the 1980s, two important things happened: comic books were for the first time bound and printed in novel-length, such as Frank Miller's The Dark Knight Returns (1986/1987), Alan Moore and Dave Gibbons' Watchmen (1986), and Art Spiegelman's Maus: A Survivor's Tale (1986), with novel-length storylines rather than collections of comic strips (which had been common before). Second, these comics also marked a change in tone, to more brutal and graphic depictions of formerly known characters such as Batman, and a more self-reflective view of the medium itself (Sabin, 2001). The change in format made it easier for shops and libraries to store comics (Sutliff Sanders, 2013), and the change in 
tone from a previously child-friendly one in the 1960s and 1970s, to a more adult-oriented style in the 1980s and 1990s increased the diversity of the comic book audience (Sabin, 2001). Further increases in interest in the comic book during the 1990s and the first decade of the 2000s could be attributed to many causes: the popular surge in Japanese manga, the many comic book film adaptations, as well as an increase in webcomics and new forums for fans of the medium to meet (Saguisag, 2017).

Although they are still not quite on a cultural par with novels, poetry or short stories, the status of comics has undergone a gradual change. Comic studies as a valid field of scholarly research started picking up in the 1990s (Lent, 2010), and today it is an established area in many parts of the world (e.g., Beaty, 2004; Cohn, 2014; Groensteen, 2007; C. Hatfield, 2006; Meskin, 2007; Platz Cortsen, 2012; Postema, 2013; Sousanis, 2015; Strömberg, 2007) ${ }^{3}$. Bart Beaty compares the academic study of comics to a toddler "taking its first steps towards maturity" (Beaty, 2004, p. 403). Today, it is relatively easy to find websites and printed materials advocating the use of comics for educational purposes ${ }^{4}$, but it is more difficult to find underlying empirical research on children using comics.

\section{Comics in the Swedish Curriculum}

Although the current dissertation is not intended to be study of a specific national or cultural context, and the results from the analysis are thought to be valid for other contexts as well, it may prove interesting for the reader to be introduced to the cultural setting of the study.

Along with the changes in comics' form and audience, they have also garnered more attention as materials for teaching. Comics

\footnotetext{
${ }^{3}$ I will not delve deeper into the historical development of comic studies as an academic discipline, but for those interested I recommend Charles Dierick and Pascal Lefèvre (1998), Randy Duncan, Matthew Smith \& Paul Levitz (2015), Will Eisner (2008a), Santiago García (2015), Groensteen (2009), and John Lent (2010).

${ }^{4}$ Examples of websites offering tools for working with comics in the classroom: http://comicsintheclassroom.net, http://grammarmancomic.com, http://www.educationworld.com/a_lesson/00-2/lp2289.shtml, http://www.educomics.org
} 
as school material is nothing new, it has existed (in the United States) since at least the 1920s (Tilley \& Weiner, 2017). In Sweden it was the 1970s, which saw a surge of new comics with the introduction of French and Belgian comic book albums such as Hergé's Tintin and Goscinny and Uderzo's Asterix (Magnusson, 2005). This led to a discussion on the educational value of comics, and many publishers, writers and artists started producing comics for educational purposes, the most influential and long lived among the Swedish ones being Rune Andréasson's Bamse, which took "ideological and ethical positions" (Magnusson, 2005, p. 221). Furthermore, Bamse explicitly addressed the child reader both through its narrative and through aspects such as answering fan mail, etc. Thus, comic book publishers, in Sweden and elsewhere, have long had child readers and their education in mind, but little is known about the use of comics for educational purposes (Tilley \& Weiner, 2017).

Looking at the policy documents (curricula and, as an example, the commentary material for Swedish) for compulsory school in Sweden (Swedish National Agency for Education, 2011a, 2011b) reveals that comics have generally been left out by educational policymakers, and it seems that comics exist mostly on the fringe of curricula, as examples of literary genre.

In the knowledge area "storytelling texts and prose" different types of texts are mentioned, which the education should contain and from which teaching can emanate when pupils are developing writing strategies. Texts in which word and picture collaborate include picture books and comic books. (Swedish National Agency for Education, 2011 b, p. 12 , translation by author) ${ }^{5}$

In the past ten years, official reports on literacy in Sweden (U. Carlsson \& Johannisson, 2012; SOU, 2012:65) point to concerns about decreasing literacy competence and reading habits among young people, and these reports demand that attention and effort be

\footnotetext{
${ }^{5}$ Swe: I kunskapsområdet "Berättande texter och sakprosatexter" nämns olika typer av texter som undervisningen ska behandla och som undervisningen kan utgå från när eleverna utvecklar strategier för att skriva. Texter där ord och bild samspelar kan till exempel vara bilderböcker eller serietidningar.
} 
put into further motivating reading. In the reports, it is claimed that children who say that they frequently read comics are more likely to also read other types of texts (U. Carlsson \& Johannisson, 2012; SOU, 2012:65). However, it is not clear how this conclusion is drawn, as the causality is not clearly shown. Thus, it has not been decisively shown what the link is between reading motivation and comic books, and further systematic study of this is needed.

At the same time, comics have been given more attention in the past decade within the Swedish literature community, public as well as academic. At the annual Swedish International Book Fair, comics are well represented, and the Swedish Comics Association (Swe: Svenska Seriefrämjandet), which has been active since 1968, has held a separate stage for comics-related events, presentations and talks since $2010^{6}$. Academically, the Nordic Network for Comics Research (NNCORE) has been active since 2011, hosting conferences bi-annually ${ }^{7}$. Since 2015 the Swedish Institute for Children's Books (Swe: Svenska barnboksinstitutet) has hosted an annual half-day event about comics for children and youth ${ }^{8}$ as an introduction to the two-day Swedish Comic Book Festival, which has been an annual event since $2000^{9}$. There is currently one Nordic journal on comics, the Scandinavian Journal of Comic Art established in 2012, and there have been ten $\mathrm{PhD}$ dissertations from the Nordic countries, most of them from 2000 onwards (Strömberg, 2016), one of which was from Sweden: Helena Magnusson's Telling Pictures (Swe: Berättande bilder) in 2005. None of the dissertations has examined comics in the field of education.

With all this attention being given to comics in the past decade or so, and the format starting to make an impact on the reading community, it is no wonder that policymakers and teachers have begun to view comics as possible material for the classroom.

\footnotetext{
${ }^{6}$ See http://serieframjandet.se

${ }^{7}$ See http://www.nncore.com

${ }^{8}$ Link to the yearly half-day on comics (Swedish): http://www.sbi.kb.se/sv/Aktuellt/Kalendarium/Program-pa-Sbi---halvdag-omserier/

${ }^{9}$ Link to the Comics Festival website: http://www.seriefestivalen.se/english/
} 


\section{Purpose and Aims}

The purpose of this study is to generate knowledge on how locally situated literacy practices - in which pupils and teachers make meaning with comics - are done. In order to accomplish this, I analyse interaction in classrooms to understand the function of comics in participants' literacy constructions.

Research questions in discursive psychology (DP) typically take the form How is $X$ done? (Wiggins, 2017). In the current study, the research questions are empirically driven and connected to the overarching purpose and aims of the project. The main purpose of the study is divided into three research questions, emanating from the analytic process, and explored in the individual papers:

- How do classroom participants construct discourses around comics as part of their literacy practices?

- How do participants construct aspects of narrative as part of their literacy practice with comics?

- How do participants construct aspects of visual literacy when working with comics in the classroom?

The study combines the fields of literacy, comic studies, and DP, and applies these to naturally occurring classroom interaction (Hepburn \& Potter, 2004; Potter, 2010). To investigate how comics are used in education, what discourses are constructed, and what actions are done, the study sets out from a discursive psychological perspective, studying how participants talk about aspects of literacy to perform social actions (Edwards \& Potter, 1992; Hepburn \& Potter, 2004; Potter, 2010). Here, these aspects are exemplified through DP features such as assessments (Wiggins, 2017), but also less explored aspects, such as constructions of literacy and narrative. As a discursive perspective has previously been used to study reception of fiction, such as novels and film (Allington, 2012; Eriksson Barajas, 2008, 2015; Eriksson, 2002a, 2002b), the current study adds to these perspectives both by studying meaning making with comics as a fictional material, and by using a multimodal perspective on interaction and literacy.

Furthermore, as much of the study of comics has been done from a cognitivist perspective, or has theorized about how readers 
read comics (see Chapter 4), it is essential to also study this as an ongoing practice. Here, DP becomes an important perspective for investigating participants' talk about reading, and how they construct aspects of literacy, such as narrative structure. DP provides the theoretical perspective of meaning making as social action in talk as well as the methodological tools of social interaction and detailed transcription.

The present study looks at the interaction between comics, teachers and pupils, how interaction with this material happens, and what social actions are constructed within this practice. Therefore, a multimodal analysis of this interaction (to study meaning making with materials, embodied actions, gaze and verbal talk), from a discursive psychological perspective (to bring possible discourses around literacy to light), can help in addressing the above questions.

\section{Significance}

National steering documents stress that teachers play an important role in ushering young children into a world of literature, fictional and non-fictional. Reading promoters, such as Aidan Chambers (1985), argue that "the adults who stand between children and books make us into the kind of readers we become. The adults who do this best put before children all kinds of story" (p. 132). As government gatekeepers of literature (cf. Sutliff Sanders, 2013), teachers and librarians (and, really, all adults) have a responsibility to consider the needs and literary desires of the individual child in the classroom, and this means having knowledge of a wide array of literary formats and stories.

The present study rests on three main areas: literature and literacy in education, social interaction and DP, and the field of comic studies and children's literature. It brings together concerns about comics and education by studying pupils' social practices and their use of comics. Moreover, going beyond much of the existing research on these issues, it links the study of literacy and interaction of pupils to their everyday experiences at school. The findings and the discussion make a contribution to the study of literacy practice from the perspective of social interaction (cf. 
Brienza, 2010) by investigating the practical use of comics as a literary form in school.

Description and justification are often difficult to separate, and the former often becomes some type of the latter (Hepburn \& Potter, 2004). This dissertation is not meant to be a how-to guide, or any kind of best practice, nor a justification of existing theories concerning comics in education. However, it is my wish that teachers working in the field will find this research useful in their practice, and find arguments for using, or not using, this type of material in their teaching. As Alexa Hepburn and Jonathan Potter put it: "the hope, of course, is that [studies] are used by people to help with their practice", but that the readers also approach this offered help with a sensible academic, sceptical view (2004, p. 182, emphasis in original).

\section{Structure of the Text}

The presentation of this study is divided into two parts. The first part details and discusses the theoretical and methodological approaches to the study, previous research on comics in education, and a discussion of the results of the study. In this Introduction, I present points of departure, problem areas, as well as the purpose, aims, focus and general outline of the study. In Chapter 2: Studying Talk-as-social-action in the Classroom and Chapter 3: Comics, Literacy, and Comics Literacy, I present the theoretical frameworks utilized throughout the dissertation. Chapter 4: Earlier Research on Comics in Education outlines previous methods, results and theories used by other researchers interested in the subject area. Chapter 5: Methodology and Research Design describes and discusses methodological considerations: presenting the context of study, the two schools and the participants, as well as discussing ethical considerations. In Chapter 6: Representing the Data, I clarify the methods of transcription used throughout the study, and discuss choices made in this process. Chapter 7: Analysing the Data details and discusses my approach to the analysis of the data material, discusses data collection and how findings were analysed. Chapter 8: Summary of Papers I-III offers a brief outline of each of the individual research papers. Finally Chapter 9: Concluding Discussion addresses a selection of themes related to the aim and 
the results of the overall study, in relation to theory on literacy. There is also a Swedish summary (Chapter 10: Svensk sammanfattning), for the Swedish-speaking readers.

The second part of the dissertation presents the empirical and analytical work of the dissertation in the form of three independent papers. These papers represent investigations of data, exploring different aspects of the use of comics in school, sharing general methodological, epistemological and ontological foundations, as well as theory on comics, even though they analytically diverge into independent lines of thought. The papers represent a progression where the first paper explores what constitutes comics literacy and discourses on comics constructed in the classroom (Paper I), followed by two papers exploring different visual means of working with comics narratives (Paper II \& Paper III).

In sum, comics are a broad literary form accessible to all age groups, and this form has garnered more interest as classroom material. In the following text, I will detail the theoretical perspectives used in the dissertation, as well as demonstrate how teachers and pupils make meaning with comics as a literary format. 



\section{Studying Talk-as-social-action in the Classroom}

It is through the daily interactions between people in the course of social life that our versions of knowledge become fabricated.

(Burr, 2015, p. 4)

Investigating "practical actions as contingent ongoing accomplishments of organized artful practices of everyday life" (Garfinkel, 1984, p. 11) is a reliable way of understanding social interaction. Studying situated classroom practice is a natural part of any research on pedagogical work interested in what is being done in the classroom (cf. Mehan, 1979). This chapter demonstrates the theoretical approaches of the present study, and how these theories are utilized for studying and understanding classroom activities. Furthermore, the theoretical perspective is discussed in relation to the study of literacy and the benefits of looking at literacy practice through an interactional lens.

\section{A Socially Constructed Study}

The present dissertation is based on the epistemological perspective of social constructionism originating from Peter Berger and Thomas Luckmann (1967), G. Nigel Gilbert and Michael Mulkay (2003), and Jonathan Potter (1996). This perspective supposes that our knowledge and understanding of the world is not objective, but that knowledge is socially constructed. As problematized by Ian Hacking (1999), Berger and Luckmann's title The Social Construction of Reality is perhaps ill-chosen, as it is not the physical, but the social reality that is referred to in their book. However, as Berger and Luckmann themselves clarify, "the sociology of knowledge must concern itself with whatever passes for 'knowledge' in a society, regardless of the ultimate validity or 
invalidity (by whatever criteria) of such knowledge" (1967, p. 3). Because people's perceptions of knowledge influence how they act in society, our role as social science researchers is to study this perception (and the effects of it), regardless of whether it is based on reality. Unlike Berger and Luckmann, however, the present analysis is focused specifically on in situ constructions of text and talk, rather than interviews and personal accounts that participants give there (see also Hepburn \& Potter, 2008; Potter, 1996). For example, Jonathan Potter (1996) acknowledges Berger and Luckmann's contributions to the theory of social science, but criticizes the fact that their book lacks analysis, that it emphasizes people's cognitivist perspective, and that accounts are re-told through interviews, which obscures "the interactional and rhetorical nature of fact construction" (Potter, 1996, p. 13). Gilbert and Mulkay (2003), in their investigations of the discourses of science, similarly emphasize the focus of social constructionism on discourses as topics of participant talk and text, rather than discourses as resources for participants to draw upon. Thus, the analysts take a step away from the cognitivist perspective of mind as expressed (Berger \& Luckmann, 1967), and focus on the constructionist perspective of mind as constructed (Gilbert \& Mulkay, 2003, p. 13). Regardless of whether or not the truth is actually out there, it is the knowledge constructed between people in everyday social practices that matters, and this can be empirically investigated (Burr, 2015). For the present dissertation, this is an important differentiation from other studies of classroom literacy and comics, which have focused on the individual decoding of text, effect studies of learning with comics, and other cognitive perspectives (see Chapter 4).

Based on the philosophy of language as formulated by Ludwig Wittgenstein (1981), social constructionism supposes that people not only construct their versions of knowledge, but also construct social action through this knowledge construction - their knowledge of the world informs their own, or others', decisions to act upon that world. Therefore, language - through which we understand the world around us - also plays a role in constructing that world (Burr, 2015). 
This dissertation engages with participants' construction of aspects of literacy, such as narration, structure, etc., as related to the use of comics. The study does not make ontological claims about "inner" thoughts or emotions (whether existing or not, what they are, etc.), but rather how these aspects are constructed between participants to perform actions (Potter, 2012). This rests on the principles of social constructionism within the field of social psychology (see, e.g., Gergen, 1973) and DP (Edwards \& Potter, 1992; Potter, 1996). Discourses constitute the different manners in which "[w]e communicate with one another, express our desires and fears, and come to understand others' feelings and concerns" (Potter, 2012, p. 120), and these can be studied as they are continually constructed and re-constructed between participants. Unlike objects of natural science, such as rocks or trees, objects of social science, i.e. people, are aware of their status as objects of research and, therefore, may alter the behaviour being studied so as to appear favourable in the eyes of the researcher (Gergen, 1973). Thus, researchers must view social science and human behaviour as historically, socially and culturally situated, and study practices as they are performed; they must not strive for all-encompassing laws of interaction or mental states. Social psychologists study people as constructing themselves in everyday practices, rather than expressing an inner "personality" (Gergen, 1973). Thus, exploring how participants do literacy practices, the current study engages with this as social construction rather than investigating how the individual creates sequential narratives in their mind (cf. McCloud, 1993).

\section{Different Aspects of Social Interaction}

When studying interaction, we find that participants utilize different modes of communication, gestures, gaze, tone of voice, the words they speak or write, as well as the use of physical materials (such as images). This perspective is called multimodality (see, e.g., Goodwin, 2000; Goodwin \& Goodwin, 2013). Small children without a functioning verbal language learn early on to use their body language to communicate (see, for a few examples, Andrén (2010), Dalgren (2017), and Hildén (2014)), but this does not mean they lose these other ways of communicating once they 
have developed a verbal language. Instead, they refine and develop these other methods based on cultural and social custom. In the context of this thesis, it is important to emphasize multimodality as a research tool for investigating talk-as-social-action as the "evidence for the organizational machinery of lessons is to be found in the words and in the gestures of the participants" (Mehan, 1979, p. 24).

This has not always been self-evident. In its early stages of investigating how participants make sense of talk, conversation analysis (CA) began by analysing telephone calls (Sacks, Schegloff, \& Jefferson, 1974) and analysts focused on the words spoken, the use of pauses, and other verbal phenomena. In this way, researchers outlined how participants methodically make sense of each other's actions (Sacks, 1992; Sacks et al., 1974; Schegloff, Jefferson, \& Sacks, 1977). Over the next forty years, the study of social interaction expanded - through the development of technology such as high-definition video cameras, small lightweight audio recorders, the ability to store large quantities of digital data, etc. (see, e.g., Mondada, 2006) - to also include the study of multiple modalities utilized in participant talk; thus, CA came to be able to analyse participant talk as something that employs all of the communicative resources available to participants (Goodwin, 2000, 2013; Goodwin \& Goodwin, 2013; Stivers \& Sidnell, 2005). This was "a consequential move for a discipline which aims at a comprehensive understanding of human interaction and which sets as its goal to uncover the practices by which social interaction is produced" (Deppermann, 2013, p. 2). Given that meaning making in any conversation involves speakers interpreting each other's actions as a whole, participants could be held accountable for both verbal and non-verbal talk (Enfield, 2011), and analysts now had the tools to study this.

These tools give us greater ability to discern participants' own perspectives on talk. Owing to our daily use of combinations of modalities, it is sometimes difficult to specify one gesture or one word as the action that the participant responds to, because "grammar and body movements are complementary devices of sense making ... and sometimes they cannot be analysed separately without losing the essence of what is conveyed" (Keevallik, 2013, 
p. 3). Thus, the study analyses video and audio recordings (see Chapter 5) to capture as much as possible of the ongoing interaction. Transcripts have been made accordingly, trying to represent the "relevant levels of detail" (Hutchby \& Wooffitt, 2008, p. 80) to convey to the reader both the visual and audible sensations the participants experience (for further discussion of transcription conventions, see Chapter 6). This means combining two perspectives with slightly different foci - multimodal social interaction and multimodal literacy - used in different ways depending on one's theoretical stance. Within social interaction studies, a multimodal perspective engages with participants' practices, and how they communicate by engaging with multiple modalities, as described above. Within literacy studies, multimodality can be viewed as "having its gaze fixed on texts and our use and production of texts", and engaging with "practices, that is how texts are used in different spaces and contexts" (Street et al., 2011 , p. 200). In this way, the multimodality of these two perspectives (interaction and literacy) comes together in its focus on the intersubjectivity between people, and people and texts. The combination of these two perspectives in this study follows the work of, for example, Gemma Moss (2003), who studies participants' reading and interaction around multimodal texts, where both the text and the interaction are viewed and analysed as multimodal.

\section{Discursive Psychology}

DP developed out of the laboratory environments of social psychology (see Edwards \& Potter, 1992), both in an attempt to study psychology in the "real" world, and to shift the perspective from studying expressions of inner mental states, to looking at how participants utilize psychological terms and "produce versions of their mental life - their motives, beliefs and so on" in order to perform actions in talk (Potter, 1996, p. 13; see also Billig, 2009; Edwards, 1996). As Potter (2012) writes:

Rather than seeing its fundamental analytic aim as being to attempt to open up the mythic black box where psychology has been thought to 
be hiding [---] it is focused on the public realm to which people have access when they are dealing with other people. (p. 120)

Thus, DP takes a participant-oriented perspective, exploring how participants themselves make sense of social action through their talk. Since its emergence in the 1980s, DP has developed into different strands of interest and methodology (Potter, 2012; Wiggins, 2017). The strand utilized in the current dissertation borrows methodologically from $\mathrm{CA}$ by conducting systematic studies of talk-in-interaction, using detailed transcriptions inspired by Gail Jefferson (2004; see also Potter, 2012). However, while CA focuses on systematic use of language for the structure of social life (Hutchby \& Wooffitt, 2008), DP is particularly interested in issues of psychology and the construction of local discourse (Wiggins \& Potter, 2007). For example, as one of the foundational works in DP, Jonathan Potter and Margaret Wetherell's Discourse and Social Psychology (1987) explores participants' construction of social categories, and, for example, accounting for dispreferred responses. As researchers we cannot investigate a participant's mind and see who they are, but we can explore how they construct themselves; their ideas, emotions, and opinions, and we can discern patterns in their communication with others (or in text). This allows us to find patterns (discourses) of talk where, as Potter and Wetherell's example shows, participants categorize themselves as not racist thereby constructing both themselves in a certain way, but also constructing local discourses in some way (e.g., that they could potentially be perceived as racist, and it is important for them not to be perceived as such).

In the current study, discourse should be understood as spoken interaction and written text (Potter \& Wetherell, 1987), the social area wherein people make sense of one another (Potter, 2012). Discourses are considered situated and culturally constructed (Potter, 2012), rather than ideologically based or institutional (Heritage, 2004; Peplow et al., 2016: chap 5). This means that participants are not assumed to be doing institutional, classroom talk, rather the analysis is focused on participants doing talk (Heritage, 2004), and whether this is done as classroom discourse (or other types of discourse) becomes a question of analysis, and 
the display of participants' own perspectives. Discourses are produced as situated social action, rather than existing irrespectively of members' interactions, and the analysis does not attempt to draw conclusions as to whether or not locally produced discourses are connected to "larger" discourses (for an overview of the different perspectives of discourse analysis, see Wiggins, 2017).

Starting with three primary aspects of interest - action orientation, situation and construction - DP aims to study how psychology is constructed in situated social interaction, i.e. how participants make sense of utterances around mental state, for example "I think" or "I feel" (Edwards \& Potter, 1992; Potter, 1996; Wiggins, 2017; Wiggins \& Potter, 2007). The current dissertation takes an interest in psychology in the form of literacy and how aspects of literacy are constructed through text and talk. Text and talk are considered to be inherent social practices, and discourses are constructed and re-constructed continually by individuals and groups in a cultural and social context with the tools and information at the participants' disposal. The research interest of the current study lies not in whether or not an idea about, say, literary structure is thought up in the individual mind, but in showing how individuals socially construct ideas of literary structure in interaction, within the context of a group discussion (Edwards \& Potter, 1992).

\section{Social Interaction and Classroom Studies}

An important step in studying interaction in any setting is to determine its social, physical and cultural context. "These contexts are always contexts of practice: it is always necessary to ask what people are doing or trying to do in that context" (Bruner, 1990, p. 118, emphasis in original). Ian Hutchby and Robin Wooffitt outline research around interaction in institutional contexts, or workplace settings, and how participants orient to these contexts. What "characterizes interaction as institutional is to do ... with the special character of speech-exchange systems that participants can be found to orient to" (2008, p. 139). For example, it is not the task of the analyst to decide whether a pupil is being treated as a pupil. Instead, DP analysts take an emic view, wherein the analyst 
considers the participants' own perspective in the talk (Potter, 2003). Therefore, instead of adhering to what is called the "bucket" theory (Heritage, 1987), in which the analyst assumes that institutional context is a pre-existing condition of talk, we need to consider the physical and psychological context as made relevant by the participants (Edwards \& Mercer, 1987).

A common idea is that school is a learning context. The current dissertation employs a social constructionist perspective of educational practice, which views pupils' and teachers' constructions of meaning together in the classroom as knowledge and learning (cf. Barnes, 1976) - but readers should note that this practice is not dependent on the institutional setting of a school. Interactionally, the construction of meaning making can be evinced through participant response and uptake (Sacks, 1992; Sacks et al., 1974) - through, for example, epistemic claims or epistemic authority developing over time (cf. Melander, 2012; Melander \& Sahlström, 2010). Thus, teaching and learning are not meant to be understood here as a transfer of subject content (for example, what reading is) from a teacher to a pupil, but rather as a co-construction of meaning and discourses (Edwards \& Mercer, 1987), where what encompasses reading is constructed and re-constructed. Douglas Barnes (1976) argued that "language as a means of learning" is about "making the learner [...] an active participant in the making of meaning" (p. 31). "Through language we both receive a meaningful world from others, and at the same time make meanings by re-interpreting that world to our own ends" (p. 101). Interactionally, sharing/replying and presenting/assessing are two different pairs in communication. Whereas some have viewed classroom interaction as primarily based on presenting/assessing (cf. the analysis of Initiative-Response-Evaluation (IRE) sequences, in e.g. Margutti and Drew (2014), McHoul (1978), and Mehan (1979)), Barnes (1976) suggests that a classroom where sharing and replying are being done leaves more room for open communication and establishment of shared knowledge. Thus, the view of learning in the current dissertation is one of learners as participants in meaning making.

There are always multiple discourses at work in any setting, as teachers and pupils collaboratively construct their social 
environment. For example, Hugh Mehan (1979) demonstrates that successful classroom participation is about more than subject knowledge. It is also about social competence, that is, knowing when to speak and when not to, knowing when to raise your hand, etc. Derek Edwards and Neil Mercer (1987) argue that participants in any classroom must make sense of a classroom wherein discourses around proper language use, seating arrangements, social etiquette, subject knowledge, etc. all must come together, and how these participants construct joint knowledge of this social practice.

This dissertation studies social interaction as material for literacy practices. Sociologist and linguists during the 1980s while studying oral literacy (i.e., becoming part of an oral communicative culture, but not a reading one), or cultures with large differences between literates and non-literates - made connections between cognitive development and literacy skills (see, e.g., Scribner \& Cole, 1981; Street, 1984). When doing research on literacy in school, common approaches include observations of individual reading, reading groups and book reviews/analyses presentations, in which pupils' results, opinions, or attitudes are in focus (for a review on this work specifically to do with comics, see Chapter 4). However, during the past twenty years, researchers using an interactional approach have also investigated the social practices of literacy groups in school contexts (Eriksson Barajas \& Aronsson, 2009; Eriksson, 2002a; Sabeti, 2011; Simonsson, 2004), analysing groups' situated interaction with and around the literary medium. The current dissertation uses this latter approach, taking part in the paradigm of NLS (Gee, 1992, 2000, 2002; Street et al., 2011), which makes a shift in perspective from previous forms of literacy theory (see, e.g., Lankshear \& Knobel, 2011). NLS approaches classroom literacy as activities within a social and cultural context, rather than as a study of individuals' mental processes in relation to reading and writing. To do this, this study investigates how literacy is continually socially constructed and reconstructed, by participants, in in situ classroom situations. This will be further explored in Chapter 3. 


\section{Concluding remarks}

In sum, this chapter has described the social constructionist basis of the current dissertation, how the theoretical and methodological perspectives of DP originate from and relates to, social constructionism, and what consequences the use of these theoretical perspectives has for the study of classroom interaction between pupils and teachers. It has been shown how multimodal interaction: verbal talk, embodied movements, gestures, gaze and non-verbal talk (sounds, such as sighs), and aspects of moving the material or pointing to it, are considered when studying interaction.

This chapter has also described how DP is used to investigate aspects relating to literacy as a social practice in school. The present analysis focuses on how participants construct discourses of comics literacy, narrative structure in comics, and speech and thought bubbles as literary devices. In this way, the analysis examines participants' actions and literacy activities in their natural context, rather than the individual minds of the participants. DP allows the researcher to combine the two interests of literacy and social interaction. In the next chapter, I will address and discuss how theories on literacy, more specifically, NLS and new literacies, relate to literacy practices and the use of comics in the classroom. 


\section{Comics, Literacy, and Comics Literacy}
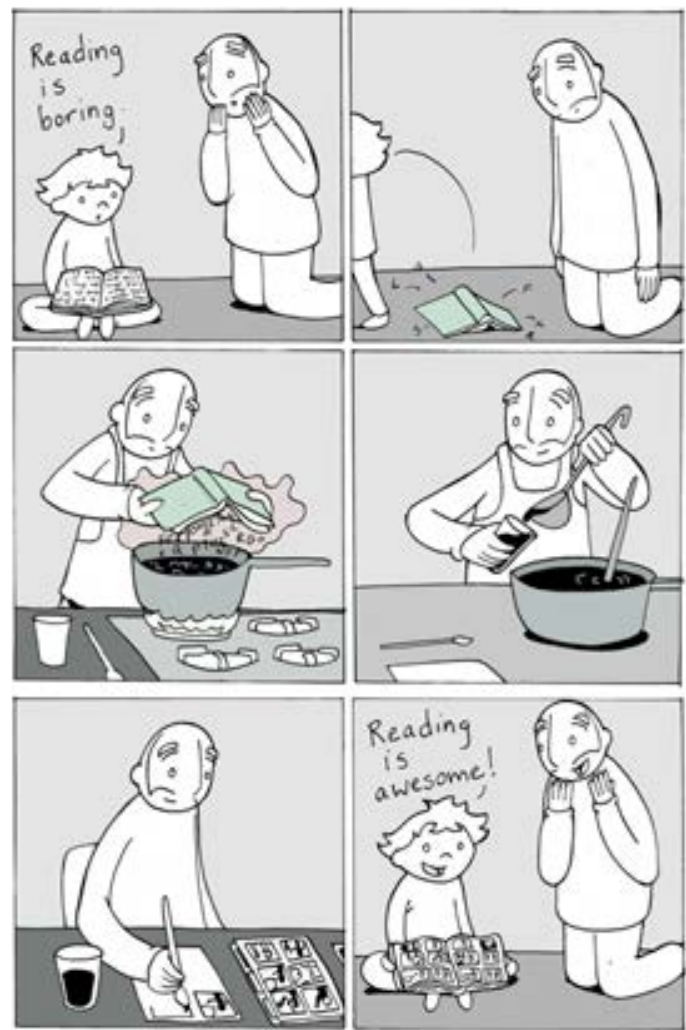

(Lunarbaboon. Graphic. May 14, 2017 (C) Lunarbaboon, used with permission) ${ }^{10}$

In the webcomic Graphic, a child is attempting to read a book and finds it "boring". This troubles his father, who goes to work to redesign (through some creative cooking) the book into a comic, to

${ }^{10} \mathrm{Http}: / /$ www.lunarbaboon.com/comics/graphic.html 
the delight of the child. At this point, one could raise the question of whether these two texts are the same, and whether or not the latter comic book is actually read at all? The current dissertation analyses and deals with questions of comics literacy as a social process of engaging with a visual and textual sequential literary form, using onomatopoetic textual/visual cues and other aspects typical for comics. Hopefully, this will challenge researchers' and teachers' perceptions of literature and literacy.

In this chapter, I discuss the theoretical aspects of what comics are, what literacy is, and how the concept of comics literacy is a result of the theoretical discussion as well as the literacy practices depicted in the empirical data of this study.

\section{What are Comics?}

Comics, comic books, manga, graphica, graphic novels, bandes dessinées, or the funnies: there are many names and definitions for the narrative sequential organization of words and pictures (McCloud, 1993; Meskin, 2007; Thompson, 2008).

Thierry Groensteen's (2007) The System of Comics (orig: Système de la bande dessinée) details a linguistic view of comics as a systematic form of literature for mediating story to readers. "This plasticity of comics", writes Groensteen, "which allows them to put in place messages of every order and narrations other than the fictional, demonstrates that before being an art, comics are well and truly a language" (p. 19). Comic scholars have made several attempts at defining comics, but it always seems to be a daunting task. Groensteen calls it "the impossible definition" (p. 12), Joe Sutliff Sanders (2013) admits that "it's a mess" (p. 58), Aaron Meskin (2017) writes that "it is controversial whether any extant proposed definitions of comics are adequate" (p. 221), and Douglas Wolk argues that with any definition "first, the medium always wriggles across that boundary, and second, whatever politics are implicit in the definition always boomerang on the definer" (p. 17). Even ideas about the origin of comics vary. For example, Scott McCloud (1993) argues for an inclusive definition of comics, including such things as early Egyptian painting, but also differentiates these from what he calls the modern comic, which originated with the invention of printing and, more specifically, 
Rodolphe Töpffer's satirical art work (see also Inge, 2017). Wolk (2007) would probably even disagree with calling comics literature, arguing instead that comics "are their own thing: a medium with its own devices, its own innovators, its own clichés, its own genres and traps and liberties" (p. 14).

Will Eisner (2008a) simply calls comics "sequential art" (p. 1), while McCloud (1993) defines them as "juxtaposed pictorial and other images in deliberate sequence intended to convey information and/or to produce an aesthetic response in the viewer" (p. 9). These definitions both have potential problems. Eisner's is too vague and, as Meskin (2007) argues, all comics are not necessarily art (p. 370). McCloud's definition is also too broad in that it encompasses, for example, Bayeux tapestries, which few people would otherwise include as comics (Meskin, 2007). Furthermore, as Meskin also points out, McCloud also includes intention in his definition, which makes it problematic, as researchers "should not assume a priori that the author or authors of a comic intend either to convey information or to produce an aesthetic response" (p. 370). In her dissertation about Swedish children's comics, Magnusson (2005) writes that the Swedish translation of the word comic book (seriealbum, more accurately translated as serial or sequential album) is more closely related to the terms often used by scholars like McCloud and Eisner, because it emphasizes the sequential nature of comic art. This translation also removes another problem pinpointed by Stan Lee, famous founder of Marvel Comics. He argues that using the two words comic book separately meant that the term comic was used as an adjective, meaning humorous or comical. Instead, he writes, the two should be written as one word: comicbook, a "generic term denoting a specific type of publication" (1993, p. 10). Indeed, the use of sequential or juxtaposed narrative more accurately defines what comics are, rather than requiring humour in the definition. Even this definition, of course, disqualifies some famous examples, such as Gary Larson's The Far Side, which consists (mostly) of single-panel cartoons (no juxtaposition, no sequence). Groensteen (2013) seemingly agrees with the notion that, in order to be a comics narrative, there must be a sequence of events with a beginning and end (although Groensteen argues that this juxtaposition could also take place 
within a single panel). Either way, it would be impossible to find a definition that includes all possible narrative art forms imaginable within the scope of comics (as well as analytically impractical, see Meskin (2007) and Meskin (2017)).

McCloud's (1993) definition would also include picture books, as they can be understood as pictorial images, and the page-to-page images could be viewed as juxtaposed (of course, some picture books today are more like comics than traditional picture books, see Chapter 3, p. 29). However, Magnusson makes a point that it is the comic book reader's ability to "survey" the sequence of images that makes comics (especially for children, as she points out) stand out from other forms of literature (p. 42), and this is similarly emphasized by, for example, McCloud (1993) and Perry Nodelman (2012). The definition used in the current dissertation, surveyable juxtaposed pictorial narratives, is a combination of McCloud's and Magnusson's two perspectives.

Of course, not all comics that the reader has experience of fall under this definition - and that is fine. In the current dissertation, the point of this definition is not to exclude or include, but rather to be able to discuss the artworks utilized by the participants from certain theoretical viewpoints. These participants have engaged with the study primarily based on their own definition of what is to be used as comics, and indeed follow what would publically be called comics, e.g., comic books (Donald Duck, The Phantom, etc.) and newspaper comic strips (Zits, Calvin and Hobbes, etc.). However, as an interesting aspect of definition, the Grade 3 teachers in this study also worked with sequence images, where one to four wordless images are laid out in sequence, and the child's task is to explain the sequence. When discussing this with the teachers, they admitted that not all of them viewed these as a form of comics before the images were used in conjunction with other comics, even though these sequences would presumably be included in the definition above. This demonstrates an important point: we need to agree on what something is in order to talk about what it is.

At this point, it is also necessary to point out the difference between educational comics, i.e. comics designed specifically for educational purposes, such as Will Eisner's Preventive 
Maintenance Monthly (1951) - a comic book used in the US military for training maintenance crew and soldiers for certain tasks - and comics used in education, but designed for entertainment, commercial interest, etc. This dissertation investigates the use of comics not (necessarily) designed for education (even though some of the comics used by the teachers in this study have been assembled for educational purposes - but more on that in Chapter 5). There is no difference in the value of these two types of text, as far as the current dissertation is concerned. Use of educational comics was not investigated because the teachers involved were not using them.

\section{Comics Terms}

There are a number of technical terms associated with comics. Over the past decade, several theorists have contributed to these concepts, among them the aforementioned McCloud (1993) and Eisner (2008a, 2008b), who have laid much of the foundation of modern comics research. Even if Eisner first and foremost had a practitioner's interest and McCloud's work (and definitions) has been extensively questioned and discussed since its publication (see, e.g., Harvey, 2001; Wolk, 2007), their influence on the academic study of comics is substantial. In the following sections, a number of comics-related terms and concepts will be described, and their influence on the current dissertation will be discussed.

\section{The Page, Panel and Gutter - the Visual Structure of Comics}

In its simplest form (as defined here), a comic is made up of 2-3 panels, black rectangles, whose edges are called the frame, placed on a white background, the page. Each panel is (possibly) separated by a gutter, an empty space designed for the specific purpose of splitting two images up (Eisner, 2008a, 2008b; McCloud, 1993). As seen in Figure 1, below, each clock exists in a panel, bordered by a frame. In the case of Figure 1, there is no gutter, because the frames overlap. However, one could still argue that there is a narrative gutter, given that the images are separated by the frames. 
In his Understanding Comics (1993), McCloud discusses and theorizes around the concept of closure, the effect of "observing the parts but perceiving the whole" (p. 63, emphasis in original). This is a similar effect to that of object permanence, the psychological concept where the mind is aware of an object's continued existence even when it is temporarily out of sight. In the case of closure, McCloud argues that our mind subconsciously makes completions of images. In Figure 1, our brain makes connections in the sequence of images, giving us the "illusion" that the hands on the clock is moving, instead of there being three different clocks showing three different times.

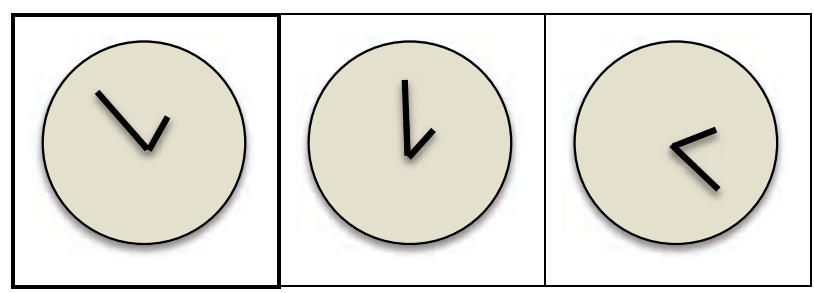

Figure 1. Clocks.

This is of course one theory of closure, whereas in Paper II, I demonstrate how children co-construct closure between panels through negotiation, rather than as an individual aspect of the mind.

\section{The contents of the panel}

Neil Cohn's research on comics as a visual grammar demonstrates, by tracing EEG, how participants read comic strips (2014). His interest in the neurocognitive aspects (i.e., what happens in the brain) of reading comics is different in focus from the current dissertation. However, Cohn's work (2007, 2013a, 2014; Cohn, Paczynski, Jackendoff, Holcomb, \& Kuperberg, 2012) has generated terms and concepts to the present analysis. 


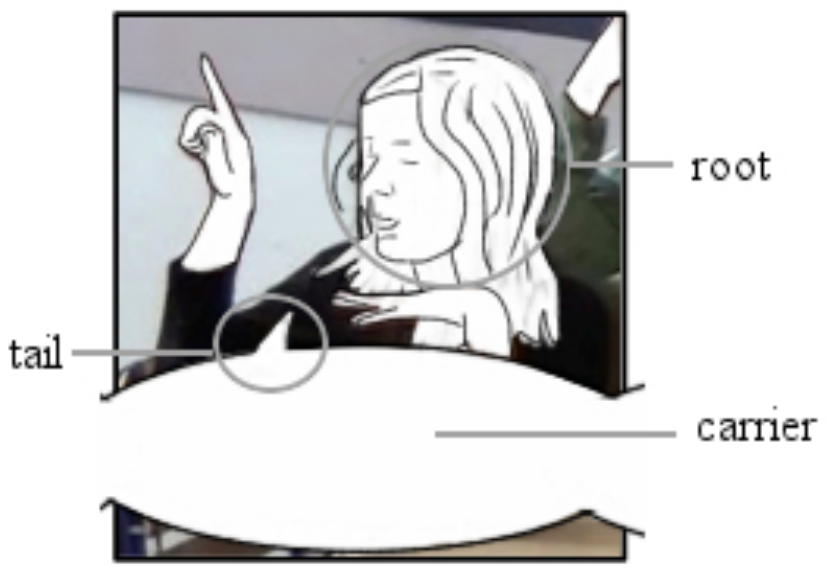

Figure 2. Comic terms (image reproduced from Wallner, 2017, p. 179).

When describing what happens in or around a comic, certain terms are necessary. Utilizing Cohn's (2013a) terms, we can identify three key features in Figure 2: the root, the person/character expressing something; the tail, the small point expanding from the bubble, identifying who is expressing something; and the carrier, the speech or thought bubble displaying the expressed message.

The concepts of root, tail and carrier have been especially useful in discussing the way that classroom participants talk about the construction of speech and thought bubbles in Paper III. The paper shows how participants in Grade 3 make distinctions between different types of bubbles, as well as the impact and use of bubbles within comics narration.

\section{Comics in Relation to Picture Books}

For the sake of the analysis and discussion, it is worth recognizing the similarities in style and structure between comic books and picture books as popular materials for use with younger children, as this has been pointed out by Charles Hatfield and Craig Svonkin (2012), Nathalie op de Beeck (2012), Perry Nodelman (2012), and others. Both materials utilize text and images for their storytelling, and most children read both literary forms. There has been a great deal of research done with picture books as a form of literacy (for some examples, see Nikolajeva, 2000, 2003; Sipe \& Brightman, 
2009). Although the current dissertation focuses on meaning making with comics, many visual and narrative aspects utilized by comics are also recurring in picture books (cf. Gibson, 2010; C. Hatfield \& Svonkin, 2012).

Sutliff Sanders (2013) argues that comic books are made for an individual reader, while picture books are intended for a reader "who chaperones the words as they are communicated to a listening reader" (p. 61). Hatfield and Svonkin (2012) question this type of "presumed opposition" between comics and picture books, where one is "seen as empowering young readers", while the other is seen as "competing with or even obstructing [...] literacy" (p. 431). They point out that this kind of ideological framing of the two formats only serves to obscure the kinship that they share. Moreover, unlike other definitions (such as Eisner's above), Sutliff Sanders' (2013) is based on intended readership, which is problematic as this approach requires making assumptions (by the analyst, publisher, writer, artist, etc.). However, op de Beck writes "picture books, whether deemed appropriate or inappropriate, possess an often-invisible modifier: they are perceived by people of all ages to be children's picture books" (2012, p. 473, emphasis in original). Thus, there exists a discourse that equates picture books with children's reading, and this is largely also true for comics. Nevertheless, the intentions of the comic book/picture book author, as far as the participants are concerned, are unknown and should have no bearing on the analysis in the current study.

Furthermore, there are also texts that transgress this definition. The comparison below, between a comic and a picture book/comic, is intended to show the similarities and differences between comics and picture books. The following is relevant to the context of the present study, because the aspects addressed and implications of the study could be relevant to this type of literature as well.

The Swedish Bamse för de yngsta (Bamse for the youngest, henceforth: BY) is a comic book produced by Egmont Publishing, the largest comic book publisher in Sweden; it targets children ages 1-4 years. This comic is intended to be read aloud to a child, and does not fit Sutliff Sanders' (2013) definition. Figure 3 displays a page from BY, and shows Skalman and Teddy, two main characters, leaving Skalman's house to go to Africa. Like a comic 
book, the pages are divided into panels, and speech bubbles display dialogue. The story is told through 36 panels over 15 pages.

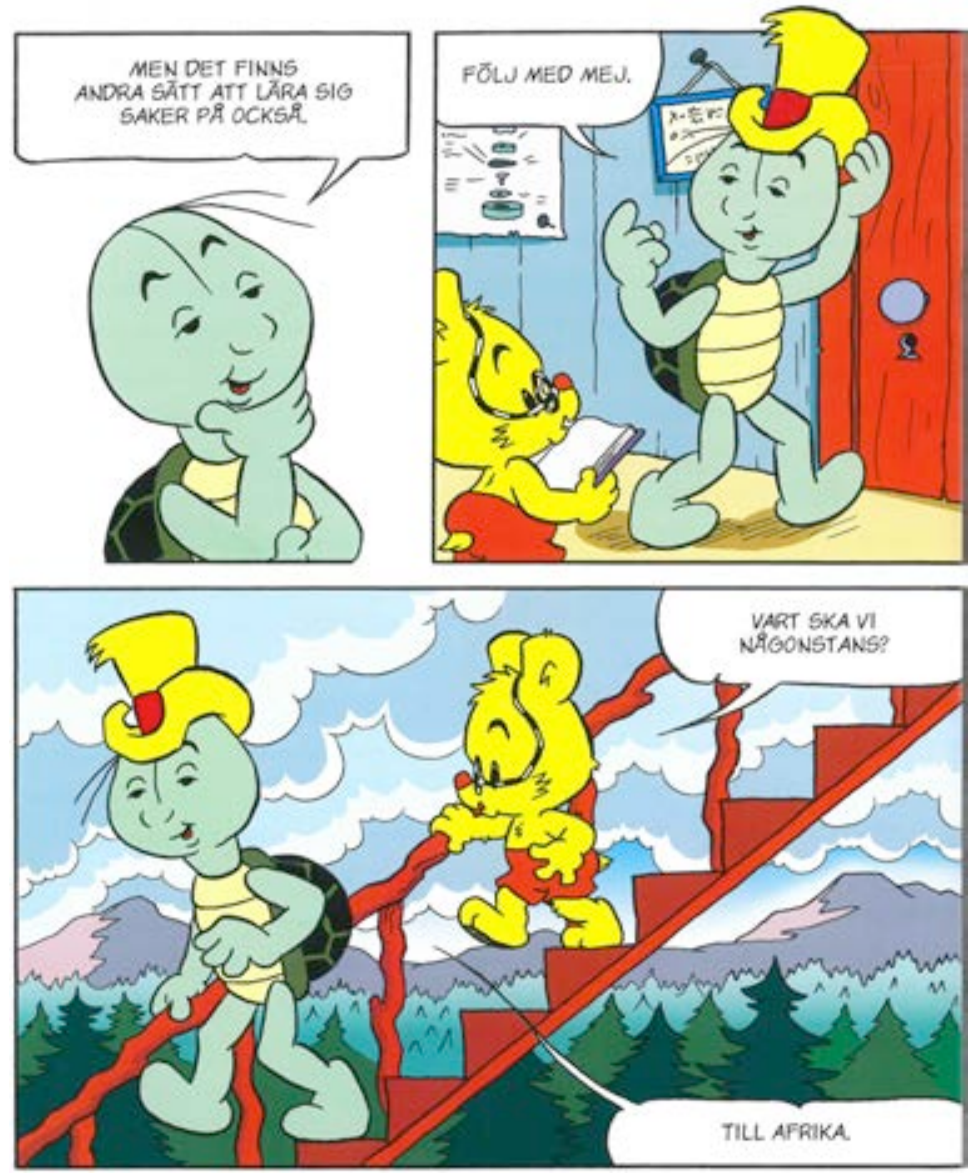

Figure 3. A page from Bamse för de yngsta (Wallin \& Blomgren, 2016, $p$. 6) (C) Rune Andréasson \& Egmont Publishing. The text is not translated, as the content is not essential to the text example.

Figure 4 shows a page from Bamse (henceforth, B). It follows the patterns of conventional comic books: the pages are divided into 19 black-bordered panels, it has narrative boxes, speech and thought bubbles, and the reader follows the story left-to-right, top-tobottom. The story, where Katten Jansson (Jansson the Cat) attempts to run an errand for Grandma, totals 28 panels over 4 pages. 
Chapter 3: Comics, Literacy, and Comics Literacy
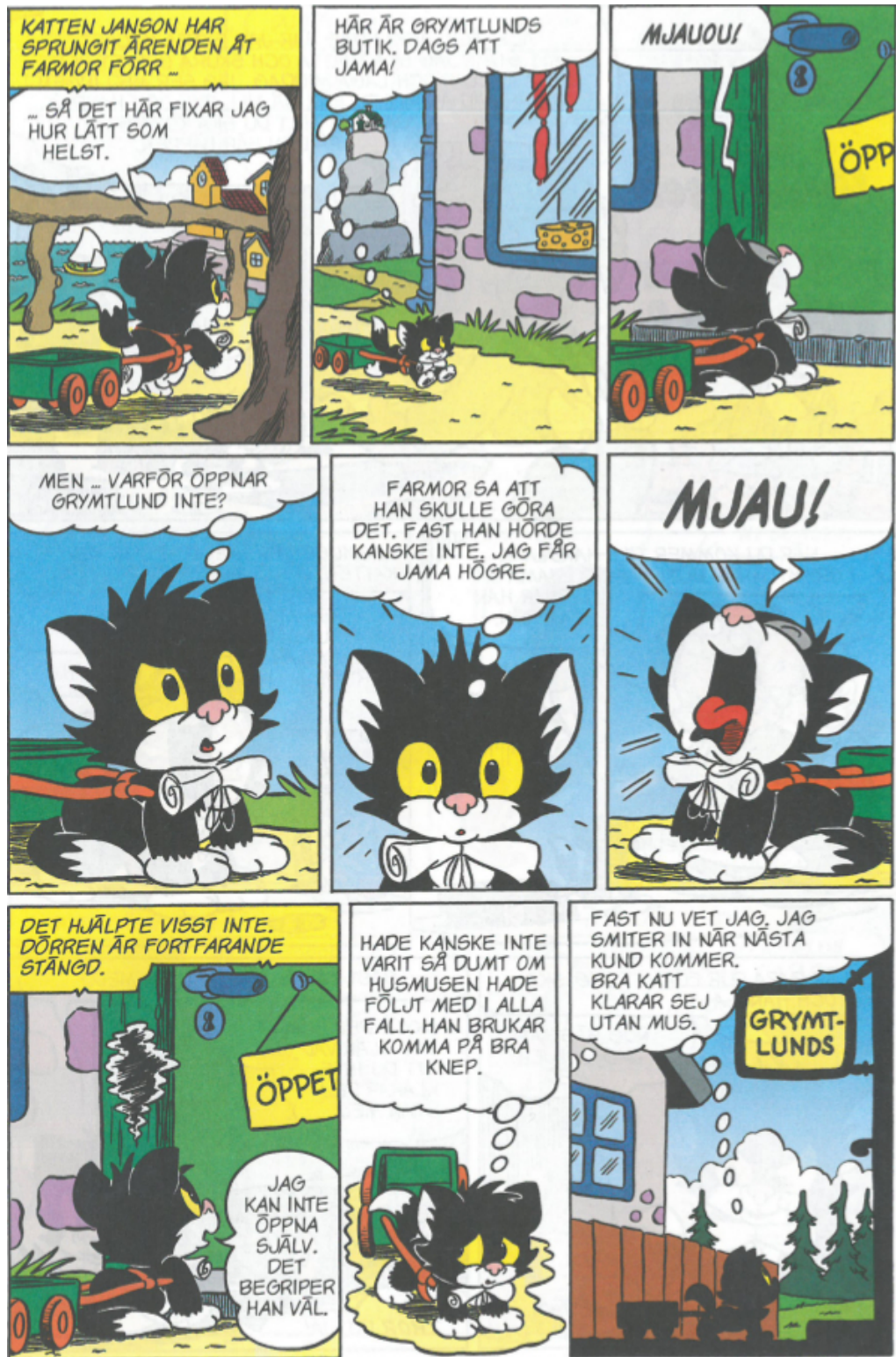

Figure 4. A page from Bamse (Axén \& Cronstam, 1997/2016, p. 46) (C) Rune Andréasson \& Egmont Publishing. The text is not translated, as the content is not essential to the text example. 
These two examples follow some of the conventions presented in the discussions above for picture books and comic books, but they also show some interesting differences from these definitions.

The pages of BY are divided into 1-3 panels, each panel being at least twice the size of those in $\mathrm{B}$, thereby following the picture book convention of having larger pictures, which can be more easily handled by two "readers" simultaneously (cf. Sutliff Sanders, 2013). Unlike the picture book convention, BY does not use the page break for surprising effects (cf. Sipe \& Brightman, 2009), but it does use the splash page of the comic book, by having some pages contain a single panel, where the environment can be displayed in more detail (albeit, the single-page panel is a picture book convention, see C. Hatfield and Svonkin (2012)). This is often accompanied by a narrative text describing the nature or animals in the scene. The amount of text differs immensely, with the story in B averaging 107 words per page, and BY averaging 18 words per page. This is a typical difference, as is the higher complexity associated with, for example, more panels on every comic page (Nodelman, 2012). Both books use capital letters in speech and thought bubbles, and the same font. The pages of BY are thicker and glossy, which allows it to be handled more roughly. This physical aspect coincides with one of Catherine Snow and Anat Ninio's (1986) contracts of literacy, where young readers have to learn (among other things) that books are for reading, not eating. Clearly, the thinner, rougher paper of $\mathrm{B}$ would be less durable in the hands of young children who might try to eat the comic.

Furthermore, the colours are also clearer in BY, but this could simply be due to the difference in paper quality. Although $B$ is shorter than BY, the story of B is also presented as one part of a book of collected stories, which totals 68 pages, while BY is the only story presented in an 18-page book. Interestingly, both books utilize narrative boxes (eight in BY and nine in B, as seen in panels 1 and 7 of Figure 4), and both use a metanarrative voice directly addressing the reader throughout the story. However, B also has a letter from the editor as an introduction to the comic book, directly addressing the reader, which shows an intention to reach the individual reader (with phrasing such as "on page 27 you can read 
how..." (Axén \& Cronstam, 1997/2016, p. 2, emphasis added). To summarize, these different aspects of the two books point to the intended readership for both texts, a singular reader for B, and an adult reading to a child for BY. Despite this, BY has a number of comic book qualities not usually associated with picture books, revealing how it pushes the boundaries of both formats.

Furthermore, regardless of the intentions underlying a text, in practice these intentions are not always realized. Even these two texts are ambiguous. For example, BY is a comic book intended for a dual readership. In Paper III, I present an example of how a teacher and pupil read a comic book together. In the example, the pupil is a struggling reader, demonstrating that comics are indeed used as chaperoned reading material. However, the two participants engaging in this reading also display various problems with pointing and following the story, as the pupil engages with other aspects of the images, etc. Sutliff Sanders (2013) also describes these problems in his article.

In a time when picture books and comics transgress the boundaries between the different formats, it is difficult to say whether it makes more analytical sense to keep them separate or to combine them. Sylvia Pantaleo's work (e.g., 2011b, 2012a, 2012b) explores the use of both picture books and comics in school contexts, demonstrating how the multimodal elements of both formats influence the work of primary school pupils. Investigating these structural and narrative elements and how they are done within educational practice makes sense, because they are formats that may be interchangeable for children of a certain age. Furthermore, exploring comics and their role in constructing children's reading and childhood using methods similar to those applied to picture books could prove fruitful for our understanding of comics.

\section{A Visual Literature}

This dissertation presupposes that comics have the status of literature. Because comics are (primarily) a visual-textual form of literacy, reading comics "involves the pictures and their meanings in relation to the language, and the key to understanding comics does not lie in the words or pictures themselves but in the 
interaction and relationships between them" (Bongco, 2000, p. 49). Thus, comics are a multimodal textual-visual form of literature (Cook, 2017; cf. also Kress, 2003; Kress \& van Leeuwen, 2001) that uses semiotic, symbolic and iconographic visuals to communicate with the reader (McCloud, 1993). This means that an analyst cannot approach comics as being, e.g., merely a textual literary form. The combination of text and image, perhaps the most common feature of comics, is not a clear-cut aspect of comics. Roland Barthes (1985) theorizes that the text "constitutes a parasitical message intended to connote the image" (p. 14), and that images do not help to illustrate words. Barthes writes "the text burdens the image, loads it with a culture, a morality, an imagination" (1985, pp. 14-15). Similarly, Gunther Kress and Theo van Leeuwen (2006) argue "language comes first, authoritatively imposing meaning on the image" (p. 26), but it is unclear to me what evidence they have for this. They continue, "language is general, bestowing similarity and order on the diverse, heterogeneous world of images" (p. 26). But, surely, language is as heterogeneous as images? The point of much of CA is precisely that language in itself is not a prerequisite for order, but rather that people use language to make sense and order out of everyday interaction. This does not always occur, however, due to the ambiguity and fluidness of language.

Kress and van Leeuwen (2006) use an illustration of a bathroom to argue that changing the image does not greatly change the meaning of the words, and that images "illustrate" words. But could not the opposite also be true? Changing the words affects the reading of the image, but changing the image also affects the reading of the words. I would argue that there is no prior or latter here, but rather whatever elements are put together influence each other, and if readers have access to one, the other, or both, they utilize whatever is present to construct their reading. Magnusson (2005) argues that some comics poorly utilize the modalities when, for example, a written caption explains something that the reader can see in the image. Barthes, however, argues that "it is impossible ... for the words to 'duplicate' the image; for in the shift from one structure to the other, secondary signifieds [sic] are inevitably elaborated" (p. 15). With this view, one could argue that 
a written caption always adds something to the depicted scene, perhaps a different perspective than provided by the reader's first glance, an ironic twist, or a clarification. Therefore, it would appear that text neither imposes on nor burdens, but rather diversifies communication of the image, and vice versa.

This view of image and text influences how we read, write, and understand comics, as well as our ability to use them as classroom materials. The technical literary aspects of comics - such as the gutter (Low, 2012), panel structure (Cohn et al., 2014; Cohn et al., 2012), and other visual/textual aspects (Hammond, 2009; Pantaleo, 2012c; Schwartz \& Rubinstein-Avila, 2006; Snyder, 2010) - make them interesting in their own right as subjects of literary analysis. However, studying how pupils' and teachers' construct and negotiate these aspects in classroom interaction gives the subject a new dimension. How do teachers and pupils work with the multimodal aspects of the comic book? How do comic book reading groups deal with the visual and textual aspects when retelling stories? How are the structural elements of comics taught and learned in the classroom? These are questions that have guided the initial part of the study - recording and viewing of the data and in order to specify and talk about these issues, I will first discuss aspects of how we understand the reading and comprehension of text and images.

\section{What is Literacy?}

The term literacy was implemented in the 1980s as a result of education reform, a sociocultural turn in educational science, and Paulo Freire $(1972,1973)$ and his work with the Critical Education movement (for an overview see, e.g., Lankshear \& Knobel, 2011). Literacy became a collective term used to talk about reading and writing practices (see, e.g., Teale \& Sulzby, 1986). Literacy has been a contested term ever since its implementation (see, e.g., Lonsdale \& McCurry, 2004), and there are two main perspectives on literacy addressed here: literacy as socially constructed practice and literacy as an aspect of ideology and power. 


\section{Literacy as Socially Constructed Practice}

Literacy is a complicated concept, and different researchers view the term in different ways. "Literacy is a social activity", David Barton (2007, p. 35) argues, and even though it initially was seen as a cognitive textual/print practice, research soon came to encompass both the social aspect of literacy, and non-textual literary forms through the perspectives of multimodality and new literacies (see, e.g., Gee, 2002; Jewitt, 2008). Jenny Cook-Gumperz (1986a) argues that literacy "is not just a matter of cognitive processing [---] literacy learning takes place in a social environment through interactional exchanges in which what is to be learnt is to some extent a joint construction of teacher and student" (p. 8). For example, an early step away from individual ability and towards a perspective of social cognition is found in the work of Sylvia Scribner and Michael Cole (1981), who define literacy as "not a matter of knowing how to read and write a particular kind of script" but as applied knowledge in specific contexts (p. 236). Scribner and Cole (1981) "approach literacy as a set of socially organized practices which make use of a symbol system and a technology for producing and disseminating it" (p. 236) in exploring what they refer to as literates and non-literates in the written language of the Vai people. They demonstrate that changes in cognition, which were previously considered to be a result of literacy, are highly affected by the sociocultural process of schooling. Both Kress and James Gee argue from the perspective of social semiotics and situated meaning, where "meaning is not in the head, but in specific social practices connected with specific sociocultural groups" (Gee, 1992, p. 51) and the "approach to communication starts from a social base" (Kress \& van Leeuwen, 2006, p. 21). Thus, literacy becomes not merely an individual skill or ability, the way we might think of it in terms of literate/nonliterate, but rather a practice people engage in as social beings, in which case an individual might be considered both literate and nonliterate depending on the social and cultural context. 
Rather than studying the individual's decoding of text, or cognitive uptake of information while reading ${ }^{11}$, the current study views literacy through the social lens, where groups of participants socially construct discourses of literacy (cf. Potter, 1996). This perspective on discourse and literacy goes back to Brian Street (1984), and his criticism of the "great divide" between orality and literacy, as well as his advocacy for an ideological, rather than an autonomous, view of literacy. Street (1988) argues for a combination of ethnography and discourse analysis to "provide a useful basis from which to construct a synthesis that develops beyond either approach in isolation" (p. 60-61). Colin Lankshear and Michele Knobel (2011) similarly emphasize the sociocultural view of literacies, defining them as "socially recognized ways in which people generate, communicate, and negotiate meanings, as members of Discourses, through the medium of encoded texts"' ( $p$. 33). They argue that "the ultimate purpose of researching literacies is to contribute toward a deeper and richer understanding of how the social and cultural world 'ticks"” (p. 33). Society's view of literacy changes as sociocultural practices change (Hiebert, 1991) and, thus, researchers need to study the social literacy practices of comics, if we are to understand the functions and effects of the literacies comics require and promote. The current dissertation retains this view of socially constructed and situated literacy, by studying how participants construct aspects like narrative structure and literary devices as social actions in the classroom.

\section{Literacy as Ideology}

The second aspect of literacy, as the Critical Education movement (Freire, 1972, 1973) and literacy scholars such as Cook-Gumperz (1986b) and Street (1984) argue, is that literacy is also an instrument of power. Scribner and Cole (1981) problematize the dichotomy of literate/non-literate and point to the different literacies as they are perceived from a sociocultural perspective. This dichotomy is also criticized by, among others, Paulo Freire

\footnotetext{
${ }^{11}$ For examples, see the work around vocabulary uptake with comics from Heidi K. Hammond and Katherine Danaher (2012) and Marietta Rossetto and Antonella Chiera-Macchia (2011).
} 
and Donaldo Macedo (1987), who argue that the label of nonliterate is always an exercise of power of an authority (who decides what literacy is the norm) upon an individual or group, similar to the arguments of the ideology model devised by Street. In his book Literacy in Theory and Practice (1984), Street criticizes what he calls the autonomous model of literacy (he reviews research from Jack Goody ${ }^{12}$ and others from the 1960s and 70s), wherein literacy is studied anthropologically, observing what researchers at the time called non-literate groups, or those with "only" oral literacy and comparing this with so-called "modern" literacies. Street (1984) considers these studies to be imperialist, and argues for an ideological model of literacy, which considers the cultural and social context of literacy, and literacy as an instrument of power, wielded by those in power against those without it. According to Street, "since the introduction of literacy is always accompanied by the introduction of new forms of social organisation, differences in thinking processes cannot, as we have seen, be attributed to literacy per se" (1984, p. 103). We cannot explore literacy in isolation. Instead, using a perspective of discourses and ideology allows researchers of literacy to disengage from the idea that literacy is universal and instead lets them investigate the specifics and possibilities of different literacies - their causes and effects - as constructed contextually and culturally. For instance, this would allow us to investigate comics literacy as a specific type of literacy, but we could also explore how this literacy is expressed, used, and adapted, in different forms in different contexts. Cook-Gumperz argues that

the first task of research is to explore in critical detail the workings of [literacy] practices; not to make judgements, but to uncover biases when they affect practices, and to deconstruct the many ways that an ideology of literacy enters into our evaluations of educational effectiveness. (1986a, p. 8)

Engaging with literacy in education through the lens of DP allows the researcher to investigate aspects of discourse and psychology -

\footnotetext{
${ }^{12}$ Goody, J. (ed.) (1968). Literacy in Traditional Societies. Cambridge: Cambridge University Press.
} 
enabling exploration of literacy ideologies, power relations and attitudes to the material. These perspectives will be further explored below (p. 41), but first I will describe two perspectives on construction of literacy practices.

\section{Literacy Practices and Literacy Events}

For the purposes of the current dissertation, following on the uses in, for example, Barton (2007) and Street et al. (2011), the terms literacy practices and literacy events are used as theoretical terms throughout this text, even though they are not used analytically in the three papers. I have chosen to use these terms here because they are relevant to the theoretical frame and discussion for the dissertation as a whole, and use of these terms does not change the analytical points or results of the individual papers.

Literacy practices is used here as the term for the "general cultural ways of utilizing literacy which people draw upon in a literacy event" (Barton, 2007, p. 37) (for school, this could be reading aloud, book reports, etc.). A literacy event is the smaller unit of analysis wherein literacy is the primary activity (such as a task or lesson). The pupils and teachers in the current study engage in the literacy practices of reading, composing, drawing, and talking about comics as well as constructing discourses around comics. In this process, they perform certain tasks that we can explore as different literacy events, where some examples could be to determine the target group of a certain comic (Paper I), structure comic-book panels (Paper II), or discuss speech and thought bubbles (Paper III).

\section{One Literacy among Many}

From the Critical Education work of Street and Freire, and the attempts to broaden the scope of what literacy entailed, another concept emerged on the scene. In 1996, building on the ideas of, among others, Street (1984) and Freire and Macedo (1987), The New London Group (1996), comprised of ten researchers on literacy and language, among them Kress and Gee, argued for an expansion of literacy pedagogy into one of many multiliteracies. Here, teachers would no longer utilize only text-based literacy in a 
growing world of images, symbols, colour, sound, and other features.

The concept of multiple literacies, as argued by Carey Jewitt, "marks a shift in focus from the idea of literacy as an autonomous neutral set of skills or competencies that people acquire through schooling and can deploy universally to a view of literacies as local and situated" (Jewitt, 2008, p. 244; see also Lankshear \& Knobel, 2011). Barton uses the term domains (2007, p. 37) in connection both to different languages and to different social practices. Gee (2002) argues for the use of literacies as people's secondary discourses "developed in association with and by having access to and practice with [---] secondary institutions [workplaces, stores, government offices, businesses, churches, etc.]" (p. 142). Gee claims that we master some of these literacies and are novices in others, giving examples such as visual literacy, computer literacy, etc. From the perspective of teacher education, Sandra Hollingsworth and Margaret Gallego (1996) argue for a view of multiple literacies as important for the "praxis of lifelong teacher education" (p. 289), being able to adapt to new media, but also as a reflexive practice of teachers' personal literacies, their views on themselves in relation to literacy. What this entails is a new way of dividing up literacies, similar to the view of discourses provided by, e.g. Edwards and Mercer (1987), so that literacies are also viewed as local and situated.

This came to make way for two similar theoretical terms used for analysing and understanding the locally constructed literacy practices under study: NLS and new literacies. These terms are closely related, but focus on different areas of interest. In reference to what is new, Lankshear and Knobel (2011) describe two aspects: the paradigmatic and the ontological (p. 27). I touched briefly on NLS in Chapter 2, in relation to studying social interaction, but I will develop this further here in relation to the concept of literacy, and the current study.

\section{New Literacy Studies and New Literacies}

The paradigmatic perspective (Lankshear \& Knobel, 2011, p. 27) refers to NLS and the sociocultural study of literacy described in the section above. NLS is the natural continuation of Street's 
argument for a combination of ideology, ethnography and discourse (Street, 1993; Street et al., 2011), in which he investigates school literacy practices as sociocultural practices, wherein ideology and power serve as both constructive of and constructed by discourses of literacy. Nevertheless, these literacy practices are changing even as this text is being written; they have been changing for some time (see, e.g., Sousanis, 2015), and will keep changing. Therefore, educational research needs to explore the influences of these changes and participants' roles in them.

The ontological perspective (Lankshear \& Knobel, 2011, p. 27) has a different focus than NLS (which focuses on sociocultural practice). The ontological perspective of new literacies instead refers to the stuff of literacy, and how it is different from the typographically based "old" literacy (Lankshear \& Knobel, 2011, p. 28). Readers should note, however, that despite these difference in perspective, studies within NLS often (but not always) utilize the perspective of new literacies (see, e.g., Moss, 2003; Pahl \& Rowsell, 2006) As the material aspect of the study, this will be further developed in the section below.

Thus, in the current dissertation, both of these two perspectives are taken into account. First, the empirical material the analysis is based on is a study of literacy as a social practice. Second, although not an new type of literacy per se, comics literacy clearly involves non-typographic reading, such as sequential reading structures, comic book bubbles, audio-text, and more (McCloud, 1993), as compared to other forms of literature. Therefore, the material classroom participants utilize throughout the data is important, and it is relevant to examine the theoretical perspectives on using comics as part of literacy practices. In itself, studying reading as a social practice is not new, and there are a number of studies to exemplify this: teacher-led group discussions on books in Grade 47 studied with regard to pedagogical dilemmas (Eriksson, 2002a, 2002b), pupils' construction of gender around the film Lilya 4-Ever (Eriksson Barajas, 2010), and an ethnomethodological approach to studying a library reading group, analysing how participants account for, and respond to, certain aspects from the literature (Allington \& Benwell, 2012). For a review of research, see Daniel Allington and Joan Swann (2009b). The current dissertation 
contributes new knowledge to this previous research by virtue of both its focus on multimodal aspects of literacy, and its specific investigation of meaning making with comics.

\section{New Literacies and Comics in the Classroom}

Studying comics as an aspect of new literacies is a research area that is still evolving (see, e.g., Ripley, 2012). There are reasons to consider widening the scope of the literature we teach, as the formats of literature keep evolving through the use of aesthetic and digital tools. Aidan Chambers (1985) claims that "teachers tend to teach in the same way as they were taught and to teach the same books read during their course" (p. 117), and I share these experiences from both my time teaching secondary school and my time at university. In my data, discourses around comics literacy and participants' views on comics are visible, as they are constructed by and construct ideologies of literacy. This demonstrates teachers' and pupils' relations to other types of literacies than the textual literacy primarily utilized and encouraged in school. The ideas, critique, and enthusiasm extending from these relations further construct intriguing pathways into new discussions on what constitutes classroom literature.

Heidi. K. Hammond (2009) argues that comics are a means for developing visual literacy, but also a way to upset the established order of textual literacy as the dominant mode of knowledge production. As Doré Ripley (2012) puts it, when using comics

students must dig deep for responsive ideas and they must become comfortable interpreting the visual/textual blend presented on the comic's page, the twentieth century precursor of twenty-first century mediums where visuals are dominant, a medium that can be interpreted and analyzed like any other text. [---] [W]hen we starting [sic] reading comics our western inclination towards speech turns toward our academic predisposition towards text and sets us on the track of the written word, especially the favored words of speech while ignoring the [sic] what's going on outside the bubble. (pp. 99100 , emphasis in original)

With a change in the use of images and video for daily consumption and production of information, "visual literacy, the 
ability to understand pictorial information, became one of the basic skills required for communication in the twenty-first century" (Duncan et al., 2015, p. xvi). However, film and animation are not like comics (or images), in that film lacks permanence, meaning that the images pass by quickly, and the action is outside the reader's control, while comics allows the reader to control the action of the visuals (N. Williams, 1995). Magnusson (2005) demonstrates another aspect of permanence in comics that most images lack, which is to give the reader a position to survey many parts of the narrative at once (by including larger grids of images, such as in Figure 4, above). Permanence is an aspect of picture books as well (and surveyability, to a degree), although this also depends on who controls the reading (Sutliff Sanders, 2013).

As argued above, the present study allows for a mix between studying sociocultural literacy practices and multimodality, and these two perspectives have been fruitfully combined previously by other researchers studying other types of literacy. In their introduction to Travel Notes From the New Literacy Studies, Kate Pahl and Jennifer Rowsell (2006) argue for the benefits of utilizing multimodality for reading and writing practices, as it "gives an analytic tool to understand artefacts such as children's drawings, and to recognize how literacy sits within a much wider communicational landscape" (p. 8; see also Street et al., 2011). As an example of classroom research, Gemma Moss (2003) also utilizes a combination of ethnography and multimodality in "understanding reading as a situated social practice" (p. 73) when working with children reading multimodal texts both in and outside schools. Here, Moss is investigating literacy events and how the multimodal aspects of the texts influence the studied events. A multimodal perspective on literacy lets Moss expand her analysis "beyond the written language or the visual representation" (p. 78), and she concludes that the text must be considered "as a material object, the affordances and resistances of the stuff from which it is made, the particular combination of the written text and image it synthesizes and co-ordinates on the given space of the page" (p. 85). Street et al. (2011) argue that this is especially important in schools, as it enables pupils with limited written or verbal communication skills to be part of the meaning making being 
studied. Indeed, with a primarily visual comics material such as that employed in Paper II, a multimodal analysis is essential to understanding the literacy practice being done.

I have chosen to explore meaning making with comics as part of NLS and through the perspective of new literacies, as this allows for an encompassing analysis. Within NLS, the researcher can analyse the locally situated social interaction around comics, how participants do literacy with comics, as well as the discourses constructed in this practice. New literacies, on the other hand, engages with the multimodality of comics as a visual, textual, and spatial form of literature. Thus, using both of these perspectives, the analyst can study the situated meaning making of a practice in which participants construct discourses of multimodal literacies, and offer critical perspectives on literacy and discourse (Gee, 2002; Street et al., 2011).

\section{Comics Literacy}

My conclusion at this point is to discuss comics as their own form of literacy - comics literacy - to use the term Hammond (2009) employs in her dissertation. Hammond defines comics literacy as "fluency in the unique language of comics and its visual grammar" (p. 42). She argues that comics literacy requires "mastery of two separate literacies, traditional text literacy and visual literacy" (p. 43), because comics have their own, easily recognizable, unique visual as well as narrative style (see, e.g., Eisner, 2008a; McCloud, 1993). Hammond (2009) never clearly defines the lines between visual literacy and comics literacy, and perhaps this is a difficult thing to do, as both concepts are intertwined. The argument in the current dissertation, however, is that the point of comics literacy is to intertwine the two, and not to discuss them separately as different literacies. Hammond's dissertation ends with a discussion on visual literacy rather than comics literacy, which unfortunately lessens some of the impact the term comics literacy could have.

Matthew Pustz (1999) also uses the concept comics literacy as a term for the intercultural and intertextual knowledge comics require from, and promote in, comic readers. His book Comic Book Culture: Fanboys and True Believers explores interesting literary aspects of the fan culture surrounding comics, as well as artists' 
and writers' ways of responding to this through their work. Thus, Pustz does not discuss comics literacy from the perspective of the reader, but from that of the comics - in terms of intertextual references to other comics and other media - and how this is part of the cultural sphere of comics fandom. Unlike in Pustz's book, the focus in the current dissertation is on the readers' constructions of literacy, rather than literacy being inherent in the material. Furthermore, Pustz does not discuss the visual/textual (in the way that Hammond (2009) does) as an aspect of comics literacy.

The current dissertation encompasses both of these perspectives, defining comics literacy as socially constructed meaning making with a sequential art narrative, entailing the intertextual and cultural competency of readers of comics, who create their own social and cultural spheres. This becomes important when considering the discourses constructed by readers.

Most notably in Paper I, but also elsewhere in the dissertation, the participants construct comics literacy in their work with the material, pinpointing the visual and textual narrative style of comics, as well as engaging with the competency required for comics reading. I will return to this in Chapter 9, where I argue for a locally constructed comics literacy that should be recognized and valued, but also examined and criticized.

\section{Concluding remarks}

In this chapter, I have detailed literary theory around comics, as well as described and discussed some aspects of relating comics to NLS and new literacies. The current dissertation combines these perspectives to explore and understand the situated social literacy practices (from the NLS paradigm) wherein participants utilize a multimodal material (the focus of new literacies).

I have discussed different aspects of defining comics and the problems inherent in this, and I utilize the definition surveyable juxtaposed pictorial narratives. This chapter has also presented some of the visual aspects of comics literacy - such as frame, panels, speech and thought bubbles - and how these can be analysed within new literacies. I have argued here that comics have a natural place within this field as a visual/textual narrative material with a cultural and social history, and that viewing comics in light 
of these theories can demonstrate comics' usefulness in the classroom. This has led to use of the term comics literacy to discuss the practices taking place in the classroom, both as a result of the current study and indicated by theoretical discussion. In the next chapter, earlier research on comics in education will be addressed. 



\section{Earlier Research on Comics in Education}

The reading of a graphic novel is an act of both aesthetic perception and intellectual pursuit.

(Eisner, 2008a, p. 2)

In this chapter, I review previous research on the use of comics in education. This research review is by no means meant to be definitive; rather a selection has been made of research investigating the use of comics in primary and secondary education, preferably research with an analytical focus on the classroom participants, rather than on the comics material itself. Furthermore, I have been limited to work written in English and Swedish, thereby research papers written in, for example, German, French, Spanish and Japanese (all prominent comics cultures, with a long history of scholarship in literature and comics) has been omitted.

\section{Comics in Education}

Research on comics in educational settings goes back as far as the 1920s, when, for example, the comic strip Texas History Movies was used in classrooms (Tilley \& Weiner, 2017). Several experimental studies done with comics appear in the 1940s, and it is possible that the number of research projects found during this particular decade stems from three things: the popularity of comics at the time (Sones (1944) reports that 95\% of 8-14 year-olds read comics), the first US publication of collections of comic strips as a magazine publication in 1933, and the foundation of what was to be the two power houses in comics: National Allied Publications (later DC Comics) in 1935 (B. W. Wright, 2001) and Timely Publications (later Marvel Comics) in 1939 (Daniels, 1991). The late 1930 s and early 1940 s also saw the origins of popular 
superhero characters such as Superman (1938), Batman (1939), Captain America (1940), and Wonder Woman (1941). Moreover, comics were part of the US school agenda at the time. Policy documents produced by the National Council of Teachers of English such as An Experience Curriculum in English (W. W. Hatfield, 1935) and The English Language Arts (Smith, 1952) both included comics, the former in brief and the latter in more depth (see Tilley, 2013).

There is a large body of highly varied research exploring the different functions of comics within different educational subjects, so large in fact that it will not be possible to detail it all here. I will discuss literacy and language in more detail, but some other examples include history (Aiken, 2010; Cromer \& Clark, 2007; Decker \& Castro, 2012), medicine (Green \& Myers, 2010; I. C. M. Williams, 2012), and stem subjects (Hosler \& Boomer, 2011; Nesmith, Cooper, \& Schwarz, 2011; Rollnick, Jones, Perold, \& Bahr, 1998). Comics, as all fiction, are expressions of culture, norms, and values, and they relate to and reason around societal issues that reflect the time of their writing (Syma \& Weiner, 2013). There is also research about different comics media; the EduComics project ${ }^{13}$, supported by the EU Lifelong Learning Programme, produced a state-of-the-art review on the use of comics in education, which is more summative than analytical in nature. The EduComics project itself was focused primarily on the use of web comics. It points to a wide interest among European teachers in the use of web comics, and has produced four international journal papers, six conference papers, a multitude of workshops, talks and presentations, one book in the making, two master's degrees and one $\mathrm{PhD}$ in progress, although it is difficult to access any definitive analytical results through the website.

Gene Yang's master's project "Comics in Education" (2003) reviews research on the use of comics in American education (some of this is described below), their history, and what he perceives as the strengths of the format. In his review, Yang lists five strengths of using comics in education: motivation, imaging, permanence, intermediary, and popularity. This distinguishes

\footnotetext{
${ }^{13}$ See http://www.educomics.org
} 
comics from other media such as film (which is not permanent) and novels (which are not visual). Furthermore, Yang's review points to comics being a popular medium with children, something that seems to have persisted at least throughout the twentieth century, and argues that this is a motivational factor. Here, Yang references Kay Haugaard (1973) and her study of her son's reading habits, wherein she reports that her son is a "reluctant" reader. Use of this term (and Haugaard is not alone in using $\mathrm{it}^{14}$ ) is problematic as it tends to stigmatize readers, rather than investigating and problematizing the material they have been offered (as popularly discussed by, e.g., Kathy G. Johnson and E Jackson (2017) in their podcast Drawing a Dialogue).

The idea to use comics to persuade a reluctant reader is also connected to the idea of intermediateness, which is what Haugaard (1973) argues - the notion that comic books are good conduits to other forms of reading. This, of course, denies comics the status of being good literature in their own right, and not merely a means to another end (Wolk, 2007). This is also a common line of argument in writing on comics - viewing comics as a solution to reading problems. For example, in their literature review, Christina Blanch and Thalia Mulvihill (2013) claim that comics help pupils relate learning to the real world, even though, as they point out themselves, "most comic book worlds are not reality" (p. 39). Regardless of whether or not comics are realistic, one could point out that this is hardly a unique aspect of comics - novels, poetry, film, music, etc., could also relate learning to the "real world". Blanch and Mulvihill further claim that comics can "instill a love of reading which can translate into life-long learning" (p. 39), citing the personal experiences of figures such as Barack Obama and Desmond Tutu to support this. This kind of anecdotal support for comics' power to shape children's love of literature is common, but needs to be verified by research.

Similarly problematic is that critics of comics in education have connected comics (like most popular culture) with delinquency

\footnotetext{
${ }^{14}$ For just some examples with comics, see Elizabeth Downey (2009); Mary Jane Heaney (2007); Joanna Schmidt (2011); Baird Shuman (1982) and Gary Wright (1979).
} 
(e.g., Wertham, 1954) and aggression (e.g., Kirsh \& Olczak, 2000). In the case of Wertham's study, however, this has later been disqualified due to lack of evidence (see Tilley, 2012). In the case of Steven Kirsh and Paul Orczak's study on violence, despite the four publications seemingly deriving from the same study (2000; 2001, 2002; 2003), their sample size is relatively small (see criticism from, e.g., Steward \& Folina, 2006), and Kirsh and Orczak themselves admit that respondents" "trait hostility accounted for more of the variance than did the level of violence in comic books" (2003, p. 57). Nor do these studies sufficiently explain how comic books are different to other media in this respect. Thus, there seem to be no clear indications that comics per se encourage problematic behaviour.

There is a clear hierarchy in the world of literature, and comics are not at the top (Groensteen, 2009; McCloud, 1993) ${ }^{15}$. This hierarchy is reproduced throughout school culture, through literature canons where comics have long been viewed as a halfbreed of the novel and the painting, as pastime enjoyment for children, at best. McCloud (1993) and several scholars since him have argued that we should broaden our view of comics as an aesthetic mode, as a part of literature and fine art, as well as the way we tell stories. Comics have taken a backseat to other forms of reading in schools, and for no real, scientific reason (McCloud, 1993; Spencer Clark, 2013). In regards to higher education, Nick Sousanis (2015) argues that visual literacy engages the reader (and author) in ways that the verbal-textual modality currently dominating academic curricula does not. Sousanis claims that the hegemony of verbal and textual literacy is maintaining social and cultural inequality that educators and academics need to cater to a wider group of readers (see also Cadiero-Kaplan, 2002).

\section{Using Comics for Literacy}

One of the early experiments conducted with comics in schools was Children's Interests in Reading the Comics (Witty, 1941a, 1941b), where comics reading of 2500 children of different ages was

\footnotetext{
${ }^{15}$ Nor on top in the hierarchy of art, see, e.g., Beaty $(2007,2012)$, but the current dissertation does not discuss comics as an art form as well, unfortunately.
} 
studied (see also Sones, 1944). This experiment reported high interest in comics on the part of both pupils and teachers and praise for the potential of the comic book format as a medium for reading. W. W. D. Sones (1944) reports similarly from his study Comics in the Classroom, conducted with about 400 children in sixth and ninth grade. Through two rounds of testing, children were first given a narrative as either a picture or print text, and a week later the roles were reversed. Sones concludes that children who first read the picture narrative seem to have a firmer grasp of the narrative immediately than do those who read the print text first. In his view, this points to the need to individualize literacy teaching (not using the term specifically), and to the potential comics have in doing this.

From another experiment, where the researchers conducted a survey with over 400 responding teachers, Katharine Hutchinson (1949) reports that teachers used the comics provided (a set of different comics ranging from Donald Duck to Flash Gordon) for American history, social behaviour, reading, science, language, writing, and more. Eighty-three per cent of participants reported having enjoyed the experiment, seventy-four per cent that it increased motivation in pupils, and seventy-nine per cent that it increased individual participation. However, respondents also criticized the project, arguing both that "comics introduce improper language", that the experiment was disruptive to the daily work of the teachers, and even that comics "make learning too easy" ( $p$. 244). On an interesting note, Hutchinson ends the article with a letter from the then Director of Books and Comic Books at Disney, Frank Reilly, who had paid attention to the experiment. In this letter, Reilly argues that the use of comics in educational settings would also result in improving the quality of the comics and, thus, be beneficial both to the comics industry and to education.

Possibly due to the introduction of the Comics Code, and the general hostility towards comics in the 1950s, there is less research on comics in education throughout the 1960s, 1970s, and 1980s (Dorrell, Curtis, \& Rampal, 1995; Tilley \& Weiner, 2017). Haugaard's (1973) essay on comics as conduits to other types of literature does appear here, but as this is based on anecdotal 
evidence from her family, it is difficult to assess the relevance of this paper.

In the 1990s, moving swiftly forward in time, Neil N. Williams (1995) argues - based on his teaching experiences of using comics with ESL students - that the combination of imagery and dialogue in comics provides his students with "the paralinguistic aspects of interaction" - the facial expressions and postures of the characters support the written dialogue (p. 3). Williams also claims other linguistic benefits of using comics, citing their authentic language use, the use of idiolects (Williams uses Calvin and Hobbes as materials), and the use of a similar social context throughout the material. Although demonstrating the aspects of comics of interest to language educators, Williams puts little analytical focus on his pupils' activities or their interaction with the material.

Based on their study on seventh-grade children reading comic books, Joanne Ujiie and Stephen Krashen (1996) claim that there is reason to believe that comic book readers generally are more frequent readers than readers of other types of fiction. However, for all the benefits that Ujiie and Krashen's study brings, it is difficult to see any causal links, and further study on this topic to verify their claims would be beneficial. Furthermore, these three studies would all gain from complementary systematic naturalistic studies of classroom interaction, wherein these arguments could be illustrated using transcribed excerpts available to the reader.

In her doctoral dissertation exploring how readers read comics, Wendy Frances Helsby (1999) claims that

in education the emphasis and weight are often more on the end product in terms of comprehension and literacy (that is the ability to be well-read and to read well) rather than on understanding the process by which understanding was created. (p. 209)

Helsby points out that pedagogic practice needs to reflect a wider view of literacy, where reading of pictures is in no way easier, merely different. Therefore, it has to be viewed differently. One cannot assume that comics reading is "easier" merely because some text is replaced with pictures, and we cannot put comics in the hands of inexperienced readers and presume that they will understand the message of the text $(1999$, p. 209). This is similar to 
Nodelman's (1988) results on picture books, which show how picture-word relations display complex narratives through motion and rhythm, as well as Mary Stoermer's (2010) surprise at not all children knowing how, or wanting to, draw comics. This may appear trivial, but as teachers experience on a daily basis, if the teacher approaches a pupil with erroneous assumptions about what the pupil will feel and think about the subject matter, it can be disastrous for the ensuing learning process.

As with all forms of reading, guidance and practice are required depending on the reader's proficiency level. Anyone who has tried to read a comic book with a three-year-old knows that the information is not automatically transferred through pictures. Helsby (1999) argues that "[t]he literacy involved within different forms of communication may be of a different style, but not of a different quality. It is the role of the educator to mediate these through a range of texts" (p. 210). Furthermore, Helsby's study also shows pupils' use of cultural and literary context and how they express cultural competency in their reading and understanding of comics. She demonstrates the importance of pupils analysing narratives, in regards to both content and structure, and how comics are apt material for this (1999).

Rocco Versaci $(2001,2008)$ uses the popularity of comics as a motivational factor for pupils' reading, and bases his arguments using his own teaching experiences as well as on literary analysis of different comic works. Furthermore, Versaci argues that one of the most fundamental contributions that comics make to the literary classroom is to have pupils question what literacy and literature are, and what reading a text can mean. In a literature review investigating academic work on comics and graphic novels, P. L. Thomas (2011) similarly argues that these types of texts can be used to challenge pupils' perception of genre. Although the current dissertation considers comics as a format, rather than genre, these ideas are highly interesting from the point of view of literacy research and literacy teaching, and require further empirical study.

The "Comic Book Project" was initiated in 2002 by Michael Bitz as a collaborative project between an educational researcher

\footnotetext{
${ }^{16}$ See http://www.comicbookproject.org
} 
and a comic book publisher (Dark Horse Comics). It initially engaged over 700 children in 33 different after-school programmes in New York City. The children designed, wrote, and drew their own comics in an effort to "build literacy and artistic skills" (Bitz, 2004, p. 575). Results showed a high level of child motivation and pride in their own work as well as self-perceived development of literacy skills. Both children and instructors found that children's writing had improved, and that they enjoyed writing their own stories (Bitz, 2004, p. 582). As an after-school programme with children and youth interested in drawing and designing comics, this study could benefit from being replicated in a formal school setting, as well as from being broadened to include additional literacy perspectives on comics.

Katherine Bucher and Lee Manning (2004) point out the value of reading comics, as comics teach pupils to decode facial as well as body expressions, symbols, metaphors and more, thus emphasizing the perspective of visual literacy. Similarly, Hammond's (2009) doctoral dissertation investigates the combination of picture and text as the strength of the comic book format. Hammond conducts interviews, written responses and field notes with 23 twelfth-grade pupils responding to the graphic novel American Born Chinese. She claims that visual literacy is a useful skill in society in general, give the increasing digitalization combining picture, text and speech, but it is unclear how printed graphic novels relate to digital literacy. Hammond argues that "readers of comics have usually mastered the traditional text literacy" (p. 43), which might be true of her twelfth-grade pupils, but is certainly not the case for many younger pupils. Regardless, she points out that comics, as picture books, are important to introducing children and young people to visual literacy, and that they need training to master it. Although the relations between visual literacy and comics literacy are never clearly defined in Hammond's work, she contributes by pointing out some literary functions of the comic book format, such as pacing, the possibility of stopping on certain panels and pages, or going back and rereading one or several panels, as well as the ability to overview several panels at once. Furthermore, some comics offer the possibility to disrupt the traditional reading order (left-to-right, or 
right-to-left, depending on your reading culture) through different panel structures (see also Cohn et al., 2014; Cohn et al., 2012). These structural options are not as easily applied to, for example, novels, so their use when working with comics requires further investigation.

A study based on the "Comic Book Project", Stoermer's (2010) doctoral dissertation attempts "to understand the pedagogy and content knowledge (pedagogical content domain) required to teach children aged seven and eight to author comics" (p. 10). Based on her results, Stoermer argues for the discovery and further development of a "grammar of comics", and that this would be "a means of assessing student-made comics using an authentic measurement developed from the art itself' (p. 267). Thus, Stoermer provides teachers with pedagogical tools and theories to work with primary school pupils who are creating comics narratives in the classroom.

Furthermore, Hammond together with Katherine Danaher (2012) also engaged in a project where they designed their own comic book readers. These readers reflected the course syllabus and supported vocabulary use for elementary and upper-intermediate adult second-language learners of English. By studying how pupils increase their vocabulary through the use of comic books in the home, the researchers pinpoint "the importance of responding to learners' specific contexts and to the creative ways in which English learners undertake autonomous learning when provided with the appropriate resources" (p. 201). This highlights the idea of comics as a motivational factor, which is something that could be further studied in situated school practice, as well as in the home.

Some take for granted that the picture-text combination is a supportive frame for reading comprehension that should be abandoned after a certain stage of learning is reached (usually linked to a specific age group), and that after reaching this stage, the reader should be able to read texts without accompanying pictures, i.e. novels, novellas, articles, etc. (e.g., Jonsson, 2006). This is an unfortunate view of reading, which seems to assume that reading level automatically increases with age, and that images are always easier to understand than text. It would be beneficial to literacy research to broaden the view of comics in education as 
reading material for all ages, working from the assumption that comics are not necessarily as childish as many readers might expect them to be (cf. Westin, 1993, 2002), but rather that comics can be found at all reading difficulty levels.

In her research on graphic narratives, Pantaleo has investigated the use of both picture books and comics. Through case studies and classroom studies - utilizing interviews, observations, and collections of pupil-produced materials - Pantaleo demonstrates pupils' awareness of the impact of the graphic perspective on narrative materials and the need for complex cognitive skills in reading as well as creating graphic narratives (see, e.g., Pantaleo, 2011a, 2012c, 2013). A possible complement to Pantaleo's research, would be to study the interactional process of the classroom - exploring the discursive literacy practices of teachers and pupils demonstrated through detailed transcription.

Some other books from the early 2000 s are also of note, as they tend to be drawn upon in the literature: 1) James Bucky Carter's (2007) Building Literacy Connections with Graphic Novels: Page by Page, Panel by Panel is a seminal guide for middle and high school teachers with many different examples of possible classroom work, 2) Nancy Frey and Douglas Fisher's (2008) Teaching Visual Literacy is a similarly excellent teaching aid for using comics and other visual media (for a review, see Robison, 2011), and 3) Terry Thompson's (2008) Adventures in Graphica provides useful examples of teaching with comics from different perspectives. These works focus on providing teachers with examples of how to use visual literacy in their classrooms, primarily supported by literary analysis of graphic texts. There are few empirical examples taken from the classrooms, thus leaving a gap for future research to fill.

Four other textbooks also discussed frequently are: 1) Stephen Tabachnick's (2009) Teaching the Graphic Novel, 2) Lan Dong's (2012) Teaching Comics and Graphic Narratives, 3) Karin Kukkonen's (2013) Studying Comics and Graphic Novels, and 4) Carrye Syma and Robert Weiner's (2013) Graphic Novels and Comics in the Classroom. All of these publications address the use of graphic novels and comics for an array of subjects within higher education. Although these books are theoretically interesting for 
the discussion of comics - they present both different theoretical frameworks and a multitude of different source texts - their focus on higher education have rendered them less relevant for the current discussion on comics use in primary and secondary school.

As detailed above, some studies have been done on the use of comics, but many of these either are not based on studies in schools or are experimental. Therefore, it is interesting to add to these perspectives new aspects of comics practices. In addition, it has thus far been difficult to find any literacy studies on use of comics in a Swedish school context ${ }^{17}$, and in this respect the study adds to national studies of literacy in educational practice.

\section{Concluding remarks}

This chapter has outlined relevant research areas dealing with the use of comics in education. Comics as we know them today (comic strips, collections of strips in full-length albums, or self-contained storylines in full-length graphic novels) have been studied since around the 1920s from a variety of perspectives: language, literacy, history, social studies, natural sciences, etc. Some studies have highlighted comics for their popularity and ability to motivate children and youths, while other studies have emphasized specific beneficial aspects of comics for specific subjects. What they have in common is that they appear to be experimental studies that place the comics material in the hands of the participants, or otherwise "telling" the participants what to do. Early research on comics was quantitative in nature and conducted using surveys for teachers or pupils, and often focused on reader experiences of comics. Other studies focused on pre- and post-testing of pupils, where comics were used as materials for specific aspects of learning. In later years, ethnography and qualitative studies have become more common, with long-term classroom observations and study of children producing comics.

\footnotetext{
${ }^{17}$ Some important Swedish research on comics to note is the work of Kristy Beers Fägersten (2012), Magnusson (2005), and Fredrik Strömberg (2003, 2007), see also Strömberg (2016). However, these works are primarily historical, literary, or linguistic.
} 
The current dissertation presents a study of natural meaning making with comics in schools, where teachers and pupils are outside the control of the researcher, the aim being to add new perspectives to the experimental studies. Furthermore, the current study also adds an interactional perspective to the previous research. This will be discussed further in the next chapter. 


\title{
5. Methodology and Research Design
}

\begin{abstract}
When literature is treated as a neutral medium of communication between two individuals, [---], its fundamental dependence on social resources and shared systems of sense-making is ignored.
\end{abstract}

(Potter, Wetherell, \& Stringer, 1984, p. 23)

This chapter details the methodological and ethical considerations of the study, as well as discussing choices made in the process of recording of and analysing the data.

\section{Naturally Occurring Literacy Interaction in School}

The idea of the present study is to study "interaction in educational contexts [---] in order to understand the nature of schooling" (Mehan, 1979, p. 6). Both the format of the texts (comics) and how the format engages pupils are in focus. Thus, the intention is to show how pupils and teachers construct discourses when working with comics, and how they utilize materials for talk as social action (Potter, 1996). What aspects are studied depends on the work the teachers and pupils are doing, and what can be found in the field (cf. Mondada, 2006).

Rather than conducting experiments or interviews, where the researcher is (more or less) in control of the participants, DP studies naturally occurring interaction, i.e., interaction that would have taken place regardless of the presence of the researcher (Mondada, 2006; Potter, 2010; Sacks, 1984). This aim takes us away from the controlled laboratory and allows the researcher to study talk about literacy aspects - such as narrative, literary devices, and discourses on literacy - through natural talk (cf. Allington \& Swann, 2009b; Eriksson Barajas, 2016). It minimizes researcher impact and influence over the interaction studied, the goal being to gather data from a "normal" school environment. 
The aim of the current dissertation is to study naturally occurring social interaction around literacy in talk and text. CA is the basis of the methodology utilized here, in that it is "a wellestablished method for explicating the order of social life via sequential analysis of everyday interaction" (Stokoe, 2003, p. 320). Because DP is similarly focused on understanding the intersubjectivity of everyday social life, it has utilized the methodology of CA, while taking a constructionist stance on discursive practices (Wiggins, 2017). Thus, DP utilizes conversation analytical methods of investigating talk-in-interaction, looking at, e.g., sequential interaction, phrasing, tone and body language, while adapting these conventions (through, e.g., choice of transcription system) to an interest in psychological and discursive issues (Potter, 1996; Wiggins, 2017) ${ }^{18}$.

\section{Finding a Field of Study}

With this methodological starting point, the first consideration was whether or not there were teachers actively working with comics in their classrooms, and whether it was possible to gain access to these classrooms. The initial research questions were designed as exploratory (e.g., how is classroom practice with comics done?), so as to encompass many different types of materials and school subjects, as well as variation in the difficulty level, style and length of comics. Thus, all school subjects, age groups and types of schools were considered to be of interest at this stage of the process. In fact, seeing how teachers work with pupils of different ages and with different subjects would give a richer empirical basis, and, therefore, be beneficial to the intended purpose of the study. Thereafter, as data were explored and findings emerged, the research questions were refined and became more detailed, focusing on specific aspects of practice, as seen above.

In the fall of 2012, emails were sent out to major regions in southern and central Sweden, reaching approximately 200 schools ranging from primary to upper secondary level. The emails

\footnotetext{
${ }^{18}$ I will not go into great detail here in differentiating between DP and CA, as it is not essential to the current dissertation. For those who are interested, I recommend Wiggins (2017, Ch. 2) and Wooffitt (2005).
} 
requested contact with teachers who used comics in their classroom and who would be willing to participate in a short pilot study. The replies were either non-existent or negative, usually stating that the medium was not in use at the school. This may be an indication that comics are not common materials in Swedish schools in general, and in the standard Swedish curricula they are, quite literally, notes in the margin (Swedish National Agency for Education, 2011a).

An obvious problem with this kind of approach is the lack of personal contact, while the advantage is that one could potentially reach many more schools in a shorter time. The initial emails went out to the contact email address of each school (usually displayed on their website, or the website of the municipality), and this was followed by a telephone call within a week (if there was no reply). In some cases it turned out that the information had not reached the school, so an email was sent out again, with the goal of reaching individual teachers. In practically all of these cases, the head of the school then forwarded the information to the teachers. Of course, this shows how this type of system creates a bottleneck of information, which increases the risk that the individual teachers never find out about the study in the first place.

Another problem encountered was the interpretation of the field and subject, for example a teacher might not consider materials they are using to be "comics", and this might reduce the number of teachers who consider themselves eligible for the study. One way to decrease this risk would be to visit a number of different classrooms and teachers to make field observations to determine if the researcher could find evidence of use of comics there, regardless of what the teachers call the material - a cumbersome and inefficient process akin to finding a needle in a haystack.

Nevertheless, there were a few positive replies to the emails; some teachers who were interested, but did not presently use comics in their classrooms, and some teachers who did use them, showing that not only is there a spark of interest among teachers for possibly using comics, but also that comics are being used in some Swedish classrooms. I was also contacted by a major teacher's union magazine, the editor of which was in the process of publishing an article on the use of comics in schools (af Sandeberg, 2013). She was kind enough to offer me an opportunity to put in an 
ad together with this article, citing my interest in teachers working with comics. This in turn led to increased interest, and it was possible for me to come into contact with more professionals interested in the subject.

Contact with the Duckburg Grade School (see full presentation below) came through Egmont Publishing (Egmont), a Nordic publisher of Disney comics, etc. Egmont had, at the time, initiated two projects: one quantitative reading study in Norway, where school children read comics, and a project in Sweden where teachers and pupils in primary schools (Grade 3 and 4) were given comic book materials to use in their lessons (Egmont Publishing, 2015). Through the aforementioned ad published together with the magazine article, Egmont contacted me and expressed their interest in having an independent researcher study their project.

Egmont's initiation of this project could have influenced teacher and pupil behaviour in some way, but there is no sign of this in the recorded material. Similarly, there is no reason to claim that participants act for the camera, unless the researcher could sequentially observe this in the video (Mondada, 2006, p. 61). As suppliers of the comic book materials, Egmont could be argued to be an influence over the study. However, the publisher was not present in the classroom to study the interaction, and teachers were free to use the provided material as they wished. Therefore, there is no reason to claim that the interaction in the classroom was not naturally occurring. For the pupils in the study, these classes would presumably be no different from other classes planned by their teacher, and it is important to remember that what is studied is how things are done, rather than why it took place, or who instigated it. Furthermore, DP strives towards studying interaction that is not staged by the researcher - with the researcher's specific goals or theories. The main idea here is also to differentiate this type of natural interaction as a source of data from interaction in the form of, e.g., interviews (Potter, 2010), where participants talk about their work or their assessments, preferences, etc. The practices done in this setting are considered naturally occurring interaction and would have been carried out regardless of the researcher's presence (Mondada, 2006; Potter, 2010; Sacks, 1984). The ethical 
aspects of the contact with Egmont are further discussed below (p. 73).

Contact with a Grade 8 classroom came through an email, where the class teacher expressed an interest in having me study the class's activities with comics. After some correspondence in which practical issues were sorted out, I was invited to meet the class. I introduced the project and myself, and handed out consent forms for the pupils and their guardians to sign.

\section{Data - Recording, Handling and Storing}

Studying naturally occurring interaction nevertheless involves making choices: the field of study, what one is interested in, how the study is to be performed, what type of data or phenomenon is of interest, etc., just like in any study. From a social constructionist perspective, all studies are a matter of producing data rather than collecting it, because the production of data entails a number of choices that the researcher makes. However, it is important to emphasize that the researcher has an effect on the data, through his/her choice of methods, transcription, translation and analysis (Abbott, 2004; Hacking, 1999). Analyses of the data in the current dissertation are presented along with transcripts to help the reader read and re-interpret the data and further validate (or disagree with) the results of the study.

Studying practitioners in their work environment includes the risk that they might become self-aware, and not welcome a researcher or outsider who might (in their view) be critical of their work. This could limit the researcher's access to the field, and it is possible that this fear of being criticized stems from a view that classroom work is comparable to some sort of idealized standard, which in itself is impossible to live up to (Hepburn \& Potter, 2004). In my experience, the practitioners involved in this study understood that they could help others by sharing their experiences while participating in the study. Because the study focuses on natural participant interaction, no interviews or surveys have been conducted, merely video observations of classroom work. This, in turn, has the advantage of not taking any extra time out of participants' daily work (Mondada, 2006; ten Have, 1990). 
In writing, I refer to the teachers and pupils (primary school and secondary school) collectively as participants. Regarding anonymity, I chose to give my participants and their schools names, instead of generic pseudonyms, such as Pupil 1/School 1. Information on individual pupils' characteristics or background has not been deemed relevant to the analysis of the interaction, as the present study focuses on situated context and participant talk (Wiggins, 2017). Therefore, statistical data on ethnicity, socioeconomic background, and mother tongue have not been collected. The names chosen for the different participants reflect their gender, but not ethnicity, language or other aspects. Besides providing a key for the analyst, as well as the reader, as to who says what, the names are generic and interchangeable, and are merely included to give the transcripts more life. Because the analytical points made in the study do not concern matters of, for example, participants' ethnicity, there is no reason to divulge this.

\section{Video Observations}

When studying classrooms, interaction and teaching methods, there are many different methods to choose from. The main method for data production in the current dissertation is video-ethnography: video recordings of interaction (see, e.g., Mondada, 2006). As DP studies naturally occurring talk-in-interaction, recorded classroom observation is an important element in understanding the everyday situation of participant interaction, because it gives the researcher access to sound as well as participants' gaze, movement, and manipulation of physical materials (the whiteboard, comics in front of them, etc.). Naturally, recordings are also affected by researchers' choice of angle, time, depth of detail, etc., but these kinds of methodological selections must be made in all studies. Thus, the researcher has the advantage of capturing sound and video without needing to process the information on site (as must be done with, e.g., observational field notes), while still being able to study all aspects of the classroom. This approach entails less risk of disturbing the everyday situation and regularity of the classroom. Therefore, video observations are considered an optimal means of recording natural data (ten Have, 1990). Interviews, for example, could contribute to an understanding of context and situation, but 
alone they are not enough for a proper analysis of the in situ practice studied, because what is interesting is the everyday, natural interaction, and interviews do not reflect the interaction normally occurring in school - in that case, the researcher would have to specifically study interview situations, which are rare in school environments (ten Have, 1990, p. 26; see also Potter, 2010).

Furthermore, video recordings allow the researcher to go back and look at the recorded data repeatedly in order to verify ideas and interesting observations, as well as to discuss the data more thoroughly with other researchers, thus increasing the validity of the analytical process (Mondada, 2006).

\section{The Field Study}

Initially, a pilot study was planned, to test different recording methods and technologies and determine what would be preferable. Contact was established with one secondary school, and a visit was planned for four lessons. However, the teacher found that the project that the class was doing had become much more relevant and chose to expand it. This - coupled with the fact that the recordings were made in three to four groups per lesson instead of with the whole class, and the addition of another school with three more classes - meant that the amount of data suddenly increased greatly in a very short time, from a smaller set of three-four hours of video - to around forty hours - in a matter of weeks. The quick addition of so much material meant that the recording methods, camera angles, storage and other technical matters had to be swiftly adapted to new circumstances, as this addition of materials was considered too important for the study to risk losing.

Unfortunately, quick adaptation to the new time frame, to the physical environments, and the amount of data also meant that a certain portion of the data was difficult to transcribe and analyse due to poor video or audio quality, bad camera angles, background noise and such. This was a calculated risk deemed necessary to take in order to gather the large amount of data that was suddenly available (and with it the variation in use of materials, the increased chance of repeated phenomena, etc.), instead of sticking to the few hours initially scheduled and risking not to have access to more data at a later point in the study. Because the methodology used in 
the present study is qualitative and analysis can be conducted using relatively small segments of data (Sacks, 1984; Wiggins, 2017), the risk of not being able to find usable material within the entire forty hours of recordings was seen as minimal (Mondada, 2006).

The recordings consist of a variety of pupils working in smaller groups or pairs, as well as whole class interaction between teacher(s) and pupil groups (which is more often a question-andanswer type of interaction). The idea is not to produce generalizable material representative of Swedish schools as a whole, but to include a rich variety of interaction so as to capture rare events if possible. As the study focuses on naturally occurring phenomena in interaction, it is also desirable to capture these phenomena, where instances can be analysed, compared and contrasted for variation. Even though small collections of segments are enough to analyse, this "makes it impossible to determine the relationship of these isolated segments to the context from which they were taken. It also makes it difficult to determine the frequency or typicality of their occurrence" (Mehan, 1979, p. 16; see also Sacks, 1984; and Wiggins, 2017). In order to accomplish this, the researcher needs to be able to roughly predict what types of data will be available for observation, what categories of informants are accessible, and what issues may arise during the study (Hepburn \& Potter, 2004).

\section{Data Material}

The total dataset consists of approximately 36 hours of video and audio data, produced in three Grade 3 classes, and one Grade 8 class. This number is approximate, as sometimes several cameras focused on the same group, and as pupils would leave and return to the table at different times, making it difficult to establish the exact amount of time. All three Grade 3 classes were attended to by at least one teacher, and during some lessons two more teachers were also present. In Grade 8, one teacher was present throughout all the lessons. 
Table 1. Overview of data

\begin{tabular}{|c|c|c|c|c|c|}
\hline $\begin{array}{l}\text { Grade, (no. } \\
\text { of classes), } \\
\text { Subject }\end{array}$ & $\begin{array}{l}\text { No. of } \\
\text { partici- } \\
\text { pants } \\
\end{array}$ & $\begin{array}{l}\text { Type of } \\
\text { interaction }\end{array}$ & $\begin{array}{l}\text { Type of } \\
\text { material } \\
\text { (see also p.71) } \\
\end{array}$ & $\begin{array}{l}\text { No. of } \\
\text { lessons } \\
\text { recorded } \\
\end{array}$ & $\begin{array}{l}\text { Unique } \\
\text { hours } \\
\text { recorded }\end{array}$ \\
\hline $\begin{array}{l}\text { Grade } 3, \\
\text { ( } 3 \text { classes), } \\
\text { Swedish } \\
\text { language }\end{array}$ & $\begin{array}{l}5 \text { teachers } \\
52 \text { pupils }\end{array}$ & $\begin{array}{l}\text { Group } \\
\text { work, pair } \\
\text { work, } \\
\text { whole class } \\
\text { instruction }\end{array}$ & $\begin{array}{l}\text { Donald Duck } \\
\text { comic books } \\
\text { and comic } \\
\text { strips, work } \\
\text { sheets, copy } \\
\text { material, } \\
\text { instructions. }\end{array}$ & 10 & 20 \\
\hline $\begin{array}{l}\text { Grade } 8, \\
\text { (1 class), } \\
\text { Social } \\
\text { studies }\end{array}$ & $\begin{array}{l}1 \text { teacher } \\
25 \text { pupils }\end{array}$ & $\begin{array}{l}\text { Group } \\
\text { work, } \\
\text { whole class } \\
\text { instruction }\end{array}$ & $\begin{array}{l}\text { Comic strips } \\
\text { from } \\
\text { newspapers } \\
\text { (various), } \\
\text { comic books, } \\
\text { toys from } \\
\text { different comic } \\
\text { books, } \\
\text { instructions. } \\
\end{array}$ & 5 & 16 \\
\hline Total: & $\begin{array}{l}6 \text { teachers } \\
77 \text { pupils }\end{array}$ & & & 15 & 36 \\
\hline
\end{tabular}

\section{Grade 3 - Duckburg Primary School}

The primary school included in this study was named Duckburg Primary School, after the fictional town where the characters in the Disney comic book Donald Duck \& Co. reside - and because the materials used in this school are Donald Duck comics. Duckburg Primary School has about 600 pupils, ranging from preschool class to secondary school (6-16 years old), located in a municipality in southern Sweden.

At Duckburg School, three classes in Grade 3 (9 years old) were studied over the course of three weeks, covering four full days of lessons. The three classes consisted of 15-18 pupils each; groups in the classroom ranged from 2-4 pupils, and on average 10 pupils were present in the classroom at any given time. 
The pupils worked with comic books and other materials from a teacher's guide provided by Egmont. The teachers were unfamiliar with this particular material, although the characters in the comics were well known. Throughout the three weeks, ten lessons were studied in which teachers worked with different types of assignments and materials taken from the comic books at hand. Pupils generally worked in groups or pairs, and four video cameras and microphones were used to record audio and video from four different tables, sometimes using two cameras for the same table, if there were fewer than four tables. A class would sometimes split into two depending on the task given, where the half that stayed in the classroom worked with the comic-book-related task, and the half that left worked with other assignments.

\section{Grade 8 - Bangalla Secondary School}

The secondary school in this study has been named Bangalla Secondary School, after the fictional country of Bangalla depicted in Lee Falk's The Phantom - as some of the materials used here are The Phantom comics. This school includes Grade 7-9 (14-16 years old), has approximately 300 pupils, and is located in a municipality in southern Sweden.

At Bangalla, one class in Grade 8 (14 years old), engaged in social science, was studied for 10 weeks. Groups would range between three and eight pupils, and the whole class consisted of 25 pupils, accompanied by one teacher. Five social science lessons were studied during this time (the class met once per fortnight on average).

These pupils worked with comics chosen by their teacher, mostly comic strips from daily newspapers or cut out or copied comic strips from comic books such as Nemi, The Phantom, Calvin \& Hobbes and many more. The lessons usually consisted of a whole-class introduction, group work, and a group presentation or discussions of the work done. Topics included: gender issues, stereotypes, mood, narration and aspects of pupils' own experiences of the world. As with the Duckburg School study, four cameras and microphones were used, and this class usually utilized both whole-class sessions and group work during a lesson. 


\section{A Note on Materials}

The materials used by the pupils and teachers varied between the two schools. The comics used by the pupils in Duckburg School were all provided by Egmont through their project Serier $i$ undervisningen [Swe: Comics in teaching] ${ }^{19}$, and is accessible through their website. The material is based on Disney's Donald Duck characters, and includes a teacher's guide (Galaczy, 2013a), materials that may be photocopied (Galaczy, 2013b), and two fulllength comic book albums (D. Carlsson, 2012, 2013). These albums are collections of Donald Duck comic book stories, the oldest from 1934 and the newest from 2012. These stories are, as stated on the publisher's website, "appropriate for use in schools" (Egmont Publishing, 2016, my translation), but there are no indications as to why these specific stories have been chosen, nor any reference to their pedagogical value, except that the ones in Välkommen till Ankeborg [Swe: Welcome to Duckburg] (D. Carlsson, 2012) have connections to certain geographical locations in the fictional Duckburg. The teachers used these materials as part of a project designed by Egmont, which the school had decided to take part in, but the teachers decided individually what materials should be used for any given class, and how. Egmont then asked for feedback on how the teachers perceived and used their products. During lessons, materials were sometimes accompanied by instructions from the class teacher, either verbally or in writing, as in any lesson situation. These types of instructions have been noted accordingly in the research papers, along with the excerpts.

The materials in Bangalla School varied over the five lessons, from comic strips cut out of daily newspapers (such as those found in Dagens Nyheter and Svenska Dagbladet) to comic book albums, both old and new, and material varying in content, language and target age group: from Donald Duck and Bamse comic books to The Phantom and Modesty Blaise, and comic strips such as Medelålders-plus ${ }^{20}$ and Hälge $e^{21}$. These comics were brought in by

\footnotetext{
${ }^{19}$ See http://www.serieriundervisningen.se

${ }^{20}$ Medelålders-plus is a Swedish comic strip by Sven Bertil Bärnarp, published in Dagens Nyheter. The main characters are a retired couple, their friends, and family, and the jokes often cater to "the good old days" or similar tropes and
} 
the class teacher, who sometimes bought them on impulse on the way to the school the same morning. The pupils were also given instructions for the different lessons, sometimes verbal, sometimes written down, either on the whiteboard or on paper. Where appropriate, this has been noted accordingly in the papers along with the excerpts presented.

\section{Data Considerations}

Naturally, the experiences from Duckburg School and Bangalla School differ owing to the difference in age groups and subject.

In Duckburg School, the pupils were mainly focused on reading, narrative, storytelling, structure and other literacy issues. This focus on literacy, and the way that pupils and teachers worked with the reading of comic books, is interesting, to say the least, due to the relatively unusual format of the material they were reading (none of the teachers had worked with comic books before). As the teachers further reported - reports that could be verified by classroom observations and video footage - pupils tended to read comic books together in pairs, talking about details in the pictures, and pointing out things to each other. This ongoing communication while reading was viewed by the teachers as a way of understanding and relating to a material that was different from regular fiction reading. The teachers themselves also pointed out the visual elements of the comics as something they valued.

Despite being literary material, I observed relatively little reading going on in the classrooms of both schools. More frequently, pupils would be working with literary structure, drawing characters and such, and only on a few occasions, mostly segueing into the next exercise, would the assignment be to read in the comic books. It turned out, as teachers told me in the latter part of the project, that pupils would occasionally ask to read the comics

discourses (https://seriewikin.serieframjandet.se/index.php/Medelålders_plus, in Swedish).

${ }^{21}$ Hälge is a Swedish comic by Lars Mortimer, in which the main character, Hälge, is a moose. The comic humorously depicts his daily life dealing with other anthropomorphic animals, as well as human hunters and others living in the vicinity of the forest (https://seriewikin.serieframjandet.se/index.php/Hälge, in Swedish). 
as part of their time at the after-school recreation centre (In Swedish: fritidshem). Although generally focusing on Swedish language studies, at one point a teacher at Duckburg School also crossed into social studies by using the fictional city of Duckburg to discuss infrastructure and necessary functions of society, comparing it to the pupils' own surroundings.

At Bangalla School, pupils similarly used images and image interpretation to discuss aspects of their own social life. Discussions around gender stereotypes and social prejudice were common, between groups or in the whole class, and references to the clothing, colours or style found in the images were frequent. As an example, the teacher at Bangalla used emotions of anger expressed in a $\mathrm{Nemi}^{22}$ comic strip to discuss the topic of emotional expressions and violence and what we view as correct and incorrect social behaviour.

Nevertheless, the teachers at both schools used basically the same methods: individual reading, discussion in small groups, drawing, oral and textual presentations, etc. - which is representative of regular Swedish classroom practices and, thus, not specific to comics use.

\section{Ethical Considerations}

The audio and video recordings have followed the principles of research ethics in the humanities and social studies concerning information, consent, confidentiality and use (Swedish Research Council, 2011). Because the study does not "use personally sensitive data $(2$ §) [---] entail physical encroachment, aim to affect subjects physically or psychologically, or entail an obvious risk of harming subjects (3 §)" (Swedish Research Council, 2011, p. 21; see also SFS, 2003:460), it has not been deemed necessary for it to undergo review by the Regional Ethical Review Board. Because all of the pupils in the current study were under the age of eighteen at the time of recording, the teachers, schoolchildren and their legal guardians were made aware of the research project through written

\footnotetext{
${ }^{22} \mathrm{Nemi}$ is a Norwegian comic by Lise Myhre about the titular character Nemi, a young Goth woman, and her everyday life dealing with romance, friends, and being part of a subculture (https://en.wikipedia.org/wiki/Nemi_(comic_strip)).
} 
and oral information, and participants were invited to participate without being pressured. Moreover, they were informed that they could leave the study at any time (see Appendices 1-4). In Grade 3, two pupils did not take part in the study, while in Grade 8, five pupils did not take part. The choice not to take part did not affect the lessons for these pupils; they were either involved in classroom activities but not filmed (at their own request), or they worked with similar tasks in an adjoining room.

The principles detailed above have also been adhered to throughout the viewing and analysis of data. Because young children might be afraid to speak their mind to an adult, and because the researcher left the room during filming, any resistance to filming that is visible in the data has been acknowledged. As an example, during one lesson, a pupil in a class demonstrated clearly that he did not appreciate being filmed; hiding his face in his hands, refusing to do the task, etc. Unfortunately, the teacher did not read these signs as being caused by the presence of the camera, but rather as a "troublesome pupil" resisting the lesson task and, as such, did not turn the camera off or move the pupil somewhere else. I chose not to analyse this section of data out of respect for the pupil. In another class, four pupils were done with the lesson task after half the lesson (20 min.), and were then encouraged by the teacher to talk about "whatever". These pupils then asked the teacher if the camera could be switched off, because this interaction had nothing to do with the research being done, and the teacher turned it off. This shows courage and an understanding on the part of the pupils and the teacher concerning the rights the pupils had with regard to filming.

The exact time of recording, names of cities, schools and participants have been changed to ensure confidentiality. The recorded data are treated as confidential, and are not stored on computers but on DVDs or separate hard drives. The data are used for the research purpose stated in the introduction (p. 8). After completion of the study, the data will be stored at the university. The study does not aim at influencing the participants; nor is it expected to involve sensitive personal data. The project has been conducted using a high standard of research ethics (Swedish Research Council, 2011); during analysis, interpretation and 
presentation of the findings, and while quoting others' research, the findings have not been twisted or ameliorated so as to support the thesis.

In regards to researcher independence, I have been given permission from Egmont (and Disney) to use their materials in my work as part of the analysis. I have received information about their project and contact information to the school included in my study (their project encompasses several other schools), but no special benefits, and I am under no obligation to present any particular results to the publishing company - the research is not being done to promote the interests of Egmont. Personally, I have no vested interest in Egmont as a company, and I stand nothing to gain or lose from their success or failure. Furthermore, Egmont representatives are aware that my results could be potentially run counter to the intentions of their project. In my view, the present work entails no bias or situations marked by ethical conflict.

\section{Concluding Remarks}

In this chapter, the methodological and ethical considerations of the current study, and the choices made in the process of recording have been discussed. For any project of this size, there are numerous decisions that need to be made, and the process requires continuous changes to be made to these decisions. Naturally, it is possible to do things differently, make different choices, and speculate over what different outcomes these choices may lead to. If readers have ideas that would make for an interesting study to complement the current one, I encourage them to pursue their ideas.

The two schools and the participants taking part in the study have been presented in this chapter, as have the recording methods, which were based on DP methodology. As researchers, we are indebted to and dependent on participants in studies of this kind, and the aim of DP studies is to present the reader with a clear and concise picture of the participants' perspectives. In the next chapter, the methods of transcription and translation for displaying these perspectives will be further discussed. 



\title{
6. Representing the Data
}

\begin{abstract}
A transcript is an evolving flexible object; it changes as the transcriber engages in listening and looking again at the tape, endlessly checking, revising, reformatting it.
\end{abstract}

(Mondada, 2007, p. 810)

This chapter describes how the data in the study were annotated, transcribed and translated, and discusses the different conventions used in the papers.

\section{Transcribing Verbal and Non-verbal Interaction}

When video and audio materials have been recorded, it is important for the analyst to make transcriptions of the talk, both to have a text mass that can be read and searched through, but also because transcribing and reading transcriptions constitute a first step in the analytical process (what aspects of talk and movements do I transcribe?). Furthermore, transcripts allow the analyst to share findings with other researchers, discuss and refine the analysis, and select passages of special interest, which increases the validity of the study (Hepburn \& Potter, 2004; Potter, 2012).

Initially, a primary transcription of the full material was made to obtain an overview of the material, the different lessons and groups. This was used together with the video data for primary analysis and, therefore, these transcripts were kept simple: a wordfor-word account of the verbal conversation, keeping to the verbal spelling (such as "va" instead of the literal "vad"), marking longer pauses, and marking rough descriptions of embodied actions where they were considered of interest (see Transkription II in Linell (1994, p. 10), which details a similar method of transcription; see also Appendix $5 \& 6$ for the transcription keys used in the papers). One benefit of this is time saving, as detailed multimodal 
transcription is very time consuming, and much of the transcribed material might not be used in the end. Thus, after having found particular phenomena of interest in the material, and having analysed them, more detailed transcriptions were made. At this point, multimodal aspects were minutely described, one benefit of which is being able to show the reader the analysis (Jefferson, 2004; Mondada, 2006, 2014).

Thus, transcription has been an ongoing process, coupled with the analytic process (Mondada, 2007; see also Chapter 7). As the analyst uses the transcripts and the video data, new phenomena within the interaction come to light, and transcripts need to be refined. Similarly, as transcripts go through a process of translation for presentations, new aspects and problems emerge that need to be addressed (see p. 82, below). This represents the two purposes served by the transcripts, according to Linell (1994): supporting analysis of the data and presenting the data to the reader.

Throughout the analysis, the video data have been the primary subject of analysis (Linell, 1994; Mondada, 2007), using the transcripts to help to clarify what is being said or to highlight actions. Furthermore, prior to publication, the transcripts have undergone a process of refinement to present the reader with the relevant points of analysis and to (possibly) adapt the transcript to journal requirements (size, length, etc., see Linell (1994); see also p. 79, below). The aim is to abide by the first principle proposed by Daniel O'Connell and Sabine Kowal (2005, p. 98): Only that which is analysed should be transcribed, and only that which makes the analysis intelligible should appear in the transcription. Lines considered irrelevant have been removed (and this has been noted in the transcript), names of participants have been abbreviated, and similar "cosmetic" adjustments have been made.

In the analysis, participants are referred to as pupil and teacher, respectively, or by their aliases. Referring to them as "teacher" and "pupil" is not meant to be descriptive or categorizing, just as giving a participant a name is not descriptive, because it does not attribute any qualities to that person. In traditional conversation analytic practice, a person needs to be made interactionally relevant as a teacher in order for him/her to be named as such (otherwise, we are attributing this category to the person, which could corrupt the 
analysis). However, there is no automatic inference made here that the membership category of teacher is necessarily reflected in the interaction (Lerner, 1995). The roles of certain participants as teachers and certain participants as pupils are reflected in the data in the same way as the relevance of the context - a school or a lesson - is. No inference is made by the analyst that certain actions take place because of participant categories; rather actions are shown to be produced through the sequential organization of talk.

\section{Graphic Transcripts}

One difficulty in working with video data in any environment is how one can take in everything that is going on, and even if one manages to select something, how does one best show it to the reader? All transcription work must deal with this difficulty, especially in multimodal settings (see Jefferson, 2004; Linell, 1994; Mondada, 2007; O'Connell \& Kowal, 2005). As a possible solution to this, the excerpts in Paper III are presented as graphic transcripts (Laurier, 2014), using conventional comic-book panels displaying participants, and speech bubbles to show the talk (see Appendix 6). This helps in displaying the sequential interaction of participants, the gestural (through panels) and verbal aspects (in bubbles) of the talk, and visually displaying tone of voice in a manner that adheres to comic conventions (through speech bubble frames, see Paper III). As the presented phenomenon of Paper III is speech bubbles and their multimodal aspects, this mode of transcription was considered the most suitable for displaying participants' tone of voice, as well as prosody and talk (for an interesting review of verbal/visual transcripts, see Eric Laurier (2014) $)^{23}$.

The graphic transcripts were produced by selecting relevant lines of dialogue from Jeffersonian transcripts (see Appendix 5) and taking the corresponding screen shots from the video to show gaze and embodied action. These screen shots were then processed as individual panels in Sketchbook photo editor, where faces and hands were traced and turned black and white, in order to preserve

\footnotetext{
${ }^{23}$ For other examples of the use of graphic transcripts, see Pentti Haddington and Mirka Rauniomaa (2014), Jonas Ivarsson (2010), Oskar Lindwall, Berner Lindström, and Jonte Bernhard (2002), Lindwall and Ivarsson (2010).
} 
anonymity. The different panels were then put together as a singlepage grid (in order of sequence), and speech bubbles were added manually. After this, using the GIMP image program, the text was transferred from the written transcript to the different speech bubbles, keeping underlined text and symbols from the Jefferson transcript. Figures 5 and 6 compare the types of transcript, both taken from Paper III (see also Appendix 6).

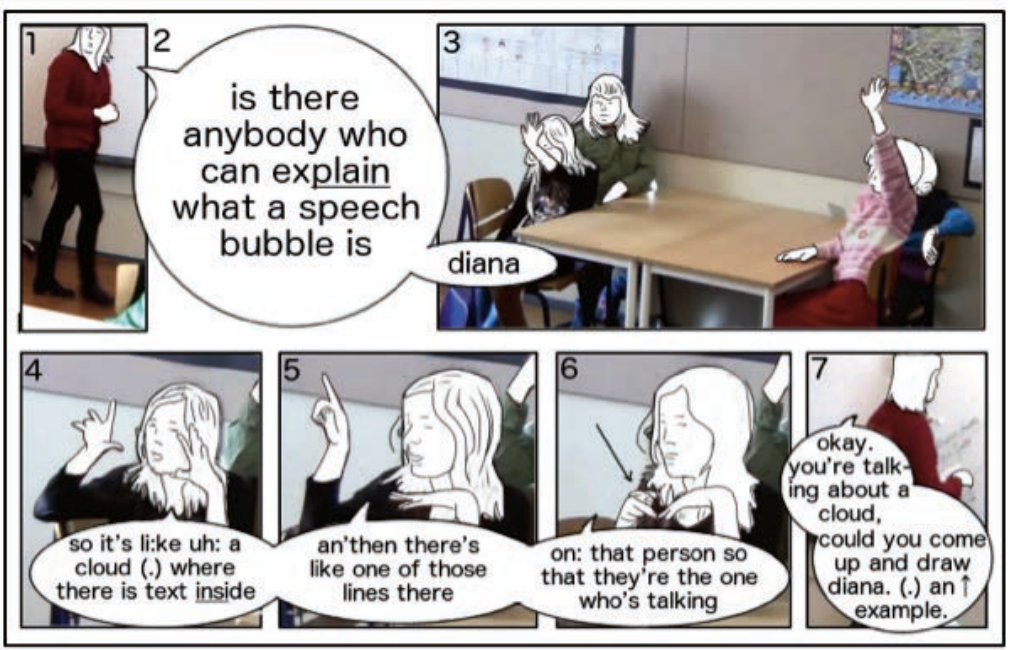

Figure 5. Example of a graphic transcript based on Jefferson (2004); and Thompson (2008), from Paper III.

\footnotetext{
$1 \mathrm{~J}$ is there anybody who can explain what a speech bubble is

2 A david raised his hand too

3 J Diana

4 D so it's li:ke uh: a cloud (.) where there is text inside
}

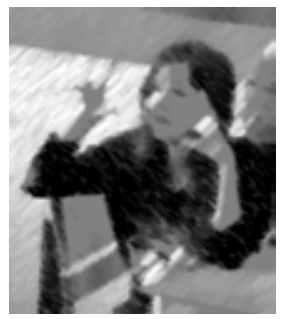


an'then there's like one of those lines there on: that person so that they're the one who's talking

$6 \mathrm{~J}$ okay. you're talking about a cloud, could you come up and draw diana. (.) an $\uparrow$ example.

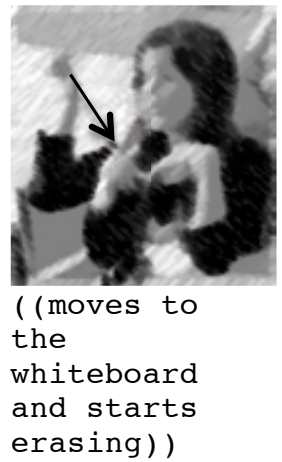

Figure 6. Example of a transcript based on Jefferson (2004).

At first, I attempted to hand draw the text in the speech bubbles as well, but for the sake of clarity, as well as to save time, I decided to simply copy the text from the transcript to the speech bubble. Eisner (2008a) argues that freehand writing is preferable, but then again he is also an accomplished artist. This way, transforming this Jefferson-based transcript into a graphic transcript took approximately two hours.

When comparing with the original transcript, one can see that there are differences between them, where the graphic transcript leaves some things out but includes other things instead. The addition of more images gives a better view of the scene, as well as the movements and positions of the different speakers. However, if we compare panel 7 in Figure 5 with line 6 in Figure 6, we notice that the explanatory text from Figure 6: "((moves to the whiteboard and starts erasing))" disappears in the graphic transcript, and readers are left to interpret the content of the panel for themselves. Similarly, the positions of the speech bubbles have to be considered, as they either need to be placed within the panel, blocking some of the visuals for the reader, or they need to be placed outside the panel (as in panel 2), thereby taking up more space on the page. Furthermore, the second line in Figure 6, Andreas" "david raised his hand too", has been omitted in the graphic transcription, as it was not considered to be of any value to the analysis at hand (this would probably have been done in the finished written transcription as well, to save space, and to not confuse the reader). What was difficult with the graphic 
transcription was to show properly any omitted lines (and therefore, it has not been done in this example).

It becomes clear then, as with any transcription production, that what the analyst chooses to leave out of the frame is as important as what visuals and textual information are displayed to the reader. Furthermore, even though it is not evident from the example in Figure 6, the choice of speech bubbles can also guide how the reader reads the transcript and the interaction. If the author chooses to display a speech bubble with a jagged frame, this might indicate to the reader that this is shouting (or talk emanating from a radio), but as with any transcription convention, this needs to be properly explained in order to avoid misunderstandings (see examples of this in Paper III).

\section{Translation}

One observation when translating during transcription is that syntax may change, which might result in the need to preserve the original language as part of the transcript. Again, in the method of translating transcriptions from Swedish to English, it has often occurred to me what specific words participants were using, and how these would affect interaction. One example of this is the recurrence of the Swedish "ju" and "faktiskt" (Swe. "of course" and "actually"), and how the idiomatic use of these words constructs certain actions within the talk (see Papers I and II). This, again, shows how the analysis of the material is never really finished, and that an analysis includes many layers.

Because the analysis has been conducted on the original Swedish talk, this has been the primary text supplied in the transcription for Paper I and II (with English commentary on gestures and such). In extenso transcriptions have been made in the original Swedish and analysed, and English translations have been provided for English-speaking readers. All transcripts have been translated by the author (who, being a qualified English teacher, is somewhat confident) and further proofread by a professional translator. In Paper III, it was considered impractical and unhelpful to the reader to attempt to include both the original Swedish and the English translation in the speech bubbles. Here, the intention was to 
include the Swedish talk in the appendices, but this was rejected by the journal.

\section{Concluding Remarks}

In this chapter, how the data in the study were annotated, transcribed and translated has been described, and the different conventions used in the different papers have been discussed.

Initially, rough transcriptions were made and used as a script for watching the videos, and as a basic search tool for terms and concepts that occurred throughout the data. As interesting aspects emerged, sequences of data were selected and transcribed in more detail using a version of the Jefferson (2004) system, adapted for my purposes. At this point, multimodal aspects of interest were also transcribed at a level of detail relevant to the analysis being made. Thus, not all movement, gaze and physical manipulation were transcribed, only those considered of interest in the analysis.

For Paper III, a different mode of transcription was used, specifically graphic transcription. As the topic of the paper was speech and thought bubbles, and there were many multimodal aspects to take into account and transcribe, it was deemed more effective to use imagery to display this, specifically the comic book conventions of panels in sequence and bubbles to show talk (using an amalgamation of Jefferson, 2004; and Thompson, 2008). Naturally, these conventions are not universal and have their own inherent problems, as do all transcription conventions. However, these graphic transcriptions were deemed useful as well as aesthetically pleasing, and able to convey the analysis well to readers not accustomed to the CA style of transcription.

Transcription and translation are interesting and difficult issues to resolve in working with social interaction data, and it is important to maintain a discussion, lest we become too content with what we have, and stop developing our tools. Transcription can be viewed as the first stop in analysing the data, which is where we will continue next. 



\section{Analysing the Data}

If detective work were easy - everyone would be doing it.

Batman $^{24}$

This chapter describes and discusses the method of analysis used throughout the dissertation, as well as the collections of data in the study and how they have been utilized in the papers.

\section{Analysing Classroom Talk with Discursive Psychology}

The analysis of empirical material throughout the current dissertation focuses primarily on the interactional sequences between participants. The structure of classroom talk has been analysed from different perspectives within the CA/DP traditions. These perspectives have been used to investigate different phenomena, such as Initiation-Response-Evaluation (or IRE) sequences (McHoul, 1978; Mehan, 1979), how teachers and pupils utilize repair sequences (Macbeth, 2004; McHoul, 1990; Schegloff et al., 1977), and demonstrations of pupils' and teachers' social and academic competence (Edwards \& Mercer, 1987, 1989; Heinemann, Lindström, \& Steensig, 2011; Mehan, 1979; Melander, 2012; Melander \& Sahlström, 2010). Building on some of these analytical perspectives, and generally following the analytical methodology of DP (Potter, 2010; Wiggins, 2017; Wiggins \& Potter, 2007), the current dissertation investigates aspects of literacy as participants' constructions of social action.

Research combining discourse and literacy practices includes, for example, Eriksson's (2002a, 2002b) work on school children's

\footnotetext{
${ }^{24}$ Loeb, J., Lee, J., \& Williams, S. (2003). Batman: Hush Volume 2. New York: DC Comics.
} 
reception of novels, Allington and Swann's (2009a) work with children's reading, Allington's (2012) work on textual analysis and critical interpretation, as well as David Peplow, Swann, Paola Trimarco, and Sara Whiteley's (2016) book, which attempts to integrate cognitive and sociocultural perspectives on the discourse of reading groups. The current dissertation relates to works such as these, but takes a multimodal perspective on children's use of comics as its specific focus.

When observing interaction, the "evidence for the organizational machinery of lessons is to be found in the words and in the gestures of the participants" (Mehan, 1979, p. 24). As participants talk, they perform social actions (Hepburn \& Potter, 2008; Potter, 1996, 2010; Potter \& Edwards, 1999; Wiggins, 2017; Wiggins \& Potter, 2007), and other participants can be considered to respond in different ways to previous talk, performing actions of their own. Sacks et al. (1974) call this the next-turn proof procedure (see also Garfinkel, 1984; and Mehan, 1979).

Analysing video and audio recordings of classroom interaction in detail places the focus on the interactional resources, sequential practices and discourses utilized by participants. By studying the participants' uptake of and orientation towards prior positioning in conversations or texts (Sacks et al., 1974), an exploratory approach is used to find interactional phenomena of interest, which are then analysed meticulously and repeatedly. This focus anchors the analysis in the participants' own perspectives on the interactions. The study of sequential analyses of coherence across utterances and episodes is vital to DP. As the context of discovery is used to go through the findings in the data, and aspects of interest are found in said data, patterns emerge that are then available for analysis and discussion (Hepburn \& Potter, 2004).

The method of analysis used is similar to the process detailed by Sally Wiggins (2017). After recording, transcriptions were made (detailed above), and this process, involving its own choices and methods, is viewed as the first step of analysis. After reading the data through the verbatim transcripts and the video materials, the analysis proceeded by coding certain actions, phrases and terms that were found to be relevant to the overall aim and purpose of the study. Verbal and physical actions and reactions, as well as 
interactional use of physical materials (Hepburn \& Potter, 2004), were all pertinent to the analysis.

For example, talk about speech and thought bubbles was found to be an interesting theme, as it was an interactional sequence related to something comics-specific. A description of this phenomenon was written up and sequences of talk were chosen and transcribed in greater detail. In studying these sequences, social actions were identified. Within DP, social actions can include participants making assessments and stating preferences, participants talking about their emotions or how they construct aspects of literacy ${ }^{25}$. Within the current study, the aspects found were related to the use of comics in different ways, such as participants stating a preference for comics over other types of literature, the construction of comic book bubbles as narrative devices, etc. At this point, the material in full was then re-reviewed to find other instances of these themes, to build collections of data in order to extract more generalizable results from singular cases, and try to find deviant cases that could validate findings (Potter, 2012). The analysis was then further refined and focused, and excerpts displaying the investigated aspects were selected for inclusion in written papers.

Many of the ideas presented by Charles Antaki, Michael Billig, Derek Edwards and Jonathan Potter (2003) ring true for the current study, as well as the methodology of DP. Antaki et al. identify six (lacking) features of analysis:

(1) under-analysis through summary; (2) under-analysis through taking sides; (3) under-analysis through over-quotation or through isolated quotation; (4) the circular identification of discourses and mental constructs; (5) false survey; and (6) analysis that consists in [sic] simply spotting features. (2003, Well- and poorly-founded criticism of analysis, fifth paragraph)

Thus, it has been my intention not merely to describe or summarize what is being said (step two in Wiggins, 2017), but also to continually ask the questions of what action is being done with this

\footnotetext{
${ }^{25}$ For an extensive and detailed list of possible aspects of study in DP, see Wiggins (2017, p. 123).
} 
utterance, what response is given to this utterance, and how this plays out sequentially in the interaction. During analysis, an effort has always been made to not take sides, but rather to analyse the interaction from the participants' perspective using the next-turn proof procedure - how does the other person respond, and what does that tell us about their understanding? - in order to grasp the intersubjectivity of the participants (Wiggins, 2017), and to display transcripts and quotations in a way that provides the reader with sufficient materials on which to base a fair interpretation of the analysis.

\section{Collections of Data}

As the rough initial transcripts were written up, these were read and colour coded, labelled and annotated, with notes on potentially interesting talking points, phrasings, potential trouble in the interaction, all related to the use of comics in different ways. Naturally, other interactional phenomena were also present in these transcripts, but the focus was always on how different aspects were related to work done specifically with comics - following on the initial research questions (see Introduction, p. 8). Therefore, aspects of repair, use of rhetorical devices, talk about gender, etc. might have been interactionally interesting, but unless this was being done as part of a practice with comics, it was not included for further analysis.

In this way, collections of data were produced (Wiggins, 2017), some of which are represented here in the form of papers. As these collections were developed, data and preliminary analyses were discussed at research seminars and between supervisors and myself. The three papers in the dissertation represent the three phenomena or strands of analysis that were most clearly defined and that seemed most fruitful at the time in relation to previous research on comics and literacy. Among the interesting aspects not included here, some examples are collections of gender production with comics, performing reading of comic strips out loud, and utilization of references and intertextuality with comics. These strands of interest have not been further pursued, or they have been part of an initial analysis but have been abandoned after having been deemed too different from the other material, or otherwise 
found wanting. It is a natural part of academic writing that the analyst discovers several different strands of interest, from which it is only possible to pursue one due to time constraints. Hopefully, these points of interest will be further analysed in the future.

Some of the collections of data were smaller in sample size, and some were more easily defined than others, even though collections as such cannot be considered finished (there is always more data!). For Paper I the primary interest was relatively abstract at first, circling around issues of identity and comic book competence as expressed by participants ${ }^{26}$. This was determined to be too broad (for example, in any school situation there are multitudes of examples of participants expressing a lack of competence in something), as it included several aspects of comics (reading, drawing, intertextual competency). Thus, the funnel was further narrowed; as an example, sequences regarding drawing were discarded, as this is not a specifically comics-related issue. Similarly, the issues of intertextual competence were also discarded, as the examples found were few, and the concept of personal literacy seemed to cover the same analytical points.

The collection for Paper II consisted originally of 17 sequences of varying length (from about 30 seconds to up to 2 minutes) from the same lesson on using cut-out comic panels. The phenomenon of gutter talk was identified first through the participants' references to image sequences, and specifically the teacher Anna's use of the phrase "in between" (see Paper II, p. 11). After exploring the interactions of the three groups in this lesson, the scope was widened to a review of the rest of the material, but it was difficult to find anything in other classes or lessons where the same type of phenomenon occurred. The same process of narrowing down what sequences in the clearest way represented gutter talk, and the different aspects of it, was then applied to this paper as well.

In the analytical process of Paper III, the focus was primarily on one lesson in Grade 3, where participants worked specifically and instructively with bubbles. When more material (than the single lesson) was reviewed, two different phenomena were

\footnotetext{
${ }^{26}$ For slightly more extended summaries of all three papers, see part two of this dissertation, as well as the individual papers.
} 
discovered to have occurred in the interaction around bubbles: speech bubbles as part of formal instruction (i.e., bubbles are taught in some way) and speech bubbles as an informal part of talk in ongoing reading. For example, Excerpt 4 in Paper III shows a teacher and pupil reading a comic together. Because the dialogue in the comic consists of speech bubbles, both the visual and textual aspects of the bubbles need to be read aloud. If there is also commentary (from either participant) on a specific bubble shape, sound or emotive expression, this is regarded as formal instruction. If the comic is merely read without comment (at least in regards to bubbles), this is considered informal bubble reading. The analysis for this paper was based on five sequences of formal instruction taken from the same lesson (all based on whole-class work), and one sequence of informal reading between a teacher and a pupil.

From these three collections of data, only a few examples are used in the final paper. It is rarely possible to include many excerpts in academic publications, due to space restrictions imposed by journals. Furthermore, because the issues explored represent a new field of interest this requires that each excerpt be given enough attention for an in-depth analysis. The excerpts displayed in the final papers are representations of the phenomena brought forth through the analysis, avoiding so-called "cherrypicking".

\section{Concluding Remarks}

This chapter has described and discussed the method of analysis utilized throughout this dissertation. Analysing a large amount of data is a daunting task, but it also offers a great deal of enjoyment and many interesting discoveries along the way. In the following chapter, I summarize the three papers that make up the empirical basis for this dissertation, where this analysis has been applied. 


\section{Summary of Papers}

\section{Paper I: Kid Friendly?}

\section{Construction of Comics Literacy in the Classroom}

(Wallner, L. Submitted, 2017-09-04)

Kid Friendly? Construction of Comics Literacy in the Classroom explores, from a new literacies perspective, how teachers and pupils construct and negotiate discourses around comic books as part of ongoing classroom interaction (Gee, 1992; Kress \& van Leeuwen, 2006). Since the mid-1990s, literacy pedagogy has been broadening the scope of what literacy entails. A view of multimodal literacy includes not only the written word, but also drawn images, photographs, symbols, sound effects, etc. (The New London Group, 1996). More than merely a cognitive ability to read and write, literacy is culturally, socially and historically constructed (Barton, 2007; Gee, 2002). Therefore, school literacy practices need to reflect the literacy practices of society, which are increasingly multimodal, including the use of digital media, newspapers, advertisement, and more. The combination of imagery and text, which is the essence of comics, makes them relevant tools for exploring new literacies in the classroom. The aim of this paper is to advance the idea of comics literacy (Hammond, 2009), where the comic format's combination of visual and textual literacy makes footprints in the discourses produced in classroom talk, as well as to investigate how participants construct these discourses as part of their interactions around the material. The paper highlights moments of comics use, and demonstrates what affordances comics have as a form of literature in primary and secondary classrooms.

The analysis is based on video material from one Grade 3 class doing language studies and one Grade 8 class doing social studies, at two different Swedish schools. Initially rough transcriptions of the data were made as a basis for indexing and word-search, and used as support when viewing the data. In preliminary viewings, sequences were found in which participants make assessments, either of their own competence or their own experience with 
comics (e.g., "I'm not a comic book reader"), or of the comics themselves (e.g., "This comic is my favourite"). After repeated viewings, nine excerpts of this kind were found, and these interactional sequences have been analysed using a qualitative discursive psychological approach, investigating how preference/dispreference is employed to perform social action. Written transcriptions were made based on the Jeffersonian style (Jefferson, 2004, see also Appendix 5, this volume), thus reproducing talk and embodied actions as they are made relevant by the participants.

The results show that participants utilize discourses of personal, visual, and textual literacy to construct comics literacy in which image and text are construed both as important to and as a hindrance to reading comics. This demonstrates the influence comics can have on a discussion of what it entails to be a reader, and how personal experiences of reading become important. As a study of social literacy practice, and from the perspective of New Literacy Studies, this demonstrates how participants' personal literacy influences their readings and the work they do in the classroom, both as teachers and as pupils (cf. Allen \& Ingulsrud, 2005). When encountering problems in their readings, participants utilize their personal literacy to account for these difficulties, e.g. when experiencing a clash between her childhood experiences of comics and present-day experiences, the teacher Jonna accounts for this trouble by arguing that comics have changed since she was a child. Furthermore, from the perspective of multimodal literacy and new literacies, this study shows that comics can be approached as a visual and textual material, which could be constructed as both supportive and a hindrance, e.g. if you did not learn to read comics - their visual and structural language - as a child, this may account for your difficulties in understanding them as an adult. These results show the importance of broadening the view of literacy and reading in school, and contribute to a view of comics as viable school literature. 


\section{Paper II: Gutter Talk}

\section{Co-constructing Narratives Using Comics in the Classroom}

(Wallner, L. Re-submitted after review, 2017-09-28).

Gutter Talk: Co-constructing Narratives Using Comics in the Classroom presents an analysis of how the gutter, the blank space constructed between comic book panels, is used to do narrative storytelling in classroom interaction. A unique story-telling format, comics are typcially instantly recognizable to readers old and young. In this paper, pupils and a teacher in a primary class collaborate in constructing a comic book narrative using ten separate comic-book panels, which they place one after another, creating a verbal and textual story as they work. In this work, they create physical gutters, blank spaces, between the comic-book panels, which also transfer into their story-telling, in the form of narrative gaps that need to be filled (Postema, 2013). As previous research has discussed the gutter primarily as a cognitive aspect of narrative (Cohn et al., 2014; Low, 2012), the current paper instead approaches it as a social practice (Gee, 2002), where the comics material is seen as a resource for social interaction, and gutter and narrative are viewed as literacy aspects constructed to perform situated social action (Potter, 2000; Potter \& Edwards, 1999, 2003).

For this paper, video data have been recorded. The data show four Grade 3 pupils and their teacher working on creating a coherent comic story out of then separate comic-book panels. This assignment comes from a teacher's guide, provided to the teachers by Egmont Publishing, as part of a school project initiated by Egmont to test comic books and teaching material in classes in Grade 3 and 4 (see Egmont Publishing, 2015). As a study of naturally occurring interaction, it is important to point out that Egmont had provided the material, but was not in control of, and did not evaluate, what the teachers did with it. Moreover, the researcher had no influence over what the teachers did or what materials they used in the classroom.

The ten panels have been taken from a Donald Duck comic book story consisting of sixty panels in total. The pupils have not 
read this story beforehand, and as the panels lack a clear coherency, this presents a challenge for the pupils. This activity was chosen as especially interesting, as it was a rare instance of participants working with and discussing narratives and the gutter in the way that is being done here. There were several groups working with this assignment in the classroom at the time, but due to issues of sound or image quality, the interaction of one group is analysed in detail. It should be noted that there are also a few sequences of the same phenomena appearing with other groups, but as this does not provide anything new to the analysis, they have been left out. Seventeen excerpts were initially found in the class, and from this, two excerpts have been selected for closer analysis and presentation.

The aim of the paper is to generate knowledge on how the use of the gutter as an interactional resource is done as social action in co-constructing narrative structures. The analysis utilizes DP to investigate how participants perform social action through talk about the gutter in comics, or gutter talk. This talk has been analysed as aspects of literacy constructed in situated interaction in order to examine what participants are doing with their constructions (Potter, 2000; Potter \& Edwards, 1999, 2003).

The results show that participants use physical placement of comic panels in connection with their verbal narratives to argue for their placement of panels in relation to the narrative as a whole, or simply in relation to the next panel. The teacher is engaged in the intersubjectivity of the participants, the goal being for pupils to understand the arguments and to "see" the narratives that others suggest. In order to do this, participants construct the gutter as a meaningful space, and utilize it to organize time, actions, and events in their narrative structures. The paper demonstrates that, in this comics literacy practice, the gutter is co-constructed as a content space that is either too narrow or too broad, and as relating chronologically and logically to surrounding panels. These narrative aspects are essential to an educational practice engaged with budding readers' and writers' understanding of how a story is constructed, how a narrative consists of a beginning, middle and end, and how to read between the lines in narrative structures. It also demonstrates a case of co-construction, where the teacher is 
highly engaged with the four pupils' work in creating a coherent narrative that they all agree with, putting emphasis on this agreement, and the way that pupils engage with each others' narratives.

\section{Paper III: Speak of the Bubble}

\section{Constructing Comic Book Bubbles as Literary Devices in a Primary School Classroom.}

(Wallner, L. (2017). Journal of Graphic Novels and Comics. 8(2), 173-192. doi:10.1080/21504857.2016.1270221)

Speak of the Bubble: Constructing Comic Book Bubbles as Literary Devices in a Primary School Classroom investigates teachers' and pupils' use of speech and thought bubbles in a classroom literacy project involving comics. Comics is a medium that combines visual and textual aspects of literacy, and much of the medium is in many ways produced specifically for children (Ripley, 2012; Sutliff Sanders, 2016), which makes comics an interesting topic for studying literacy practices. Essential to the comic book form, speech and thought bubbles display the speaker's identity and emotional state, as well as the sequence of interaction (Cohn, 2013a; Eisner, 2008a; Yannicopoulou, 2004). When the teacher in the present paper, Anna, introduces a lesson on the topic of speech and thought bubbles, she asks "Why are they different?", thereby signifying that the different visual aspects used with bubbles as literary devices may be neither familiar nor obvious to all readers. Thus, the aim of this study is to increase our knowledge about how bubbles are constructed as literacy devices in classroom practice.

The analysis is based on video data of naturally occurring classroom interaction (Potter, 2010), in which participants in a class in Grade 3 (ages 9-10) and their teachers talk about bubbles. The material the class is working with comes from a project initiated by Egmont publishing to test Donald Duck teaching materials with Grade 3 and 4 classes throughout Sweden (see Egmont Publishing, 2015). As of the video recordings, the pupils had not yet started working with the copyable materials, but the teachers had familiarized themselves with them before the lesson. 
Here, as with Paper II, Egmont had provided the material, but was not in control of, and did not evaluate, what the teachers did with it. In addition, the researcher had no influence over what the teachers did or what materials they used in the classroom.

The analysis focuses on the action-oriented aspects of DP: emphasis, word repetition, uptake, and the use of signs, symbols, and text in the comics. After an initial viewing of the material as a whole (36 hours with four classes in two different schools), the use of speech and thought bubbles was considered to be of interest, as it aligned with the overall focus of the study on investigating visual aspects of comics use. The aspect of "reading" bubbles, i.e. how participants express different bubbles in the process of reading a comic, was put aside, in favour of the lesson presented here, where the class is engaging in talk about bubbles. Throughout this lesson, there are many sequences of talk about bubbles, which in some way mirror what is being done in the four excerpts presented and analysed in the paper. Instead of analysing, for example, how each different bubble is negotiated, the more general talk about bubbles is discussed, and excerpts are used as examples of this talk.

The results show how participants negotiate combinations of shapes, symbols, and text to construct common knowledge concerning bubbles. Teachers encourage pupils to contribute their understandings of different bubbles, and create a collection of different bubbles to use as a starting point for a discussion on the narrative uses of different bubbles. Throughout the rest of the lesson, the teacher Anna uses pupils' own drawn bubbles, adding to them a variety of multimodal utterances, thereby illustrating how narrative focalization can be done, where what the characters of the comics know and what the reader knows is different; she also demonstrates how character prosody is constructed, and where the tone of voice or the emotional quality of the utterance is displayed. The study of how bubbles are constructed contributes to a larger theme of studying classroom instruction using comics as resources for doing literacy. This shows how the use of bubbles can add to a discussion of prosody, emotion and delivery of narrative messages, as well as how narrative focalization can be displayed visually in comics, rather than textually. 


\section{Concluding Discussion}

In the current dissertation, I set out to generate knowledge about how locally situated literacy practices are done in situations where pupils and teachers use comics. I have analysed classroom interaction between pupils and teachers, and their use of comics, to try to understand the function of comics in participants' constructions of discourses around comics literacy.

From the analytical process, three research questions emerged:

- How do classroom participants construct discourses around comics as part of their literacy practices?

- How do participants construct aspects of narrative as part of their literacy practice with comics?

- How do participants construct aspects of visual literacy when working with comics in the classroom?

In this chapter, a selection of themes is addressed related to the purpose and aims of the overall study. I discuss results from the empirical analyses in relation to the theoretical approaches used in the study, the implications for educational practice, and the possibilities of future research into the area.

\section{Comics Literacy in the Classroom}

The current dissertation establishes two important perspectives on comics literacy constructed in classroom interaction. First, the empirical studies show what signifies comics literacy. Second, the studies demonstrate how comics literacy is constructed as part of ongoing literacy practices in the classroom.

\section{What Signifies Comics Literacy}

The results of the current dissertation identify constructions of comics literacy in the ongoing interaction between teachers and pupils in their work with comics material - what comics literacy is.

First, comics literacy is signified by the combination of image and text specific to comics, how this combination is utilized in the construction of sequential narratives, and how it influences the 
literary devices of the format, such as speech and thought bubbles, and participants' readings thereof.

Second, another signifying trait of comics literacy is participants' construction of discourses around comics, their drawing on personal literacies constructed with comics, participants' relation to comics and the characters inhabiting them, and their construction of the material as unique among other types of fictional materials. Below, these two aspects of comics literacy are further discussed from the perspective of new literacies and theories from comic studies.

\section{Comics as Visual/Textual Literature}

Throughout the analyses in the three papers included here, the visual aspects of comics were significant to the ongoing activities and interactions in the classroom. Therefore, it could be argued that this interaction should be analysed as visual literacy (as is done by, e.g. Hammond (2009)). However, as the analyses in the three papers show, comics literacy centres on the combination of visual and verbal/textual aspects of comics and how participants construct this with the material in the classroom - this is one of the significant aspects of comics literacy. Unlike Hammond (2009), I argue that comics do not require "mastery of two separate literacies, traditional text literacy and visual literacy" (p. 43), but rather that comics require comics literacy, and that it is difficult, and perhaps analytically unnecessary, to divide it into two different literacies. The participants in Paper III demonstrate the social construction of bubbles as semiotic symbols (Scribner \& Cole, 1981), whose shape influences how textual messages can be constructed.

New literacies engages with multimodal texts, and the use of, for example, visual/text combinations (Lankshear \& Knobel, 2011); it also questions how we look at texts and what we call texts. However, in Paper II, participants do not use text, but merely the comic book panels as a basis for constructing verbal story telling. Even though the pupils eventually write their story down, the main part of the literacy event circles around constructing a verbal story from the images - a story that keeps being reconstructed as participants negotiate the different parts of the 
narrative. Thus, the role of the visuals is essential in that they allow the pupils to move the pieces of the story around, as well as both inspiring and restricting the pupils in their storytelling. Simultaneously, speech bubbles (even though they are empty) still play a role as visual elements of narrative, as participants use them as visual cues for when to construct dialogue between characters (and sometimes as monologue), which, in turn, drives the story forward.

In sum, comics literacy is constructed by participants as multimodal, wherein singular modes (e.g., textual and visual) are dependent on, and influence, each other in shaping the sequential narrative and the way that narratives are read and produced. Participants further demonstrate this through their use of multimodal interaction in order to represent, instruct, or negotiate the different aspects of comics verbally and physically. In the next section, I will discuss construction of discourses around comics literacy as the second part of what constitutes this literacy.

\section{Comics Discourses}

In his book, Pustz (1999) argues that knowledge of, and participation in, comics fan culture is part of what signifies comics literacy. Comics literacy, argues Pustz, "contributes to the construction of comic book culture by limiting the audience and giving it a body of common knowledge" (p. 112). While Pustz employs a material angle, focusing more on "comics steeped in comics literacy" (p. 112), the current dissertation explores the readers' co-construction of comics discourses, arguing that this is a significant aspect of comics literacy.

The three papers presented in this dissertation show how reader experiences, their knowledge in the culture and history of comics, is made relevant for classroom meaning making with comics. A participant who has read different comic genres, and at different reading levels, also has several literacy domains to draw upon (Barton, 2007), because different artists use different techniques and because comics conventions, for example the use of speech bubbles, tend to change over time. Thus, the collective knowledge of a classroom of pupils, having read different genres, stories, and styles, is a useful tool in making meaning with comics, as shown, 
more specifically in Paper III - where pupils contribute their own meaning in relation to different speech bubbles. With this knowledge of different experiences with the format, it would seem that regularity, and recurring experiences of similar formats, is important. This is of course the case with any reading, and comics, especially collections of strips, offers the reader a repetitive pattern similar to that of language text-books, with small variations and repeated use of similar characters (N. Williams, 1995). This domain knowledge (Barton, 2007), e.g. knowledge of comics' structure, can then be used to further engage with other types of materials, and other types of narratives.

Paper I demonstrates how teachers and pupils relate to comics through the construction of different discourses of comics - these discourses are a significant part of comics literacy. The paper shows how participants construct these discourses through, for example, the visual and textual elements of comics, as well as what they define as difficult or easy, based on their own personal reading experiences, what Allen and Ingulsrud (2005) call personal literacies, of what comics "are". In the classroom, personal literacies clash, as we see with the Grade 8 group, and in order to agree on a joint narrative, or a solution to the task, they must negotiate their different personal literacies to achieve joint meaning making (cf. Edwards \& Mercer, 1987). This perspective seems similar to that of Gee (2002), who argues that we master different literacies in different areas, comics being one of these areas. However, with comics literacy, as with other areas of visual literacy, computer literacy, etc. where does the researcher draw the line between one literacy and the next? These participants' personal literacies contain elements of comics, novels, poetry, etc. and it is unlikely that a researcher would be able to map them all. What is possible in the current dissertation is to show how participants draw on their own experiences and construct their personal discourses around comics - as they draw on personal discourses around comics in order to do social action. For example, it is clear from the excerpts in Paper I that some participants construct a discourse of comics as "easy reading", and when they encounter comics material that does not correspond to this view, they account for this 
in some way. This manner of doing comics literacy is what I will discuss next.

\section{Doing Comics Literacy in the Classroom}

Having established what signifies comics literacy, I will now turn to a discussion of how this literacy practice is done - how participants construct multimodal comics literacy in the classroom.

\section{Doing Multimodal Comics Literacy}

Working with comic books is a multimodal literacy practice, wherein participants utilize all means at their disposal (cf. Jewitt, 2008). Having access to comics material encourages physical manipulation, as can be seen in Paper II, where participants work with narrative structure, using multiple comic-book panels to construct a sequence of images portraying a story that they create. In connection to the work of Cohn et al. (2014), for example, this display of visual and verbal narrative is interesting in relation to the interactional elements brought up by the participants. Cohn et al. explore how the visual narrative grammar, introduced by Cohn (2013b), is abstracted from participants' ERPs (event-related potentials), meaning that they "build expectations image-by-image by using their knowledge of a more abstract narrative structure" (p. 69), and that this is done from visual/structural stimuli, rather than semantic or verbal. The study in Paper II instead investigates practices in which teachers and pupils co-construct these visual structures; how they arrange, negotiate and modify their narratives, co-constructing story elements physically in the gutter and relating in different ways to time and place. These participants actively invoke these structural elements, and they create their own logic within their constructed narrative, based on the preceding pictures as well as the ones to follow. Both teachers and pupils engage in this negotiation, moving panels around, bringing new panels up for discussion, and suggesting story elements tied to different panels. Thus, the narrative truly becomes the product of the group, rather than the individual, and the meaning of individual panels, and elements within them, is similarly constructed and re-constructed by more than one person. This co-construction demonstrates one 
strength of comics literacy. Contrary to Hammond's (2009) claims that most pupils have "mastered" textual literacy (based on her studies in secondary school), many nine-year-olds have not and, therefore, arguments in their negotiations do not stem from interpretation of textual elements, but rather from visual elements allowing participants to engage in discussion on terms other than understanding and producing text (Street et al., 2011). When the sequential narrative is constructed, this can be done entirely without text (and, hypothetically, also without speaking), which allows for a kind of participation different from using written narratives.

These results seem to corroborate David Low's idea that "adopting practices that are applicable across many contexts, and which solidify reading as an active, imaginative, critical, and richly semiotic process of meaning making, is a good approach" (Low, 2012, p. 382), especially within a national curriculum that requires teachers to work with "[h]ow a narrative text can be organized with an introduction, sequence of events and an ending" (Swedish National Agency for Education, 2011a, p. 212). At the moment, many teachers in Swedish primary schools work with picture sequences, where a simple layout of three to four pictures is used to demonstrate this very aspect of narratives cited above (as did the participants in my data, but unfortunately there was not room to include this in the analysis for the current dissertation). However, perhaps a disservice is done to the pupils if these picture sequences are made too simple, as it lessens the discussion that is required to achieve a possible solution. Furthermore, if the narrative is performed orally in the whole class, the focus becomes rather on which pupil has the language capacity to express the correct solution, rather than on engaging with, and discussing, possible narrative sequences. As seen in Paper II, the comic panels used by the pupils are frustratingly difficult to combine, and have no clear solution, thus forcing the participants, teachers and pupils alike, to engage in negotiations around narrative and sequential logic. As argued by, e.g., Moss (2003), materiality needs to be addressed in our literacy work in schools. We should not limit analysis to what stories the pupils work with, but also include the forms in which these stories are presented. In comics, structure, pacing, size of 
material, choice of colours as well as font, and other multimodal aspects, become essential to narrative production - and the analysis thereof.

Paper III shows how teachers work with multimodal aspects of comics, using text, visual elements, sound, and body language to teach speech and thought bubbles. The teacher Anna in Grade 3 uses embodied movements, sounds, drawing on the whiteboard, as well as written text and speaking, which can be viewed as multimodal interaction (Kress, 2010; Kress \& van Leeuwen, 2001). Thus, she utilizes multimodal interaction to illustrate a multimodal material, in this case conveying a sense of focalization (narrative perspective), and the audible sensation and emotion of the bubbles. Using Cohn's (2013a) comic terms, the teacher takes the place of the root, and enacts the sound and sensory qualities (loudness, anger) of the speech bubble, the carrier, whereas pupils are more focused on formal aspects of designating the tail (how to determine who speaks), as well as the shape of the bubble. It becomes clear that not all participants agree on the shape of bubbles. Bearing in mind that speech and thought bubbles differ across cultures, time periods, and artistic styles (unlike Eisner's (2008a; 2008b) instructions), this also demonstrates that these literacy practices are socially and culturally situated (cf. Cook-Gumperz, 1986b; Gee, 1992), and that the view of what constitutes literacy needs to change and adapt accordingly (cf. Hiebert, 1991).

\section{Doing Discourses of Comics Literacy}

From an ideological perspective on literacy (Gee, 2002; Street, 1984), it is clear that comics discourses are constructed by, as well as constructive of, comics literacy. In talk, participants draw on their personal experiences, and as in the case of the teacher Jonna in Paper I, her experiences are used as arguments for certain courses of action within the talk. Her personal experiences of Donald Duck comics clash with the comics that she is now encountering. Thus, conflicting discourses are constructed where Jonna's personal literacy, including reading comics as a child, appreciates Donald Duck as appropriate reading for children, while her role as a teacher reading these comics in the present argues that they are not. These two discourses may not be easily reconciled. As 
a way of solving her personal conflict, Jonna accounts for her difficulties with the material to the fact that it has evolved over time. These constructions of comics discourses show how different discourses become dominating perspectives in the classroom at different times, which in turn influences what literacy constructions are done. Thus, discourses are part of constructing the talk, but are also re-constructed through the talk. When the participants negotiate common meaning (cf. Edwards \& Mercer, 1987) out of the material, it is important to recognize the different comics discourses - essential to comics literacy - and their influence on classroom practices, whether this is in preparation for teaching or during lessons.

\section{Comics as Children's Literature}

A common comics discourse is that of comics as children's literature - with language and content appropriate for children (the degree to which this excludes adults from being able to read comics may vary).

Versaci $(2001,2008)$ argues that comics play an important role in challenging the classroom view on what literacy entails and what can be called literature, and this relates to how comics are viewed. On a national educational level, the Swedish national curriculum for primary school states that "teaching should stimulate pupils" interest in reading and writing" (Swedish National Agency for Education, 2011a, p. 211). Versaci (2001) argues that comics indeed "provide teachers with the perfect opportunity to help create new impressions among students, and [---] allow students to understand, ultimately, that "high" and "low" are somewhat artificial designations that historically have had much more to do with prejudice than merit" (p. 66). Thus, the discourse of comics as children's literature (which, in some cases, means that they are considered "low" culture) could be used as a basis for classroom activities to stimulate the level of interest in reading, writing and literacy that the Swedish curriculum strives for. Despite the fact that Versaci himself works at a college, he argues that discussing what literacy can be is important at a younger age, when pupils are less entrenched in their views, and perhaps more open to new ideas around literacy (2001). In Paper I, the pupils in Grade 8 discuss 
Donald Duck as children's literature, pointing to visual and verbal aspects of the comics as reasons for this. This discussion prompts the pupils to analyse the use of text and images in order to determine readability, and it triggers a discussion about what it means to be literate, what literacy entails for small children, and whether or not one can be considered literate if one reads pictures. All in all, a discourse of comics as children's literature is crossed with discourses on literature and literacy - providing an example of how discourses around comics literature are done as a significant part of comics literacy.

The constructions of comics literacy being done in these papers demonstrate the ideas of literacy scholars such as Gee (2002), Hollingsworth and Gallego (1996), and Hiebert (1991), suggesting that literacies need to be continually challenged and reconstructed in social practice, rather than viewed as set skills to be achieved. The perspective of new literacies encourages teachers to embrace new types of materials, in this case comics, as objects for literacy, as well as to reflect on their personal literacies, and literacy discourses, and their relations to comics material.

\section{Teachers' Work with Comics Literacy}

In this section, I will show some of the strengths of a comics literacy perspective by giving examples of teachers' work with comics literacy in the current study, as related to literacy theory.

Stoermer's (2010) study investigates what is required of the teacher's pedagogical knowledge in order to teach comics composition. She demonstrates how children, given their creativity, surprise the teacher with unexpected solutions to problems, or innovative uses of materials that the teacher provides. In Paper II, the pupils confuse their teacher by doing things differently from how they were originally imagined - and pupils' focus on creating the correct sequential narrative delays the lesson and disrupts the idea of what it should entail. These perspectives enforce the idea that comics can provide a creative outlet in storytelling, as well as new angles from which to work with narratives in the classroom. Paper II also demonstrates how work with composing comics narratives encourages negotiations on the reading gaps (Low, 2012; Postema, 2013), as well as creativity when it comes to filling in 
these gaps in the narrative structure, discussing issues such as: What happens between the frames? How much time passes between panels? How do we know that the scene has changed? Thus, gaps between images encourage critical perspectives on sequential narratives.

Moreover, the activities analysed in Paper II show the strength of the comics narrative being in visual form, as it allows pupils to make interpretations of the pictures, physically manipulate, place and replace them, and construct their story visually, as well as verbally, for their peers and teacher. This could help pupils who lack written or verbal language confidence or capabilities (Street et al., 2011), but also as a scaffold for teachers in their instructions for assignments with narrative sequences, as the teacher in Paper II demonstrates.

I showed previously how the discourse of comics as children's literature is a significant part of comics literacy. This does not mean that comics are intrinsically children's literature, but rather this discourse depends on the social construction of the participants. Comics exist that are written for marketed to children, just as there are comics (or novels, or picture books, etc.) written for and marketed to adults or youths. The pupils in Grade 8 show awareness of this, as they designate some comics as being for children (e.g., Donald Duck), and some not (e.g., Modesty Blaise). This again displays the ideologies surrounding literature and literacy (Gee, 1992, 2002; Street et al., 2011), and how some comics tend to be constructed as being specifically for children. Considering that the Donald Duck comics are constructed as children's literature by the Grade 8 pupils - but as being too difficult for children by the Grade 3 teachers - shows how these ideologies of comics literacy are socially and contextually constructed. These ideological constructions influence different reading practices in different ways for different groups (CookGumperz, 1986a; Gee, 1992). Furthermore, following Versaci (2001), I also argue that it is important at younger ages to affirm pupils' reading choices, instead of imparting to them an impression of appropriate or inappropriate reading - as well as to show that a range of literacies and formats are available to them. Yang (2003) concludes, in his research review, that there are many examples in 
the research of educators and researchers who are surprised at how accepting most pupils are of reading comics in the classroom. As shown in the previous section, the personal literacy ideologies that teachers and pupils have in relation to comics impact classroom talk, and how discourses of comics are constructed there.

Another example of this is the teacher Jonna, in Paper I, who has trouble reconciling her personal experiences of Donald Duck as children's comics with the comics she is presently facing, which seem to contain language content too difficult for her pupils. She accounts for her trouble by arguing that modern comics have become more linguistically advanced, and the two teachers seem to be happy with this. Of course, this would not solve the potential problems of reconciling the reading levels of the comics with that of individual pupils. Were it the case that pupils were engaging with the comics individually, this might become a problem, but as the literacy practices of the classroom consists of group or pair work, the co-construction that is done contributes to the personal literacies of the pupils, as well as to their future experiences with comics and other sequential and visual literacies. This provides a positive example of how teachers' and pupils' personal literacies are utilized as strengths, rather than disadvantages, within the social practice of the classroom - when individual literacies are allowed to contribute to, and co-construct, common knowledge around comics.

\section{Future Studies}

For future studies, it would be interesting to approach comics as reading material both in school and, for example, in the home environment. These two perspectives (home and school) have been approached before (e.g., Haugaard, 1973; Marsh, 2003), but not as naturally occurring interactional practices. Such an approach would enable researchers to demonstrate qualitative analyses systematically and provide an interactional perspective, which would further complement previous theory on comics discourse. It could also add discourses constructed in the home environment to the discourses presented in the current dissertation, thus making it possible to broaden the knowledge on how comics discourses are constructed. This could improve our current knowledge on comics 
literacy and how young children's construction of comics literacy is done.

Moreover, during my recordings, I witnessed a few occasions where a teacher read a comic book out loud together with a pupil (there was, in fact, little of this co-reading or read-alouds found in the data). Although I only barely managed to capture this on film, the topic of co-reading comics aloud, combined with the comics structure, panel grids, and other visual aspects, intrigued me. Although there have been some studies on how readers read comics, these are neurocognitive studies, and usually conducted either with tools such as brain scans or eye tracking or with interview studies (Cohn et al., 2014; Cohn et al., 2012). Thus it would add to this research to study the process of reading of comics as naturally occurring social interaction, and observe the practices of reading and interacting from a multimodal perspective. Through this, it would be possible to generate knowledge on how children construct the reading of comic books in situ, and to better understand the co-construction of comics reading that is done when adults and children read together. As this is some of the first reading that children do, and especially as visual literacy, it could shed new light on understanding early visual literacy, and how discourses on comics literacy and visual literacy are constructed between older and younger readers.

Several authors have indicated that comics specifically cater to the literary needs of boys (Brozo, 2012; Davies \& Brember, 1993; Laycock, 2007; Lenters, 2007; Merisuo-Storm, 2006; Wilson, 2009), and Swedish statistics seem to confirm this view, as among Swedish teenagers, more boys than girls read comics (U. Carlsson \& Johannisson, 2012; OECD, 2014). However, in the statistics, it is rarely clear which voices are being heard. The market forces of comics, and the way comics attract readers, need to be taken into account. But how is this important for our understanding of what boys enjoy reading vs. what girls enjoy reading? Traditionally, comics have had young boys as a main target group, and it is no surprise that this is reflected in the reading demographic. However, this is something that has been changing for a while, especially with the rise and spread of other genres and formats, such as Japanese manga and autobiographical graphic novels (Thompson, 
2008). Because of this, it would be interesting to do further studies of school literacy practices with comics, to see how gender is done in these practices and what discourses are constructed around gender and comics.

\section{Final Thoughts}

The current dissertation contributes new knowledge about comics literacy and the use of comics in school practices. The study has implications for school literacy practices, and the way policymakers and teachers approach comics and other literature as a material in schools. The results shown in this study indicate that there is much to gain from acknowledging comics as a material for literacy practice, not only from a policy-making perspective, but also from the perspective of individual teachers and pupils. There is a vast sea of possibilities in the world of comics, but at the moment teachers are often left to their own devices to find, read, review, and incorporate comics in accordance with curricula. In my view, much of this has to do with comics being a relatively unfamiliar form of school literature - a form that is not encouraged in schools or in teacher education at university. Previous research and the present results also show that there are strong discourses around comics, both in regards to quality and contents, that teachers need to address.

The expansion of comics literacy allows researchers to focus specifically on the details and practices of this form of literacy, and expand upon as well as criticize the ideas presented here. To further narrow down and define specific fields of literacy places limitations on what we can do as researchers, and how we can relate to these different fields, but it also gives us tools with which to be more precise in our discussions and analyses. In further studies of meaning making with comics, it is essential that we identify the detailed aspects of comics literacy, and the way that these are drawn upon in our talk about, and work with, comics literacy. 



\section{Svensk sammanfattning}

I detta avsnitt ges en sammanfattning av avhandlingen på svenska. Sammanfattningen speglar de teoretiska och metodologiska perspektiv som avhandlingsarbetet är grundat på, redogör för de analysverktyg och den analys som gjorts av datamaterialet, samt diskuterar de viktigaste resultaten av studien. Då detta är en sammanfattning så redogörs det här kortfattat för dessa avsnitt. Intresserade läsare uppmuntras att även ta del av den engelskspråkiga delen av avhandlingen och de individuella vetenskapliga papper (i texten hänvisade till som Paper I-III). Jag har översatt samtliga begrepp och citat i denna sammanfattning, och originalen återfinns i avhandlingens engelskspråkiga del.

\section{Bakgrund}

Denna avhandling undersöker användningen av serietidningar $(\text { serier })^{27} \mathrm{i}$ två svenska skolor genom mikroanalyser av interaktion mellan elever, och mellan elever och lärare. Serier har blivit en mer vanligt förkommande typ av litteratur för både barn och vuxna $i$ Sverige och publiceringen av serier riktade till barn har växt under de senaste åren (The Swedish Institute for Children's Books, 2016). I förarbetet till denna studie genomfördes en mejlundersökning bland 200 svenska skolor som visade att serier används i svensk skola, och i t.ex. USA är det en inte ovanlig praktik (Tilley \& Weiner, 2017). Trots detta är det ändå svårt att hitta studier som undersöker detta som en naturlig pågående praktik (d.v.s. där forskaren inte har initierat ett klassrumsexperiment, se t.ex. Potter (2010)).

Förutom intresset för serier så har läs- och skrivforskning, så kallad literacy-forskning (hädanefter literacy ${ }^{28}$ ), expanderat sitt omfång sedan 1980-talet - främst representerat av fältet new literacy, vilket utöver text-baserad läsning även omfattar förståelse

\footnotetext{
${ }^{27}$ Begreppen serier/serietidningar innefattar här alla former av serietidningar, serieromaner, seriestrippar, m.m.

${ }^{28} \mathrm{Jag}$ har hittills inte funnit någon bra översättning av begreppet literacy, utan för enkelhets skull använder jag det engelska ordet här. Se även Carina Fast (2008).
} 
och kommunikation av bild, ljud, och gester (multimodal literacy, se t.ex. Barton, 2007; Street, m.fl., 2011). Utöver denna breddning av material så har forskning om literacy även genomgått ett teoretiskt paradigmskifte, karaktäriserat främst av området New Literacy Studies (NLS) där fokus har skiftat från att studera individuell läsning ur ett kognitivt/psykologiskt perspektiv till ett fokus på läsning som social praktik - där interaktionen och kontexten runt läsning står i centrum (Gee, 1992, 2000; Street, m.fl., 2011). Serietidningen är ett utmärkt material för att studera dessa nya former av literacy - framförallt på grund av seriens kombinationer av bild och text - vilket gör den till en god grund för multimodala text-studier (hur elever och lärare läser och skapar bild- och textberättelser).

Dessa ovan nämnda faktorer gör denna studie mycket relevant både som en diskussion av forskning och teoretiska perspektiv på literacy, men förhoppningsvis även för lärare i klassrummet som arbetar med literacy och som kan gagnas av nya perspektiv på hur läsande och skrivande kan göras.

\section{Syfte och frågeställningar}

Syftet med denna avhandlingsstudie är att bidra med kunskap till hur lokalt situerade literacy praktiker görs, i vilka elever och lärare skapar mening med serietidningar. För att uppnå detta analyseras klassrumsinteraktion för att förstå den funktion som serier har i deltagarnas literacy-konstruktioner. Utifrån ett induktivt arbetssätt formulerades tre övergripande forskningsfrågor för studien:

- Hur konstruerar klassrumsdeltagare seriediskurser som en del av sin literacypraktik?

- Hur konstruerar deltagare narrativa aspekter som en del av sin literacypraktik med serier?

- Hur konstruerar deltagare aspekter av visuell literacy när de arbetar med serier i klassrummet?

Studien kombinerar literacy, serieforskning, och diskursiv psykologi (DP) och applicerar dessa på naturligt förekommande klassrumsinteraktion (Hepburn \& Potter, 2004; Potter, 2010). För att undersöka hur serier används, vilka diskurser som konstrueras, och vad som görs, så utgår studien ifrån DP (Edwards \& Potter, 
1992; Hepburn \& Potter, 2004; Potter, 2010) som används för att studera hur deltagare talar om literacy. Aspekter som kan vara av intresse kan till exempel vara bedömningar (assessments, se Wiggins, 2017), men också ovanligare, och mer literacy-specifika, aspekter som konstruktioner av literacy och berättandeperspektiv. Ett diskursivt perspektiv har tidigare använts för studier av reception av fiktion såsom romaner och film (Allington, 2012; Eriksson Barajas, 2008, 2015; Eriksson, 2002a, 2002b), och denna avhandling adderar till dessa studier genom att undersöka meningsskapande med serier som fiktion, men också genom ett multimodalt perspektiv på interaktion och literacy.

DP är här ett centralt perspektiv, då mycket av forskningen om serier har gjorts utifrån ett kognitivt perspektiv. DP tillåter forskaren att undersöka literacy inte som ett inre tillstånd, eller en representation av detta, utan hur deltagarna själva talar om och konstruerar dessa aspekter i sociala interaktioner, i detta fall t.ex. berättandestrukturer och pratbubblor som litterära verktyg. DP bidrar därigenom både med ett teoretiskt perspektiv på hur deltagare skapar mening i samtal, men också ett metodologiskt perspektiv för att undersöka detta.

\section{Teoretiska perspektiv}

Denna studie kombinerar teoretiska perspektiv på social interaktion, literacy, samt litteraturvetenskaplig teori om serier som material. Här redogörs kortfattat för dessa perspektiv, och deras användning $\mathrm{i}$ avhandlingen.

\section{Social interaktion och diskursiv psykologi i klassrummet}

Genom att närma sig skolpraktik som naturligt förekommande interaktion (här används främst teori och metodologi från Edwards och Potter (1992), Potter (1996), Wiggins och Potter (2007), samt Wiggins (2017)), kan forskare inom DP undersöka och analysera hur lärare och elever konstruerar diskurser och litterära aspekter av serier och literacy, t.ex. narrativ, pratbubblor, m.m. Den aktuella studien undersöker literacy inte som individuella, inre processer, utan som deltagarnas konstruktioner i social kontext. Här förutsätts 
inte att det sagda "finns" på något objektivt sätt i någon sorts inre medvetande, utan det centrala är den konstruktion som görs $\mathrm{i}$ samtalet tillsammans med övriga deltagare. Detta teoretiska perspektiv möjliggör undersökandet av literacy-aspekter genom hur de används av deltagare som sociala handlingar (Wiggins \& Potter, 2007). Avhandlingen använder sig av DP för att undersöka aspekter av literacy, och hur detta konstrueras i klassrumsinteraktion. Exempel på detta är hur deltagares kunskaper och uppfattningar om serier skapar diskurser (Paper I), berättandestruktur och att läsa mellan seriebilderna (Paper II), samt hur emotionella uttryck görs genom pratbubblor (Paper III).

\section{Vad är en serie?}

Det finns många olika former av serier, även om det vanligaste läsaren kanske tänker på är barnserier som Bamse eller Kalle Anka. Dock finns sedan länge en rik mängd serier riktade till både vuxna och tonåringar, t.ex. Liv Strömquist (Einsteins fru) and Nanna Johansson (Välkommen till din psykos), för att nämna två svenska exempel (för en överblick av begreppet, se bl.a. Strömberg, 2003). Denna avhandling är språkligt begränsad till engelska och svenska, och då seriematerialet som används i de undersökta skolorna även speglar anglosaxisk och nordisk serie-tradition så har avhandlingens teoretiska kapitel fokuserat främst på detta. Även om det säkerligen finns mycket intressant forskning från länder som Frankrike, Belgien, Japan och Spanien så har denna forskning enbart använts om den också återfinns på engelska eller svenska.

Definitionen av serier har länge debatterats, precis som seriens ursprung. Forskare som Thierry Groensteen (2007), Scott McCloud (1993) och Will Eisner (2008a) arbetade under 1980- och 1990talet med att utveckla teori om serier och skapandet av serier, och kom fram till olika definitioner beroende på vad som skulle inkluderas i begreppet serier (Eng: comics). Eisner (2008a) kallar serier helt enkelt för "sekventiell konst" (s. 1), medan McCloud använder det mer omständliga "motställda och andra bilder $\mathrm{i}$ medveten sekvens menad att förmedla information och/eller producera en estetisk respons i tittaren" (s. 9). Båda dessa förklaringar innebär vissa problem. I denna avhandling använder jag följande definition: juxtaposed pictorial narratives (ungefär 
motställda bildberättelser, jfr också McCloud, 1993), alltså två eller fler bilder placerade bredvid varandra för att berätta en historia av något slag. I sin avhandling Berättande Bilder (2005) pekar Helena Magnusson på ytterligare ett inslag som är särskilt för serier, vilket är att de är överblickbara, dvs. läsaren har tillgång till flera bilder i serien på en gång. Denna definition skiljer serien från t.ex. film där bilderna inte är motsatta och tittaren upplever inte två eller fler bilder bredvid varandra (N. Williams, 1995), men även annan konst som många läsare kanske skulle kalla serier, som Gary Larsons Far Side räknas bort här, då dessa (oftast) består av endast en bild. Trots detta används för denna avhandling en kombination av dessa två definitioner, nämligen överblickbara motställda bildberättelser (surveyable juxtaposed pictorial narratives).

\section{Serien som visuell literacy}

Serien är en multimodal textuell-visuell form av litteratur (Cook, 2017; jfr också Kress, 2003; Kress \& van Leeuwen, 2001) som använder sig av semiotiska, symboliska och ikonografiska visuella medel för att kommunicera med läsaren (McCloud, 1993). Detta innebär att analys av serier inte kan fokusera enbart på det textuella. Kombinationen av text och bild är det mest karaktäristiska draget hos serier, men förhållandet dem emellan är komplicerat. Roland Barthes (1985) teoretiserade att text och bild har ett dysfunktionellt förhållande, och att texten parasiterar på bilden (s. 14). Barthes skriver att texten "tynger ner bilden och fyller den med en kultur, moralitet, en föreställning" (1985, ss. 1415). På liknande sätt menar Gunther Kress och Theo van Leeuwen (2006) att "språket kommer först, och auktoritärt laddar bilden med mening" (s. 26), även om de inte verkar bidra med empiriska bevis på detta. Magnusson (2005) visar, genom en studie av serier för barn, hur text och bild i serier ibland kan användas bristfälligt, då en text som sätts till bild inte tillför något utöver det läsaren (uppenbart) kan se i bilden - vilket ses som ett syfte med kombinationen av dessa modaliteter.

Denna avhandling utgår ifrån ett perspektiv där mening ur bild och text konstrueras socialt, och att det ligger på läsaren att skapa denna mening utifrån kombination av både bild och text, som kan vara både tvetydiga och svårtolkade - dvs. ingendera aspekt har 
nödvändigtvis tolkningsföreträde. På detta sätt används analyser av social interaktion för att visa hur läsare gör läsningar av det material, både bild och text, som de hanterar. Därigenom kan analysen visa hur läsare använder sig av bild- och textkombinationer på olika sätt för att konstruera narrativ.

Att på detta sätt studera elevers och lärares konstruktioner och förhandlingar av bild- och textrelationen i klassrummet ger detta forskningsområde en ny dimension. Hur arbetar lärare och elever med multimodala aspekter av serier? Hur hanterar läsgrupper de visuella och textuella aspekterna när de återberättar eller läser serier? Hur görs de strukturella aspekterna av serier till lärandeaspekter i undervisning? Detta är frågor som har väglett de inledande delarna av denna studie: inspelning och genomgång av data. För att kunna diskutera dessa frågor kommer jag först att redogöra för hur läsare kan göra literacy i klassrummet.

\section{Vad är literacy?}

Begreppet literacy infördes på 1980-talet som ett resultat av utbildningsreform, en sociokulturell vändning inom utbildningsvetenskap, och den brasilianske forskaren Paulo Freire (se t.ex. 1972, 1973) och hans arbete inom the Critical Education movement (Eng: rörelsen för Kritisk Utbildning; för en översikt se t.ex. Lankshear \& Knobel, 2011). Literacy blev därigenom en svepande term för att diskutera läs- och skrivpraktiker (se t.ex. Teale \& Sulzby, 1986) och har varit ett omdiskuterat begrepp sedan dess (Lonsdale \& McCurry, 2004). Två huvudsakliga aspekter av literacy diskuteras i denna text: literacy som socialt konstruerad praktik och literacy som en aspekt av ideologi och makt.

\section{Literacy som social aktivitet}

Literacy "är inte bara en fråga om kognitivt processande" (CookGumperz, 1986a, s. 8) utan något som skapas och återskapas i sociala praktiker (se även Barton, 2007). Som exempel så undersöker Sylvia Scribner och Michael Cole (1981) Vai-folket i västra Afrika, och vad forskarna hänvisar till som läs- och skrivkunniga och icke läs- och skrivkunniga, genom att studera literacy och användande av symbolspråk och teknologi som en del 
av den sociala samhällspraktiken. De visar hur kunskapsförändringar som tidigare förklarats som kognitiva starkt påverkats av sociala och kulturella skolprocesser. Denna avhandling använder sig av detta sociokulturella perspektiv på literacy genom att studera hur diskurser av läsning och litteratur skapas i skolsituationen. Detta innebär en kombination av etnografi och diskursanalys vilket möjliggör en diskussion av dels ideologiska aspekter av literacy (Street, 1984, 1988; Gee, 2002) och dels hur deltagare gör läsande och skrivande av serier som konstruktioner i klassrumssamtal (jfr Potter, 1996; Wiggins \& Potter, 2007).

\section{Literacy som ideologi}

Det andra perspektivet av begreppet literacy är det ideologiska perspektivet, framfört framförallt av Freire $(1972 ; 1973)$, Jenny Cook-Gumperz (1986b), och Brian Street (1984). Dessa forskare demonstrerar literacy som maktredskap och hur dominerande samhällsfunktioner såsom forskare, stat, m.fl., kan använda sig av begrepp som litterär/icke-litterär för att främja vissa grupper av människor (se även Scribner \& Cole (1981) och Freire \& Donaldo Macedo (1987)). I sin bok Literacy in Theory and Practice (1984) kritiserar Street (1984) det han kallar den autonoma modellen där literacy tidigare studerats antropologiskt som en oberoende kunskap som alla kan uppnå. I stället bör literacy studeras utifrån en ideologisk modell där sociala och kulturella förhållanden inkluderas. Literacy, menar Street (1984), kan inte studeras oberoende av dessa faktorer. I denna avhandling diskuteras det ideologiska perspektivet $\mathrm{i}$ form av diskurser som konstrueras i interaktion mellan deltagare, snarare än ett objektivt maktperspektiv som förutsätts påverka samtalen.

\section{New Literacy Studies och new literacies}

I utvecklingen av literacy-forskningen under 1980- och 1990-talet breddades perspektivet på vad literacy kunde vara. Med t.ex. forskargruppen The New London Group (1996) utvecklades multiliteracies (Eng: mång-literacy), vilket omfattar en breddning av material för läsning, t.ex. symboler, bilder, färger, ljud och andra aspekter (Kress \& van Leeuwen, 2001), men även en syn på 
literacy som synonymt till kunskap, och därav applicerbart i olika former av computer literacy, media literacy, technological literacy, m.m. (se Gee, 2002; Hollingsworth \& Gallego, 1996; Jewitt, 2008; Lankshear \& Knobel, 2011). Denna breddning av begreppet beredde väg för två perspektiv som är vägledande i denna avhandlingsstudie: New Literacy Studies (NLS) och new literacies.

NLS är ett forskningsparadigm som fokuserar dels på ett sociokulturellt perspektiv på literacy-forskning (i kontrast till det individuella, kognitiva perspektivet) och dels på ett ideologiskt perspektiv på literacy där sociala och kontextuella faktorer såsom makt diskuteras (Street, 1993; Street, m.fl., 2011; se även Lankshear \& Knobel, 2011). NLS ser ideologiska faktorer som både konstruerade, och konstruerande av literacypraktiker (Street, m.fl., 2011). Det är dock viktigt att komma ihåg att rådande literacypraktiker har förändrats under lång tid och fortsätter att förändras i skrivande stund (se t.ex. Sousanis, 2015), vilket gör dem viktiga att studera och förstå.

New literacies är ett perspektiv inom NLS där de materiella, multimodala, aspekterna av olika former av läsning tas in, t.ex. bild, ljudtext, rörliga bilder, färger, former, etc., och new literacies breddar på detta sätt synen på vad som kan läsas/skrivas och vad läsande och skrivande innebär (se t.ex. Lankshear \& Knobel, 2011 och Ripley, 2012). Kate Pahl och Jennifer Rowsell (2006) argumenterar för fördelarna med att använda ett multimodalt perspektiv genom att det ger "ett analytiskt verktyg för att förstå artefakter såsom barns teckningar, och för att förstå hur literacy återfinns inom ett bredare kommunikativt landskap" (s. 8).

Att studera literacy som social praktik är i sig själv inget nytt. Det finns ett flertal studier som undersökt, till exempel, lärarledda gruppdiskussioner om skönlitteratur i år 4-7 och pedagogiska dilemman (Eriksson, 2002a, 2002b), elevers konstruktion av genus i relation till filmen Lilja 4-Ever (Eriksson Barajas, 2010), och ett etnometodologiskt perspektiv för att studera en läsgrupp på bibliotek, där deltagares förhandlingar kring litteratur analyseras (Allington \& Benwell, 2012). För en översikt av forskning, se Daniel Allington och Joan Swann (2009b). Det som denna avhandlingsstudie tillför till tidigare studier är dels dess fokus på multimodala aspekter av literacy, och dels den specifika 
undersökningen av deltagares meningsskapande med serier. På detta sätt gör denna studie ett unikt bidrag till forskningen om literacy i skolpraktik.

\section{Comics Literacy - serie-literacy}

En av slutsatserna så långt i denna text är att diskutera serier utifrån sitt eget begrepp - comics literacy (serie-literacy) - och jag använder här termen från Heidi K. Hammonds (2009) avhandling, och Matthew Pustz (1999). Hammond definierar serie-literacy som "flyt i seriens unika språk och visuella grammatik" (s. 42). Hon menar att serie-literacy kräver att läsaren behärskar både textliteracy och visuell literacy (s. 43). Hon klargör aldrig gränsen mellan dessa båda former av literacy, och i min mening är denna separation onödig, då poängen med serie-literacy är just att kombinera dem till en enda.

Pustz (1999) använder sig också av begreppet comics literacy, men som ett uttryck för det intertextuella och interkulturella perspektivet på serieläsning där satir, serieskapares förmåga att referera till andra serieskapare, eller karaktärers förmåga till självreflektion står i centrum. Därav gör Pustz inte en empirisk studie av läsarna av serier, utan utgår ifrån serien som material. Dock så saknas här ett literacyperspektiv som diskuterar seriens bild- eller text-språk, på det sätt som Hammond (2009) gör.

Den aktuella avhandlingstexten kombinerar dessa två perspektiv på serie-literacy och definierar detta som socialt konstruerat meningsskapande med narrativ sekventiell konst, där läsare utvecklar intertextuell och kulturell kompetens. Detta kommer att diskuteras vidare $i$ den sammanfattande slutdiskussionen av denna text.

\section{Forskning om serier i skola}

Forskning om serier i skola går tillbaka så långt som till 1920-talet i USA där projekt med serier undersökte användningen av seriestrippar i klassrummet (Tilley \& Weiner, 2017). Utvecklingen av serieformen och produktionen av billiga seriealbum ledde till att den blev en massivt populär form av barnlitteratur under 1930- och 1940 -talet. W. W. D. Sones (1944) rapporterar att $95 \%$ av 8 till $14-$ 
åringar vid denna tid läste serier. Här uppstår även de två stora förlag som fram till vår tid kommit att dominera marknaden: DC Comics 1935 (B. W. Wright, 2001) och Marvel Comics 1939 (Daniels, 1991).

Jag kommer här av platsskäl utelämna stora delar av serieforskningen under 1900-talet, men en sak som ofta diskuteras i relation till serier och som bör tas upp även här är debatten som eskalerade under 1950-talet (men som hade grott sedan början av århundradet), där serier blev beskyllda för att leda till bl.a. ungdomsbrottslighet. Centralfiguren i denna debatt blev psykologen Frederic Wertham som publicerade boken Seduction of the Innocent (1954, Eng: Förförelsen av oskyldiga) där han lade fram sina argument mot serien som läsmaterial för unga. Werthams studier kom senare under kritik för bristande bevismaterial (se t.ex. Tilley, 2012), men debatten satte sina spår och förlagen som publicerade serier införde under 1950-talet en form av självcensur i form av en stämpel som skulle garantera oroliga föräldrar att serien inte innehöll olämpligt material. Forskning på senare tid har även argumenterat för att serieläsare skulle visa högre tendenser till våldsamhet än andra (Kirsh \& Orczak 2000, 2001, 2002, 2003). Dock så har Steven Kirsh och Paul Orczaks studier ett relativt litet urval, de erkänner själva att deras deltagares inneboende aggressivitets-nivåer utgjorde ett större grund för tendenser till våld än vad våldet i serierna gjorde (2003, s. 57), och dessutom så förklarar de inte varför våld i serier skulle skilja sig från våld i andra former av media. Därigenom verkar det i nuläget inte finnas någon grund till att serier är en riskfaktor för unga.

Det finns relativt mycket forskning om serier som ett material $i$, eller för, skola, då materialet i sig är mycket mångsidigt och innehåller i princip alla genres som återfinns inom skönlitteratur. Därtill har serier producerats specifikt för olika form av utbildning, t.ex. Will Eisners Preventive Maintenance Monthly (1951) som använts av den amerikanska militären för utbildning av soldater för olika typer av marktjänst och underhåll. Inom skola så har serier diskuterats utifrån en mängd olika ämnesdidaktiska perspektiv såsom historia (Aiken, 2010; Cromer \& Clark, 2007; Decker \& Castro, 2012), medicin (Green \& Myers, 2010; I. C. M. Williams, 2012), och naturvetenskapliga ämnen (Hosler \& Boomer, 2011; 
Nesmith et al., 2011; Rollnick et al., 1998). Här kommer jag dock att fokusera på serier som material för literacy.

\section{Serier för literacy}

Experiment-studier i USA på 1940-talet (Witty, 1941a, 1941b; Sones, 1944; Hutchinson, 1949) intresserade sig mycket för serien som läsmaterial och genomförde flertalet enkätstudier med både lärare och elever om detta (i Wittys studie deltog 2500 elever i olika åldrar, och i Hutchinsons studie deltog 400 lärare). Resultaten från dessa studier pekar på att användning av serier t.ex. höjer motivationen, gör att elever deltar i högre grad, och gör att eleverna finner materialet roligt att använda (Hutchinson, 1949). Under 1960, 1970 och 1980-talen är det svårare att finna forskning om serier, där en anledning kan vara den kritik som riktades mot seriemediet och den debatt som rasade över formatet under 1950talet. Under 1990-talet återfinns däremot forskning om serier som material för andraspråksinlärning där Neil H. Williams (1995) argumenterar för att kombinationen av bilder och text fungerar som stötta i läsningen.

Tre avhandlingar bör nämnas här. Wendy Frances Helsby (1999) argumenterar för att pedagogisk praktik bör reflektera en bredare bild av vad literacy innebär, där läsning av bilder inte nödvändigtvis är lättare utan annorlunda, och att det därför också måste förstås annorlunda från text. Hammond (2009) diskuterar, baserat på intervjuer och skriftlig respons från 23 gymnasieelever, hur användandet av bild och text upplevs som en styrka i serieformatet och diskuterar det utifrån ett perspektiv av visuell literacy. Mary Stoermer (2010) försöker "förstå det pedagogiska kunskapsinnehåll (pedagogical content knowledge) som krävs för att lära barn i sju och åtta års ålder att skapa serier” (s. 10). På detta sätt bidrar Stoermer med begrepp och verktyg för lärare att arbeta med serieskapande i grundskola.

Ett problem som kan uppstå i skolmiljö är när bild- och textkombinationen (däribland serier, men även bilderböcker) förutsätts vara en stötta för läsförståelse som bör överges efter ett visst stadium (se t.ex. Jonsson, 2006). Detta synsätt förutsätter att individens läsnivå automatiskt ökar med ålder och underskattar läsningen av bilder genom att förutsätta att bilder är lättare att 
förstå än text. Här skulle en möjlig utveckling kunna vara att bredda synen på serier som läsmaterial och t.ex. utgå ifrån att inte alla serier är barnsliga (jfr Westin, 1993, 2002) utan att de återfinns inom alla svårighetsnivåer av läsning.

Sylvia Pantaleo (2011a, 2012c, 2013) har även gjort fallstudier, intervjuer, och klassrumsobservationer med barn i grundskola som arbetar med serier och bilderböcker. Hon visar hur barnens medvetenhet om serieformens påverkan på läsning och de kompetenser som krävs av, och utvecklas med, denna läsform. Det skulle vara intressant att komplettera Pantaleos arbete med studier av t.ex. den dagliga sociala interaktionen och de litterära och diskursiva praktikerna som görs i klassrummet.

Denna (om än korta) genomgång visar den bredd av studier som finns av serier i skola, men det saknas ett perspektiv på den naturliga verksamheten där forskaren inte genomför experiment. Detta perspektiv skulle kunna ge ytterligare insikt i detta fält. Därtill saknas studier av serier som en litterär praktik i svensk skola, vilket gör att denna avhandlingsstudie även bidrar till nationella studier av literacy i skolpraktik.

\section{Metod, datainsamling och deltagare}

Video- och ljudinspelningar har gjorts med tre klasser i årskurs 3 ( 9 års ålder) och en klass i årskurs 8 (14 års ålder), vilket har gett totalt 77 elever och 6 lärare i två olika svenska städer. Totalt 15 lektioner har spelats in där eleverna arbetar i omväxlingsvis helklass, par och i grupp, och originalmaterialet omfattar 36 timmar video. Videoetnografi är central inom modern interaktionsforskning då gester, blickar, och användning av fysiskt material (i det här fallet seriematerialet), tillsammans med tal, är en del av det analytiska grundmaterialet (se t.ex. Mondada, 2006). Detta gör transkription mödosamt då transkriptioner behöver vara detaljerade, vilket tar lång tid och mycket arbete. För att underlätta detta har materialet initialt grovtranskriberats; deltagarnas tal har transkriberats och intressanta gester eller liknande har noterats $i$ marginalen. Efter detta har jag sett om videos och intresseväckande inslag har transkriberats $\mathrm{i}$ detalj, inklusive gester, blick, och deltagarnas användning av material. 
På detta sätt har olika samlingar skapats (se Wiggins, 2017) med olika fokus utifrån det övergripande forskningsintresset för hur deltagare konstruerar literacy med serier $i$ undervisning. Till exempel så blev läsarnas samtal om s.k. gutter space ett tidigt fokus (detta kom senare att bli Paper II) då läraren Anna explicit pratar om "mellanrummet" mellan bilderna och hur detta är viktigt för strukturen och berättelsen. När detta hade valts som fokus så sågs videon igen, och jag gick tillbaka och undersökte övriga materialet ytterligare för att se om liknande sekvenser kunde finnas.

\section{Resultat}

De empiriska studierna presenteras genom tre individuella vetenskapliga artiklar i andra delen av avhandlingen. Resultaten ifrån Paper I visar att när deltagarna använder serier som grund för interaktion om literacy i klassrummet så konstruerar deltagarna diskurser av serie-literacy som både visuell och textuell. Dessutom så visar Paper I hur deltagarna konstruerar diskurser i form av personliga erfarenheter av serier, där de konstruerar serier som en form av barnlitteratur, men även att serier kan vara för svårt för vissa barn. I Paper II visas att seriemediets sekventiella berättarteknik möjliggör för lärarna att väcka diskussioner i elevgrupper i yngre åldrar om berättande med hjälp av bilder. De flesta lärare i grundskolans yngre åldrar arbetar antagligen med sekvensbilder idag, men t.ex. Paper II visar att en längre sekvens med bilder som har svaga intersubjektiva kopplingar tvingar elever att skapa egna kopplingar i mellanrummen, och eleverna får större handlingsutrymme att använda sin egen kreativitet. Paper III visar hur elever och lärare samkonstruerar pratbubblor som verktyg för berättande i seriemediet. Deltagarna bidrar med olika varianter av bubblor och för en diskussion om bubblornas visuella former, och genom multimodala instruktioner, där läraren använder både kroppsspråk, gester, ljud, och text, skapas både känslouttryck och ljudupplevelser i text.

\section{Diskussion}

I denna del av texten diskuteras ovanstående syfte, frågeställningar och resultat i teman som framkommit i analysen, och relateras till 
teorier om serier och literacy. Till sist ges en kortfattad redogörelse för framtida studier som skulle vara av intresse inom området.

\section{Serie-literacy i klassrummet}

Ett av de viktigaste bidragen som studien gör är utvecklandet av begreppet comics literacy (serie-literacy). Detta begrepp är ursprungligen hämtat från Hammond (2009) och Pustz (1999), men utvecklas här baserat på både teoretiska diskussioner och analys av det empiriska materialet. Två centrala perspektiv av serie-literacy ska här diskuteras. Först hur de empiriska studierna visar vad som kännetecknar serie-literacy, och sedan hur serie-literacy görs som en del av klassrummets literacypraktik.

\section{Vad som kännetecknar serie-literacy}

För det första så kännetecknas serie-literacy av den kombination av bild och text som är specifik för serier; hur denna kombination görs i konstruktioner av sekventiella narrativ, hur detta påverkar de litterära verktyg som formatet innefattar (t.ex. pratbubblor, berättarperspektiv, m.m.), samt deltagarnas läsning av detta.

För det andra så kännetecknas serie-literacy av deltagarnas konstruktioner av diskurser av serier, deras användning av personlig literacy som skapas med serier, och deras konstruktioner av materialet som unikt bland andra former av fiktion.

Nedan diskuteras dessa två aspekter.

Serien som visuell och textuell litteratur

Serier är en visuell form av litteratur som huvudsakligen använder sig av bilder och symboler för att berätta historier. Det finns exempel på både "text-tunga" serier (som Martin Kellermans Rocky), men det finns också exempel på serier helt utan text (som Shaun Tans Ankomsten). I analysen av samtliga tre papper som ingår i denna avhandling så förekom visuella aspekter av materialet i de aktiviteter och interaktioner som förekom. Därav skulle kunna argumenteras för att denna interaktion och dessa aktiviteter bör analyseras ur ett perspektiv av visuell literacy (som görs av t.ex. Hammond (2009)). Dock, som analysen av de tre papperen visar, så är kombinationen av bild och text - och hur deltagare konstruerar detta med klassrumsmaterialet - centralt för serie- 
literacy. I dessa analyser så kräver inte serier att eleverna behärskar textuell och visuell literacy utan dessa elever arbetar med att behärska dessa perspektiv i kombination. Eleverna i Paper III visar hur social konstruktion av prat- och tankebubblor som semiotiska symboler (Scribner \& Cole, 1981) medverkar till att skapa de textmeddelanden som läggs inom bubblorna.

New literacies diskuterar och analyserar multimodala texter och användandet av t.ex. bild- och textkombinationer (Lankshear \& Knobel, 2011), och ifrågasätter hur vi ser på texter och vad vi kallar texter. I Paper II använder deltagarna inte text utan enbart "tysta" serierutor (utan text i pratbubblorna) som bas för att skapa en verbal och visuell berättelse. Även om elevernas slutuppgift är att skriva ner sin berättelse så skapar och omskapar de berättelsen verbalt många gånger där olika deltagare förhandlar olika delar av berättelsen. Detta demonstrerar vikten som det visuella materialet får då eleverna använder seriebilderna för att placera och omplacera olika delar av den narrativa strukturen, både som hjälp och som hinder för berättandet. Samtidigt så använder deltagarna de tysta pratbubblor som finns i bilderna som visuella ledtrådar för när deras narrativ bör innehålla dialog (eller monolog) vilket också används för att driva berättelsen framåt.

\section{Seriediskurser}

I sin bok Comic Book Culture argumenterar Pustz (1999) för att kunskap om, och deltagande i, seriekultur är en del av vad som kännetecknar serie-literacy. Medan Pustz använder sig av en materiell analys, där materialet innehåller serie-literacy (s. 112), så utgår denna avhandling i stället ifrån ett perspektiv där deltagarna samkonstruerar seriediskurser och argumenterar för detta som kännetecknande för serie-literacy.

De tre papper som presenteras här visar hur deltagares erfarenheter och kunskaper om seriers kultur och historia görs relevant för meningsskapande med serier i klassrummet. En deltagare som är bekant med olika serie-genres och olika läsnivåer av serier har också olika literacy-domäner att utgå ifrån (Barton, 2007), då olika serieskapare använder olika tekniker där t.ex. form på pratbubblor kan förändras över tid, eller från tecknare till tecknare. Paper I demonstrerar hur lärare och elever relaterar till 
serier genom konstruktioner av olika seriediskurser utifrån visuella och textuella aspekter av serier, men även hur serier definieras som svåra eller enkla, och vad serier "är", baserat på deltagarnas personliga erfarenhet av läsning, det Allen \& Ingulsrud (2005) kallar deras personliga literacy. Dessa erfarenheter krockar med andras i klassrummet, och en samkonstruktion av dessa sker i dessa möten, för ett gemensamt meningsskapande (jfr. Edwards \& Mercer, 1987). Därför är den kollektiva kunskap som samlas i ett klassrum, där olika genres, berättelser, och stilar möts, ett viktigt verktyg för att skapa mening med serier.

\section{Att göra serie-literacy i klassrummet}

När det nu etablerats vad serie-literacy är, så ska jag vända mig till en diskussion av hur serie-literacy görs - hur deltagare konstruerar multimodal serie-literacy i klassrummet.

\section{Att göra multimodal serie-literacy}

Att arbeta med serier innebär en multimodal literacypraktik där deltagare använder alla till buds stående men (jfr Jewitt, 2008). Tillgång till seriematerial uppmuntrar fysiska manipulationer, som kan ses i Paper II där deltagarna arbetar med narrativa strukturer genom att använda flera serierutor för att konstruera en berättelse. Neil Cohn m.fl. (Cohn, 2013b; Cohn, m.fl., 2014;) visar kognitiva perspektiv att studera deltagares mentala konstruktioner av sekventiella narrativ, men i Paper II undersöks detta i stället som en social samkonstruktion, där deltagare arrangerar, förhandlar, och modifierar berättelser och skapar nya delar av berättelsen i gutters (mellanrum) - de utrymmen som utgör mellanrummen mellan seriebilderna. Här diskuteras strukturella element relaterade till tid och plats och deltagarna skapar en logik i berättelsen som inte får ha alltför stora eller för små glapp. Detta visar styrkan i serienarrativ där visuella strukturer kan arbetas med på ett tydligt sätt, vilket underlättar för elever som inte bemästrat textproduktion eller läsning (Street, m.fl., 2011). Detta kan relateras till styrdokumenten för svensk grundskola där lärare förväntas arbeta med narrativ text och berättandestrukturer (Swedish National Agency for Education, 2011a). 
Paper III demonstrerar hur deltagarna arbetar med prat- och tankebubblor och de multimodala aspekter (Kress, 2010; Kress \& van Leeuwen, 2001) som detta innefattar. Här använder läraren kroppsspråk, röstkvalitet, bild, och text för att iscensätta de pratbubblor som eleverna ska lära sig. Detta används för att arbeta med berättarteknik (så kallad fokalisering). Det blir tydligt att elever och lärare inte är helt överens om hur bubblorna kan se ut, eller vad de representerar, vilket pekar på den samlade kunskap som skapas här, och de samkonstruktioner som görs för att nå fram till detta. Med tanke på att teknikerna för att visualisera pratbubblor skiftar mellan olika kulturer och mellan olika tecknarstilar så är detta också en styrka att deltagarna får olika uppfattningar om hur bubblor kan tolkas och vilken effekt det har på läsningen, då vad vi tolkar in i begreppet literacy hela tiden förändras (jfr Hiebert, 1991).

\section{Att göra seriediskurser}

Med ett ideologiskt perspektiv på literacy (Cook-Gumperz, 1986a; Street, 1984) så är det tydligt att seriediskurser konstrueras av, och konstruerar, serie-literacy. I klassrumssamtalen hänvisar elever och lärare till personliga erfarenheter av serier, och dessa erfarenheter används som argument för att få något att hända. Läraren Jonna, $\mathrm{i}$ Paper I, relaterar till sina egna erfarenheter av Kalle Anka och upplever en konflikt $i$ att hennes erfarenheter av serien som lämplig för barn inte går ihop med hennes nya erfarenheter av att den serie hon vill använda i klassrummet känns för komplicerad för hennes elever. Hon hanterar detta genom att argumentera att serier utvecklas med tiden och att serier har blivit mer avancerade sedan hon själv var barn. Dessa konstruktioner visar hur seriediskurser konstrueras och blir dominerande perspektiv (t.ex. serien som barnlitteratur). När deltagare skapar samförståelse (Edwards \& Mercer, 1987) av ett material så är det viktigt att vara medveten om dessa diskurser och hur de påverkar samtalet i klassrummet när de uppstår.

I Paper I så diskuterar eleverna i årskurs 8 Kalle Anka som en form av barnlitteratur baserat på visuella och språkliga aspekter. Denna diskussion manar eleverna att analysera användandet av text och bilder i serien och hur detta talar till olika målgrupper, men det 
väcker också en diskussion om när barn börjar läsa och vad läsning $\ddot{a} r$ överhuvudtaget. Detta ger ett gott exempel på hur en diskussion om serier som barnlitteratur kan främja skapandet av nya literacydiskurser. Det är naturligtvis inte så att serier automatisk är barnlitteratur utan det finns serier för barn såväl som för ungdomar och vuxna. Däremot så måste både forskare och lärare vara medveten om att det finns starka diskurser runt seriemediet.

\section{Lärares arbete med serie-literacy}

Stoermers (2010) studie pekade på hur lärare kan arbeta med serier i grundskola. I denna studie finns även ett flertal exempel på de styrkor som serie-literacy innefattar, i det arbete som sker i det empiriska materialet. Ett exempel på detta är aktiviteterna i Paper II, som visar narrativets styrka inom serie-literacy. Användandet av lösa seriebilder för att skapa berättelser uppmanar deltagarna att manipulera och flytta runt det fysiska materialet och föra en metadiskussion om berättande och berättandeformen, och den logik som förs genom en visuell berättelse, tillika en textuell, berättelse. Här finns också en möjlighet för elever och lärare att diskutera och argumentera för konstruktionen mellan bilderna, och utveckla sin kreativitet i samspel med andra för hur en berättelse kan skapas.

\section{Framtida studier}

För framtida studier i ämnet finns flera intressanta ingångar. En möjlighet är att studera hur serier används $\mathrm{i}$ hemmet och kontrastera detta med användningen i skola. Forskare, t.ex. Haugaard (1973) och Marsh (2003), har tidigare undersökt serier som läsning i hemmet, men detta har gjorts som enkät eller intervjustudier vilket skulle göra det intressant att undersöka hur seriediskurser skapas i interaktion i hemmet, för att se hur detta görs och om det finns tydliga skillnader från diskurser i skola. På detta sätt kanske det även skulle vara möjligt att se hur yngre barn börjar läsa serier tillsammans med föräldrar, för att på bättre sätt kunna undersöka läsning av serier, och parläsning av serier, där en vuxen läser tillsammans med ett barn. Det förekom relativt lite läsning i mitt inspelade material, vilket gjorde det svårt att studera detta systematiskt. 
Det finns flertalet studier av serier som ett material för pojkars läsning (Brozo, 2012; Davies \& Brember, 1993; Laycock, 2007; Lenters, 2007; Merisuo-Storm, 2006; Wilson, 2009), men även här saknas studier på interaktion och studier med diskursiva perspektiv. Att göra vidare studier på serieläsning med ett genusperspektiv är därför också något som skulle vara intressant.

\section{Avslutningsvis}

Denna avhandling bidrar till kunskap om serie-literacy och användningen av serier i skolpraktiker. Studien har implikationer för literacypraktik i skolan, och hur policyskapare och lärare arbetar med serier och annat material i skolan. Resultaten visar att det finns mycket användbart i seriematerialet när detta studeras med ett literacyperspektiv - både materiella och diskursiva aspekter. Serietidningen rymmer många möjligheter, men som lärare så krävs det eftertanke och en kunskap om materialet för att kunna använda det förtjänstfullt. I vidare studier av meningsskapande med literacy i klassrummet kan vi säkerligen identifiera ytterligare detaljerade aspekter av serie-literacy och de sätt som dessa används för att konstruera, tala om, och arbeta med serietidningar. 



\section{References}

Abbott, A. (2004). Methods of Discovery - Heuristic for the Social Sciences. New York, NY: W. W. Norton \& Company.

af Sandeberg, J. (2013, Feb 8). Intresse för serier i undervisningen [Interest for Comics in Teaching]. Skolvärlden. Retrieved from: http://skolvarlden.se/artiklar/intresse-serier-i-undervisningen

Aiken, K. G. (2010). Superhero History: Using Comic Books to Teach U.S. History. OAH Magazine of History, 24(2), 41-47. doi:10.1093/maghis/24.2.41

Allen, K., \& Ingulsrud, J. E. (2005). Reading Manga: Patterns of Personal Literacies among Adolescents. Language and Education, 19(4), 265280. doi:10.1080/09500780508668681

Allington, D. (2012). Private Experience, Textual Analysis, and Institutional Authority: The Discursive Practice of Critical Interpretation and its Enactment in Literary Training. Language and Literature, 21(2), 211-225. doi:10.1177/0963947011435864

Allington, D., \& Benwell, B. (2012). Reading the Reading Experience: An Ethnomethodological Approach to "Booktalk". In A. Lang (Ed.), From Codex to Hypertext : Reading at the Turn of the Twenty-first Century (pp. 217-233). Amherst: University of Massachusetts Press.

Allington, D., \& Swann, J. (2009a). Reading Groups and the Language of Literary Texts: A Case Study in Social Reading. Language and Literature, 18(3), 247-264. doi:10.1177/0963947009105852

Allington, D., \& Swann, J. (2009b). Researching Literary Reading as Social Practice. Language and Literature, 18(3), 219-230. doi:10.1177/0963947009105850

Andrén, M. (2010). Children's Gestures from 18 to 30 months. (Doctoral dissertation), Lund university, Lund.

Antaki, C., Billig, M., Edwards, D., \& Potter, J. (2003). Discourse Analysis means doing Analysis: A Critique of Six Analytic Shortcomings. Discourse Analysis Online, 1(1), (n/a). Retrieved from: http://www.shu.ac.uk/daol/previous/v1/n1/index.htm

Axén, S., \& Cronstam, T. (1997/2016). Katten Jansson och Husmusen VEM behöver VEM - mest? [Jansson the Cat and the Pet Mouse WHO needs WHO - the most?]. In C. Borelius (Ed.), Bamse världens starkaste björn [Bamse - the World's strongest Bear (Vol. 8/9, pp. 45-48). Malmö: Egmont Publishing.

Barnes, D. (1976). From Communication to Curriculum. Harmondsworth, UK: Penguin Books. 
Barthes, R. (1985). The Responsibility of Forms: Critical Essays on Music, Art, and Representation (R. Howard, Trans.). Oxford: Basil Blackwell.

Barton, D. (2007). Literacy: An Introduction to the Ecology of the Written Language ( $2^{\text {nd }}$ ed.). Malden, Oxford, and Carlton: Blackwell.

Beaty, B. (2004). Review Essay: Assessing Contemporary Comics Scholarship. Canadian Journal of Communication, 29(3), 403-409.

Beaty, B. (2007). Unpopular Culture: Transforming the European Comic Book in the 1990s. Toronto, Buffalo \& London: University of Toronto Press.

Beaty, B. (2012). Comics versus Art. Toronto, Buffalo \& London: University of Toronto Press.

Beers Fägersten, K. (2012). The Use of English in the Swedish-language Comic Rocky. In F. Bramlett (Ed.), Linguistics and the Study of Comics (pp. 239-263). Basingstoke: Palgrave Macmillan.

Berger, P. L., \& Luckmann, T. (1967). The Social Construction of Reality: A Treatise in the Sociology of Knowledge. New York: Anchor Books.

Billig, M. (2009). Discursive Psychology, Rhetoric and the Issue of Agency. Semen: Revue de sémio-linguistique des textes et discours, 27, 1-20. Retrieved from: http://semen.revues.org/8930

Bitz, M. (2004). The Comic Book Project: Forging Alternative Pathways to Literacy. Journal of Adolescent \& Adult Literacy, 47(7), 574-586.

Blanch, C. L., \& Mulvihill, T. M. (2013). The Attitudes of Some Students on the Use of Comic Books in Higher Education. In C. K. Syma \& R. G. Weiner (Eds.), Graphic Novels and Comics in the Classroom (pp. 35-49). Jefferson: McFarland.

Bloome, D., Katz, L., Hong, H., May-Woods, P., \& Wilson, M. (2003). Methodologies in Research on Young Children and Literacy. In J. Larson \& J. Marsh (Eds.), The SAGE Handbook of Early Childhood Literacy (pp. 381-399). London, Thousand Oaks \& New Delhi: Sage.

Bongco, M. (2000). Reading Comics: Language, Culture, and the Concept of the Superhero in Comic Books. New York \& London: Garland Publishing.

Bramlett, F., Cook, R. T., \& Meskin, A. (Eds.). (2017). The Routledge Companion to Comics. New York \& Abingdon: Routledge.

Brienza, C. (2010). Producing Comics Culture: A Sociological Approach to the Study of Comics. Journal of Graphic Novels and Comics, 1(2), 105-119. doi:10.1080/21504857.2010.528638 
Brozo, W. G. (2012). Building Bridges for Boys: Graphic Novels in the Content Classroom. Journal of Adolescent \& Adult Literacy, 55(6), 550. doi:10.1002/JAAL.00064

Bruner, J., S. (1990). Acts of Meaning. Cambridge \& London: Harvard University Press.

Bucher, K. T., \& Manning, L. M. (2004). Bringing Graphic Novels into a School's Curriculum. Clearing House, 78(2), 67.

Burr, V. (2015). Social Constructionism ( $3^{\text {rd }}$ ed.). New York: Routledge.

Cadiero-Kaplan, K. (2002). Literacy ideologies: Critically Engaging the Language Arts Curriculum. Clearing House, 79(5), 372-381.

Carlsson, D. (Ed.) (2012). Välkommen till Ankeborg [Welcome to Duckburg]. Malmö: Egmont Kärnan.

Carlsson, D. (Ed.) (2013). Kalle Anka och hans vänner [Donald Duck and his Friends]. Malmö: Egmont Kids Media.

Carlsson, U., \& Johannisson, J. (2012). Läsarens marknad, marknadens läsare [The Reader's Market, the Market's Readers]. Stockholm: Nordicom \& Litteraturutredningen.

Carter, J. B. (Ed.) (2007). Building Literacy Connections with Graphic Novels: Page by Page, Panel by Panel. Urbana, IL: National Council of Teachers of English.

Chambers, A. (1985). Booktalk: Occasional Writing on Literature and Children. London: The Bodley Head.

Cohn, N. (2007). A Visual Lexicon. The Public Journal of Semiotics, $1(1), 35-56$.

Cohn, N. (2013a). Beyond Speech Balloons and Thought Bubbles: The Integration of Text and Image. Semiotica, 197, 35-63. doi:10.1515/sem-2013-0079

Cohn, N. (2014). Building a Better 'Comic Theory': Shortcomings of Theoretical Research on Comics and how to overcome them. Studies in Comics, 5(1), 57-75. doi:10.1386/stic.5.1.57_1

Cohn, N. (Ed.) (2013b). The Visual Language of Comics: Introduction to the Structure and Cognition of Sequential Images. London: Bloomsbury.

Cohn, N., Jackendoff, R., Holcomb, P. J., \& Kuperberg, G. R. (2014). The Grammar of Visual Narrative: Neural Evidence for Constituent Structure in Sequential Image Comprehension. Neuropsychologia, 64, 63-70. doi:10.1016/j.neuropsychologia.2014.09.018

Cohn, N., Paczynski, M., Jackendoff, R., Holcomb, P. J., \& Kuperberg, G. R. (2012). (Pea)nuts and Bolts of Visual Narrative: Structure and Meaning in Sequential Image Comprehension. Cognitive psychology, 65(1), 1-38. doi:10.1016/j.cogpsych.2012.01.003 
Cook, R. T. (2017). Metacomics. In F. Bramlett, R. T. Cook, \& A. Meskin (Eds.), The Routledge Companion to Comics (pp. 257-266). New York \& London: Routledge.

Cook-Gumperz, J. (1986a). Introduction: the social construction of literacy. In J. Cook-Gumperz (Ed.), The Social Construction of Literacy (pp. 1-15). Cambridge: Cambridge University Press.

Cook-Gumperz, J. (Ed.) (1986b). The Social Construction of Literacy. Cambridge: Cambridge University Press.

Cromer, M., \& Clark, P. (2007). Getting Graphic with the Past: Graphic Novels and the Teaching of History. Theory and Research in Social Education, 35(4), 574-591.

Dalgren, S. (2017). Att göra pedagogisk praktik tillsammans - Socialt samspel i förskolans vardag [Doing Educational Practice Together Social Interaction in the Everyday Life of Preschool]. (Doctoral dissertation), Linköping University, Linköping University.

Daniels, L. (1991). Marvel: Five Fabulous Decades of the World's Greatest Comics. New York: Harry N. Abrams.

Davies, J., \& Brember, I. (1993). Comics or Stories? Differences in the Reading Attitudes and Habits of Girls and Boys in Years 2, 4, and 6. Gender and Education, 5(3), 305-320.

Decker, A. C., \& Castro, M. (2012). Teaching History with Comic Books: A Case Study of Violence, War, and the Graphic Novel. History Teacher, 45(2), 169-188.

Deppermann, A. (2013). Multimodal Interaction from a Conversation Analytic Perspective. Journal of Pragmatics, 46, 1-7. doi:10.1016/j.pragma.2012.11.014

Dierick, C., \& Lefèvre, P. (Eds.). (1998). Forging a New Medium: the Comic Strip in the Nineteenth Century. Brussels: VUB University Press.

Dong, L. (2012). Teaching Comics and Graphic Narratives: Essays on Theory, Strategy and Practice. Jefferson: McFarland.

Dorrell, L. D., Curtis, D. B., \& Rampal, K. R. (1995). Book-Worms Without Books? Students Reading Comic Books in the School House. The Journal of Popular Culture, 29(2), 223-234. doi:10.1111/j.0022-3840.1995.2902_223.x

Downey, E. M. (2009). Graphic Novels in Curriculum and Instruction Collections. Reference \& User Services Quarterly, 49(2), 181-188.

Duncan, R., Smith, M. J., \& Levitz, P. (2015). The Power of Comics: History, Form, and Culture ( $2^{\text {nd }}$ ed.). London \& New York: Bloomsbury.

Edwards, D. (1996). Discourse and Cognition. London: Sage. 
Edwards, D., \& Mercer, N. (1987). Common Knowledge: The Development of Understanding in the Classroom. London \& New York: Methuen.

Edwards, D., \& Mercer, N. (1989). Reconstructing Context: the Conventionalization of Classroom Knowledge. Discourse Processes, 12, 91-104.

Edwards, D., \& Potter, J. (1992). Discursive Psychology. London: Sage.

Egmont Publishing. (2015). Serier i undervisningen (Om oss) [Comics in Teaching (About Us)]. Retrieved from: http://www.serieri undervisningen.se/om-oss/

Egmont Publishing. (2016). Material [Materials]. Retrieved from: $\mathrm{http}: / /$ serieriundervisningen.se/kalle-anka-material/

Eisner, W. (2008a). Comics and Sequential Art: Principles and Practices from the Legendary Cartoonist / Will Eisner. (Rev. ed: Comics \& sequential art. 1985). New York: W. W. Norton \& Company.

Eisner, W. (2008b). Graphic Storytelling and Visual Narrative (Rev. ed: Graphic storytelling. 1996). New York: W.W. Norton \& Company.

Enfield, N. J. (2011). Elements of Formulation. In J. Streeck, C. Goodwin, \& C. LeBaron (Eds.), Embodied Interaction: Language and Body in the Material World (pp. 59-66). Cambridge: Cambridge University Press.

Eriksson Barajas, K. (2008). Beyond Stereotypes? Talking about Gender in School Booktalk. Ethnography and Education, 3(2), 129-144. doi:10.1080/17457820802062367

Eriksson Barajas, K. (2010). The Pimp and the Happy Whore: "Doing Gender" in Film Talk in a School Setting. Scandinavian Journal of Educational Research, 54(6), 581-596. doi:10.1080/00313831. 2010.522847

Eriksson Barajas, K. (2015). Discursive Reception Studies - A Path toward Knowledge about Fiction in Everyday Life. Journal of Literary Theory, 9(1), 1-21. doi:10.1515/j1t-2015-0002

Eriksson Barajas, K. (2016). Methodological Reflections on Investigating the Reception of Fiction in Public Spaces. CLCWeb: Comparative Literature and Culture, 18(2), 281-299. doi:10.1177/096394 7009105854

Eriksson Barajas, K., \& Aronsson, K. (2009). Avid Versus Struggling Readers: Co-construed Pupil Identities in School Booktalk. Language and Literature, 18(3), 281-299. doi:10.1177/096394700 9105854

Eriksson, K. (2002a). Booktalk Dilemmas: Teachers' Organisation of Pupils' Reading. Scandinavian Journal of Educational Research, 46(4), 391-408. doi:10.1080/0031383022000024570 
Eriksson, K. (2002b). Life and Fiction - On Intertextuality in Pupils' Booktalk. (Doctoral dissertation), Linköping University, Linköping.

Fast, C. (2008). Literacy - i familj, förskola och skola [Literacy - In Family, Preschool, and School. Stockholm: Studentlitteratur.

Freire, P. (1972). Pedagogy of the Oppressed. Harmondsworth: Penguin.

Freire, P. (1973). Cultural Action for Freedom. Harmondsworth: Penguin.

Freire, P., \& Macedo, D. (1987). Literacy - Reading the Word \& the World. South Hadley: Bergin \& Garvey.

Frey, N., \& Fisher, D. (Eds.). (2008). Teaching Visual Literacy: using Comic Books, Graphic Novels, Anime, Cartoons, and More to Develop Comprehension and Thinking Skills. Thousand Oaks: Corwin Press.

Galaczy, M. (2013a). Kalle Anka i skolan: En lärarhandledning för årskurs 3 och uppåt [Donald Duck in School: A Teacher's Guide for Grade 3 and up]. Retrieved from: http://serieriundervisningen.se/wpcontent/uploads/2013/09/KalleAnka-lararhandledning.pdf

Galaczy, M. (2013b). Kopieringsunderlag - Kalle Anka i skolan: en lärarhandledning för årskurs 3 och uppåt [Copyable Materials Donald Duck in School: A Teacher's Guide for Grade 3 and up]. Retrieved from: http://serieriundervisningen.se/wp-content/uploads/ 2014/03/KA_Kopieringsunderlag.pdf

García, S. (2015). On the Graphic Novel. Jackson: University Press of Mississippi.

Garfinkel, H. (1984). Studies in Ethnomethodology. Cambridge: Polity Press.

Gee, J. P. (1992). The Social Mind: Language, Ideology, and Social Practice. New York, Westport \& London: Bergin \& Garvey.

Gee, J. P. (2000). Teenagers in New Times: A New Literacy Studies Perspective. Journal of Adolescent and Adult Literacy, 43(5), 412420.

Gee, J. P. (2002). Social Linguistics and Literacies: Ideology in Discourses $\left(2^{\text {nd }}\right.$ ed., 1996). London: RoutledgeFalmer.

Gergen, K., J. (1973). Social Psychology as History. Journal of Personality and Social Psychology, 26(2), 309-320.

Gibson, M. (2010). Picturebooks, Comics and Graphic Novels. In D. Rudd (Ed.), The Routledge Companion to Children's Literature. London \& New York: Routledge.

Gilbert, G. N., \& Mulkay, M. (2003). Opening Pandora's Box: A Sociological Analysis of Scientists' Discourse (Rev. ed., 1984). Cambridge: Cambridge University Press. 
Goodwin, C. (2000). Action and Embodiment within situated Human Interaction. Journal of Pragmatics, 32, 1489-1522.

Goodwin, C. (2013). The Co-operative, Transformative Organization of Human Action and Knowledge. Journal of Pragmatics, 46, 8-23. doi:10.1016/j.pragma.2012.09.003

Goodwin, C., \& Goodwin, M. H. (2013). Building Human Action by Transforming Different Kinds of Semiotic Materials. Paper presented at the Annual Meeting of the American Anthropological Association, Chicago. Nov. 20-24.

Green, M. J., \& Myers, K. R. (2010). Graphic Medicine: Use of Comics in Medical Education and Patient Care. BMJ (British Medical Journal), 340(7746), 574-577.

Groensteen, T. (2007). The System of Comics (B. Beaty \& N. Nguyen, Trans.). Jackson: University Press of Mississippi.

Groensteen, T. (2009). Why Are Comics Still in Search of Cultural Legitimization? (S. Smolderen, Trans.). In A. Magnussen \& H.-C. Christiansen (Eds.), Comics \& Culture: Analytical and Theoretical Approaches to Comics (pp. 29-41). Copenhagen: Museum Tusculanum Press.

Groensteen, T. (2013). Comics and Narration (A. Miller, Trans.). Jackson: University Press of Mississippi.

Hacking, I. (1999). The Social Construction of What? Cambridge \& London: Harvard University Press.

Haddington, P., \& Rauniomaa, M. (2014). Interaction Between Road Users: Offering Space in Traffic. Space and Culture, 17(2), 176-190. doi:10.1177/1206331213508498

Hammond, H. K. (2009). Graphic Novels and Multimodal Literacy: A Reader Response Study. (Doctoral dissertation), Graduate School of the University of Minnesota.

Hammond, K., \& Danaher, K. (2012). The Value of Targeted Comic Book Readers. ELT Journal, 66(2), 193-204. doi:10.1093/elt/ccr051

Harvey, R. C. (2001). Comedy at the Juncture of Word and Image: The Emergence of the Modern Magazine Gag Cartoon Reveals the Vital Blend. In R. Varnum \& C. T. Gibbons (Eds.), The Language of Comics: Word and Image (pp. 75-96). Jackson: University Press of Mississippi.

Hatfield, C. (2005). Alternative Comics: An Emerging Literature. Jackson: University Press of Mississippi.

Hatfield, C. (2006). Comic Art, Children's Literature, and the New Comics Studies. The lion and the unicorn: a critical journal of children's literature, 30(3), 360-382. doi:10.1353/uni.2006.0031 
Hatfield, C., \& Svonkin, C. (2012). Why Comics Are and Are Not Picture Books. Children's Literature Association Quarterly, 37(4), 429-435. doi:10.1353/chq.2012.0046

Hatfield, W. W. (1935). An Experience Curriculum in English: A Report of the Curriculum Commission of the National Council of Teachers of English. New York \& London: D. Appleton-Century Company.

Haugaard, K. (1973). Comic books: Conduits to culture? The Reading Teacher, 27(1), 54-55.

Heaney, M. J. (2007). Graphic Novels: A Sure Bet for Your Library. Collection Building, 26(3), 72-76.

Heinemann, T., Lindström, A., \& Steensig, J. (2011). Addressing Epistemic Incongruence in Question-answer Sequences through the Use of Epistemic Adverbs. In T. Stivers, L. Mondada, \& J. Steensig (Eds.), The Morality of Knowledge in Conversation (pp. 107-130). Cambridge: Cambridge University Press.

Helsby, W. F. (1999). Comics in Education. The Link between Visual and Verbal Literacy: How Readers read Comics. (Doctoral dissertation), University of Southhampton, Southhampton. Retrieved from: https://eprints.soton.ac.uk/194425/1/00110707.pdf

Hepburn, A., \& Potter, J. (2004). Discourse Analytic Practice. In C. Seale, G. Gobo, J. Gubrium, \& D. Silverman (Eds.), Qualitative Research Practice (pp. 180-196). London: Sage.

Hepburn, A., \& Potter, J. (2008). Discursive Constructionism. In J. A. Holstein \& J. F. Gubrium (Eds.), Handbook of Constructionist Research (pp. 275-293). New York: Guilford Press.

Heritage, J. (1987). Ethnomethodology. In A. Giddens \& J. Turner (Eds.), Social Theory Today (pp. 224-272). Cambridge: Polity Press.

Hiebert, E. H. (1991). Introduction. In E. H. Hiebert (Ed.), Literacy for a Diverse Society (pp. 1-6). New York: Teachers College Press.

Hildén, E. (2014). Kommunikation mellan de yngsta förskolebarnen i fri lek. Meningsskapande genom den levda kroppen [Communication between the Youngest Preschool Children in Free Play. Meaning Making through the Lived Body]. (Licentiat dissertation), Karlstad University, Karlstad.

Hollingsworth, S., \& Gallego, M. (1996). Toward a Collaborative Praxis of Multiple Literacies. Curriculum Inquiry, 26(3), 265-292.

Hosler, J., \& Boomer, B. K. (2011). Are Comic Books an Effective Way to Engage Nonmajors in Learning and Appreciating Science? $C B E$ Life Sciences Education, 10(3), 309-317.

Hutchby, I., \& Wooffitt, R. (2008). Conversation Analysis (2 ${ }^{\text {nd }}$ ed). Cambridge: Polity Press. 
Hutchinson, K. H. (1949). An Experiment in the Use of Comics as Instructional Material. The Journal of Educational Sociology, 23(4), 236-245. doi:10.2307/2264559

Inge, T., M. (2017). Origins of Early Comics and Proto-Comics. In F. Bramlett, R. T. Cook, \& A. Meskin (Eds.), The Routledge Companion to Comics (pp. 9-15). New York \& London: Routledge.

Ivarsson, J. (2010). Developing the Construction Sight: Architectural Education and Technological Change. Visual Communication, 9(2), 171-191. doi:10.1177/1470357210369883

Jefferson, G. (2004). Glossary of Transcript Symbols with an Introduction. In G. H. Lerner (Ed.), Conversation Analysis: Studies from the First Generation (pp. 13-31). Amsterdam \& Philadelphia: John Benjamins.

Jewitt, C. (2008). Multimodality and Literacy in School Classrooms. Review of Research in Education, 32, 241-267. doi:10.3102/0091732X07310586

Johnson, K. G., \& Jackson, E. (2017). Drawing a Dialogue [Audio podcast], Episode 1: Comics Defined + The "Reluctant Reader". Retrieved from: http://itunes.apple.com

Jonsson, C. (2006). Läsningens och skrivandets bilder. En analys av villkor och möjligheter för barns läs- och skrivutveckling [The Picture of Reading and Writing. An Analysis of Conditions and Opportunities for Children's Reading and Writing Development]. (Doctoral dissertation), Umeå University, Umeå.

Keevallik, L. (2013). The Interdependence of Bodily Demonstrations and Clausal Syntax. Research on Language and Social Interaction, 46(1), 1-21. doi:10.1080/08351813.2013.753710

Kirsh, S. J., \& Olczak, P. V. (2000). Violent Comic Books and Perceptions of Ambiguous Provocation Situations. Media Psychology, 2(1), 47-62.

Kirsh, S. J., \& Olczak, P. V. (2001). Rating comic book violence: contributions of gender and trait hostility. Social Behavior and Personality, 29(8), 833-836.

Kirsh, S. J., \& Olczak, P. V. (2002). The effects of extremely violent comic books on social information processing. Journal of Interpersonal Violence, 17(11), 1160-1178.

Kirsh, S. J., \& Olczak, P. V. (2003). Comic Book Violence. In F. K. Blucher (Ed.), Perspectives of Violence (pp. 81-92). Hauppage: Nova Science Publishers.

Kress, G. (2003). Literacy in the New Media Age. London: Routledge.

Kress, G. (2010). Multimodality: A Social Semiotic Approach to Contemporary Communication. London \& New York: Routledge. 
Kress, G., \& van Leeuwen, T. (2001). Multimodal Discourse: The Modes and Media of Contemporary Communication. Oxford: Oxford University Press.

Kress, G., \& van Leeuwen, T. (2006). Reading Images: The Grammar of Visual Design ( $2^{\text {nd }}$ ed.). New York: Routledge.

Kukkonen, K. (2013). Studying Comics and Graphic Novels. Chichester: Wiley Blackwell.

Lankshear, C., \& Knobel, M. (2011). New Literacies. Berkshire: McGraw-Hill \& Open University Press.

Laurier, E. (2014). The Graphic Transcript: Poaching Comic Book Grammar for Inscribing the Visual, Spatial and Temporal Aspects of Action. Geography Compass, 8(4), 235-248. doi:10.1111/ gec3.12123

Laycock, D. (2007). Going Graphic: Using Graphic Novels to engage Boys in School Reading. Access (10300155), 21(1), 13-17.

Lee, S. (1993). Introduction. In L. Daniels (Ed.), Marvel: Five Fabulous Decades of the World's Greatest Comics. London: Virgin Books.

Lent, J. A. (2010). The Winding, Pot-holed Road of Comics Art Scholarship. Studies in Comics, 1(1), 7-33.

Lenters, K. (2007). From Storybooks to Games, Comics, Bands, and Chapter Books: A Young Boy's Appropriation of Literacy Practices. Canadian Journal of Education, 30(1), 113-136.

Lerner, G. H. (1995). Turn Design and the Organization of Participation in Instructional Activities. Discourse Processes, 19, 111-131.

Lindwall, O., \& Ivarsson, J. (2010). Differences that make a Difference: Contrasting the Local Enactment of two Technologies in a Kinematics Lab. In S. Ludvigsen, A. Lund, I. Rasmussen, \& R. Säljö (Eds.), Learning Across Sites: New Tools, Infrastructures and Practices (pp. 364-380). London: Routledge.

Lindwall, O., Lindström, B., \& Bernhard, J. (2002). Organizing Time and Space: Technology, Task Structure, and Embodied Inquiry in a Kinematics Lab. In R. Säljö \& J. Linderoth (Eds.),Utm@ningar \& e-frestelser: IT och skolans lärkultur [Ch@llenges \& E-temptations: IT and the Learning Culture of School] (pp. 119-144). Stockholm: Prisma.

Linell, P. (1994). Transkription av tal och samtal: teori och praktik [Transcription of Talk and Conversation: Theory and Practice]. Linköping: Linköping University.

Lonsdale, M., \& McCurry, D. (2004). Literacy in the New Millenium. Adelaide: NCVER/Australian Dep. of Education, Science \& Training. 
Low, D. (2012). "Spaces Invested with Content": Crossing the "Gaps" in Comics with Readers in Schools. Children's Literature in Education, 43(4), 368-385. doi:10.1007/s10583-012-9172-5

Macbeth, D. (2004). The Relevance of Repair for Classroom Correction. Language in Society, 33, 703-736. doi:10.10170S004740 4504045038

Magnusson, H. (2005). Berättande bilder. Svenska tecknade serier för barn [Telling Pictures. Swedish Comic Books for Children]. Göteborg \& Stockholm: Makadam.

Margutti, P., \& Drew, P. (2014). Positive Evaluation of Student Answers in Classroom Instruction. Language and Education, 28(5), 436-458. doi:10.1080/09500782.2014.898650

Marsh, J. (2003). Early Childhood Literacy and Popular Culture. In N. Hall, J. Larson, \& J. Marsh (Eds.), Handbook of Early Childhood Literacy (pp. 112-125). London, Thousand Oaks \& New Delhi: Sage.

McCloud, S. (1993). Understanding Comics: The Invisible Art. New York: William Morrow Paperbacks.

McHoul, A. W. (1978). The Organization of Turns at Formal Talk in the Classroom. Language in Society, 7(2), 183-213.

McHoul, A. W. (1990). The Organization of Repair in Classroom Talk. Language in Society, 19(3), 349-377.

Mehan, H. (1979). Learning Lessons - Social Organization in the Classroom. Cambridge \& London: Harvard University Press.

Melander, H. (2012). Transformations of Knowledge within a Peer Group. Knowing and Learning in Interaction. Learning, Culture and Social Interaction, 1, 232-248. doi:10.1016/j.lcsi.2012.09.003

Melander, H., \& Sahlström, F. (Eds.). (2010). Lärande i interaktion [Learning in Interaction]. Stockholm: Liber.

Merisuo-Storm, T. (2006). Girls and Boys Like to Read and Write Different Texts. Scandinavian Journal of Educational Research, 50(2), 111-125. doi:10.1080/00313830600576039

Meskin, A. (2007). Defining Comics? The Journal of Aesthetics and Art Criticism, 65(4), 369-379.

Meskin, A. (2017). Defining Comics. In F. Bramlett, R. T. Cook, \& A. Meskin (Eds.), The Routledge Companion to Comics (pp. 221-229). New York \& London: Routledge.

Miodrag, H. (2017). Comics and Literature. In F. Bramlett, R. T. Cook, \& A. Meskin (Eds.), The Routledge Companion to Comics (pp. 390398). New York \& London: Routledge.

Mondada, L. (2006). Video Recording as the Reflexive PreservationConfiguration of Phenomenal Features for Analysis. In $\mathrm{H}$. 
Knoblauch, B. Schnettler, J. Raab, \& H.-G. Soeffner (Eds.), Video Analysis: Methodology and Methods (pp. 51-67). Frankfurt am Main: Lang.

Mondada, L. (2007). Commentary: Transcript Variations and the Indexicality of Transcribing Practices. Discourse Studies, 9(6), 809821. doi:10.1177/1461445607082581

Mondada, L. (2014). The Local Constitution of Multimodal Resources for Social Interaction. Journal of Pragmatics, 65, 137-156. doi:10.1016/j.pragma.2014.04.004

Moss, G. (2003). Putting the Text Back into Practice: Junior-age Nonfiction as Objects of Design. In C. Jewitt \& G. Kress (Eds.), Multimodal Literacy (pp. 73-87). New York: Peter Lang.

Nesmith, S., Cooper, S., \& Schwarz, G. (2011). Exploring Graphic Novels for Elementary Science and Mathematics. School Library Media Research, 14.

Nikolajeva, M. (2000). Bilderbokens pusselbitar [The Picture Book's Puzzle Pieces]. Lund: Studentlitteratur.

Nikolajeva, M. (2003). Verbal and Visual Literacy: the Role of Picturebooks in the Reading Experience of Young Children. In N. Hall, J. Larson, \& J. Marsh (Eds.), Handbook of Early Childhood Literacy (pp. 235-248). London, Thousand Oaks \& New Delhi: Sage.

Nodelman, P. (1988). Words About Pictures - The Narrative Art of Children's Picture Books. Athens: University of Georgia Press.

Nodelman, P. (2012). Picture Book Guy Looks at Comics: Structural Differences in Two Kinds of Visual Narrative. Children's Literature Association Quarterly, 37(4), 436-444. doi:10.1353/chq.2012.0049

O'Connell, D. C., \& Kowal, S. (2005). Basic Principles of Transcription. In J. A. Smith, R. Harré, \& L. Van Langenhove (Eds.), Rethinking Methods in Psychology (pp. 93-105). London, Thousand Oaks \& New Delhi: Sage. (Reprinted, 1995).

OECD. (2014). PISA 2012 Results in Focus: What 15-year-olds know and what they can do with what they know. Retrieved from: http://www.oecd.org/pisa/keyfindings/pisa-2012-resultsoverview.pdf

op de Beeck, N. (2012). On Comics-Style Picture Books and PictureBookish Comics. Children's Literature Association Quarterly, 37(4), 468-476. doi:10.1353/chq.2012.0060

Pahl, K., \& Rowsell, J. (Eds.). (2006). Travel Notes from the New Literacy Studies: Instances of Practice. Clevedon: Multilingual Matters. 
Pantaleo, S. (2011a). Grade 7 Students Reading Graphic Novels: 'You Need To Do a Lot of Thinking'. English in Education, 45(2), 113131. doi:10.1111/j.1754-8845.2011.01093.x

Pantaleo, S. (2011b). Middle Years Students' Collaborative Talk about The Red Tree: 'A Book that really works your Mind'. Australian Journal of Language and Literacy, 34(3), 260-278.

Pantaleo, S. (2012a). Exploring Grade 7 Students' Responses to Shaun Tan's "The Red Tree". Children's Literature in Education, 43(1), 5171.

Pantaleo, S. (2012b). Meaning-making with Colour in Multimodal Texts: An 11-year-old Student's Purposeful 'Doing'. Literacy, 46(3), 147155.

Pantaleo, S. (2012c). Middle-School Students Reading and Creating Multimodal Texts: A Case Study. Education 3-13, 40(3), 295-314. doi:10.1080/03004279.2010.531037

Pantaleo, S. (2013). Paneling "Matters" in Elementary Students' Graphic Narratives. Literacy Research and Instruction, 52(2), 150-171. doi:10.1080/19388071.2012.754973

Peplow, D., Swann, J., Trimarco, P., \& Whiteley, S. (2016). The Discourse of Reading Groups: Integrating Cognitive and Sociocultural Perspectives. New York \& London: Routledge.

Platz Cortsen, R. (2012). Comics as Assemblage: How SpatioTemporality in Comics is Constructed. (Doctoral dissertation), University of Copenhagen, Copenhagen.

Postema, B. (2013). Narrative Structures in Comics: Making Sense of Fragments. Rochester: RIT Press.

Potter, J. (1996). Representing Reality - Discourse, Rhetoric and Social Construction. London, Thousand Oaks, \& New Delhi: Sage.

Potter, J. (2000). Post-cognitive Psychology. Theory \& Psychology, 10(1), 31-37.

Potter, J. (2003). Discursive Psychology: between Method and Paradigm. Discourse \& Society, 14(6), 783-794.

Potter, J. (2010). Discursive Psychology and the Study of Naturally Occurring Talk. In D. Silverman (Ed.), Qualitative Analysis: Issues of Theory and Method ( $3^{\text {rd }}$ ed., pp. 187-207). London: Sage.

Potter, J. (2012). Discourse Analysis and Discursive Psychology. In H. Cooper (Ed.), APA Handbook of Research Methods in Psychology: Vol. 2. Quantative, Qualitative, Neuropsychological, and Biological (pp. 119-138). Washington: American Psychological Association Press. 
Potter, J., \& Edwards, D. (1999). Social Representations and Discursive Psychology: From Cognition to Action. Culture and Psychology, 5(4), 447-458.

Potter, J., \& Edwards, D. (2003). Rethinking Cognition: On Coulter on Discourse and Mind. Human Studies, 26, 165-181.

Potter, J., \& Wetherell, M. (1987). Discourse and Social Psychology: Beyond Attitudes and Behaviour. London: Sage.

Potter, J., Stringer, P., \& Wetherell, M. (1984). Social Texts and Context: Literature and Social Psychology. London: Routledge \& Kegan Paul.

Pustz, M. J. (1999). Comic Book Culture: Fanboys and True Believers. Jackson: University Press of Mississippi.

Pustz, M. J. (2017). Comics and Fandom. In F. Bramlett, R. T. Cook, \& A. Meskin (Eds.), The Routledge Companion to Comics (pp. 267274). New York \& London: Routledge.

Ripley, D. (2012). Classroom Comics: Children's Medium and the New Literacy. Interdisciplinary Humanities, 29(1), 99-113.

Robison, C. L. (2011). Review of Teaching Visual Literacy. ImageText Interdisciplinary Comics Studies, 6(1). Retrieved from: http://www.english.ufl.edu/imagetext/archives/v6_1/robison/index.s html

Rollnick, M., Jones, B., Perold, H., \& Bahr, M. A. (1998). Puppets and Comics in Primary Science: The Development and Evaluation of a Pilot Multimedia Package. International Journal of Science Education, 20(5), 533-550.

Rossetto, M., \& Chiera-Macchia, A. (2011). "Visual Learning is the best Learning - it lets you be Creative while Learning": Exploring Ways to begin Guided Writing in Second Language Learning through the Use of Comics. Babel, 45(2-3), 35-40.

Sabeti, S. (2011). The Irony of 'Cool Club': the Place of Comic Book Reading in Schools. Journal of Graphic Novels and Comics, 2(2), 137-149. doi:10.1080/21504857.2011.599402

Sabin, R. (2001). Comics, Comix \& Graphic Novels: A History of Comic Art. London: Phaidon Press.

Sacks, H. (1984). Notes on Methodology. In J. M. Atkinson, J. Heritage, \& G. Jefferson (Eds.), Structures of Social Action (pp. 21-27). Cambridge: Cambridge University Press.

Sacks, H. (1992). Lectures on Conversation [1964-1972]. Oxford: Basil Blackwell.

Sacks, H., Schegloff, E. A., \& Jefferson, G. (1974). A Simplest Systematics for the Organization of Turn-taking for Conversation. Language, 50(4), 696-735. 
Saguisag, L. (2017). Children's Literature and Childhood Studies. In F. Bramlett, R. T. Cook, \& A. Meskin (Eds.), The Routledge Companion to Comics (pp. 433-442). New York \& London: Routledge.

Schegloff, E. A., Jefferson, G., \& Sacks, H. (1977). The Preference for Self-Correction in the Organization of Repair in Conversation. Language, 53(2), 361-382.

Schmidt, J. (2011). Graphic Novels in the Classroom: Curriculum Design, Implementation, and Reflection. English Journal, 100(5), 104-107.

Schwartz, A., \& Rubinstein-Avila, E. (2006). Understanding the Manga Hype: Uncovering the Multimodality of Comic-Book Literacies. Journal of Adolescent \& Adult Literacy, 50(1), 40-49.

Scribner, S., \& Cole, M. (1981). The Psychology of Literacy. Cambridge \& London: Harvard University Press.

SFS. (2003:460). Lag om etikprövning av forskning som avser människor [Act Concerning the Ethical Review of Research Involving Humans]. Stockholm: Department of Education.

Shuman, B. R. (1982). Reading with a Purpose: Strategies to Interest Reluctant Readers. Journal of Reading, 25(8), 725-730.

Simonsson, M. (2004). Bilderboken i förskolan - en utgångspunkt för samspel [Picture Books in the Preschool - an Interactional Perspective]. (Doctoral dissertation), Linköping University, Linköping.

Sipe, L. R., \& Brightman, A. E. (2009). Young Children's Interpretations of Page Breaks in Contemporary Picture Storybooks. Journal of Literacy Research, 41, 68-103. doi:10.1080/10862960802695214

Smith, D. V. (1952). The English Language Arts. New York: AppletonCentury-Crofts.

Snow, C., E., \& Ninio, A. (1986). The Contracts of Literacy: What Children Learn from Learning to Read Books. In W. Teale, H., \& E. Sulzby (Eds.), Emergent Literacy: writing and reading (pp. 116138). Norwood: Ablex Publishing.

Snyder, J. (2010). Applying Multimodal Discourse Analysis to Study Image-enabled Communication. Paper presented at the Proceedings of the iConference 2010, February $3-6$.

Sones, W. W. D. (1944). The Comics and Instructional Method. The Journal of Educational Sociology, 18(4), 232-240. doi:10.2307/ 2262696

SOU. (2012:65). Läsandets kultur [Reading Culture]. Stockholm. Retrieved from: http:/www.regeringen.se/sb/d/108/a/200257. 
Sousanis, N. (2015). Unflattening. Cambridge \& London: Harvard University Press.

Spencer Clark, J. (2013). "Your Credibility Could Be Shot": Preservice Teachers' Thinking about Nonfiction Graphic Novels, Curriculum Decision Making, and Professional Acceptance. Social Studies, 104(1), 38-45. doi:10.1080/00377996.2012.665957

Steward, J. H., \& Folina, F. (2006). Informing Policies in Forensic Settings: A Review of Research Investigating the Effects of Exposure to Media Violence on Challenging/Offending Behaviour. The British Journal of Forensic Practice, 8(2), 31-46.

Stivers, T., \& Sidnell, J. (2005). Introduction: Multimodal interaction. Semiotica, 156(1/4), 1-20.

Stoermer, M. (2010). Teaching Between the Frames: Making Comics with Seven and Eight Year old Children, a Search for Craft and Pedagogy. (Doctoral dissertation), Indiana University, Bloomington.

Stokoe, E. (2003). Mothers, Single Women and Sluts: Gender, Morality and Membership Categorization in Neighbour Disputes. Feminism \& Psychology, 13(3), 317-344.

Street, B. V. (1984). Literacy in Theory and Practice. Cambridge, New York, \& Melbourne: Cambridge University Press.

Street, B. V. (1988). Literacy Practices and Literacy Myths. In R. Säljö (Ed.), The Written World: Studies in Literate Thought and Action (pp. 59-72). Berlin \& Heidelberg: Springer-Verlag.

Street, B. V. (Ed.) (1993). Cross-Cultural Approaches to Literacy. Cambridge: Cambridge University Press.

Street, B. V., Pahl, K., \& Rowsell, J. (2011). Multimodality and New Literacy Studies. In C. Jewitt (Ed.), The Routledge Handbook of Multimodal Analysis (pp. 191-200). New York: Routledge.

Strömberg, F. (2003). Vad är tecknade serier?: en begreppsanalys [What are Comic Books?: An Analysis of Terms]. Malmö: Seriefrämjandet.

Strömberg, F. (2007). Manga! Japanska serier och skaparglädje [Manga! Japanese Comics and Creator's Joy]. Malmö: Seriefrämjandet.

Strömberg, F. (2016). Comics Studies in the Nordic Countries - Field or Discipline? Journal of Graphic Novels and Comics, 7(2), 134-155. doi:10.1080/21504857.2016.1141574

Sutliff Sanders, J. (2013). Chaperoning Words: Meaning-Making in Comics and Picture Books. Children's Literature, 41, 57-90. doi:10.1353/chl.2013.0012

Sutliff Sanders, J. (2016). How Comics Became Kids' Stuff. In M. A. Abate \& J. Sutliff Sanders (Eds.), Good Grief! Children and Comics (pp. 9-28). Columbus: Billy Ireland Cartoon Library \& Museum. 
Swedish National Agency for Education. (2011a). Curriculum for the Compulsory School, Preschool Class and the Recreation Centre. Stockholm: Swedish National Agency for Education. Retrieved from: http://www.skolverket.se/publikationer?id=2687.

Swedish National Agency for Education. (2011b). Kommentarsmaterial till kursplanen $i$ svenska [Commentary for the Curriculum for Swedish]. Stockholm: Swedish National Agency for Education. Retrieved from: http://www.skolverket.se/publikationer?id=2567.

Swedish Research Council. (2011). Good Research Practice. Stockholm: Swedish Research Council. Retrieved from: http://www.vr.se/ download/18.3a36c20d133af0c1295800030/1321519981391/Good+ Research+Practice+3.2011 webb.pdf.

Syma, C. K., \& Weiner, R. G. (Eds.). (2013). Graphic Novels and Comics in the Classroom. Jefferson: McFarland.

Tabachnick, S. E. (Ed.) (2009). Teaching the Graphic Novel. New York: MLA.

Teale, W., H., \& Sulzby, E. (1986). Introduction: Emergent Literacy as a Perspective for Examining How Young Children Become Writers and Readers. In W. Teale, H., \& E. Sulzby (Eds.), Emergent Literacy: writing and reading (pp. vii-xxv). Norwood: Ablex Publishing.

ten Have, P. (1990). Methodological Issues in Conversation Analysis. Bulletin de Méthodologie Sociologique, 27(1), 23-51.

The New London Group. (1996). A Pedagogy of Multiliteracies: Designing Social Futures. Harvard Educational Review, 66(1), 6092.

The Swedish Institute for Children's Books. (2016). Bokprovning på Svenska barnboksinstitutet: En dokumentation [Book tests at the Swedish Institute for Children's Books: A Documentation]. Stockholm: The Swedish Institute for Children's Books. Retrieved from: http://www.sbi.kb.se/Bilder/bokprovning 2016/Bokprovning Argang_2015.pdf.

Thomas, P. L. (2011). Adventures in Genre!: Rethinking Genre through Comics/Graphic Novels. Journal of Graphic Novels and Comics, 2(2), 187-201. doi:10.1080/21504857.2011.633090

Thompson, T. (2008). Adventures in Graphica. Portland: Stenhouse Publishers.

Thrasher, F. M. (1949). The Comics and Delinquency: Cause or Scapegoat. The Journal of Educational Sociology, 23(4), 195-205. doi:10.2307/2264555 
Tilley, C. L. (2012). Seducing the Innocent: Fredric Wertham and the Falsifications That Helped Condemn Comics. Information \& Culture, 47(4), 383-413. doi:10.1353/lac.2012.0024

Tilley, C. L. (2013). Using Comics to Teach the Language Arts in the 1940s and 1950s. In C. K. Syma \& R. G. Weiner (Eds.), Graphic Novels and Comics in the Classroom: Essays on the educational power of sequential art (pp. 12-22). Jefferson: McFarland.

Tilley, C. L., \& Weiner, R. G. (2017). Teaching and Learning with Comics. In F. Bramlett, R. T. Cook, \& A. Meskin (Eds.), The Routledge Companion to Comics (pp. 358-366). New York \& London: Routledge.

Ujiie, J., \& Krashen, S. D. (1996). Comic Book Reading, Reading Enjoyment, and Pleasure Reading among Middle Class and Chapter I Middle School Students. Reading Improvement, 33(1), 51-54.

Versaci, R. (2001). How Comic Books Can Change the Way Our Students See Literature: One Teacher's Perspective. The English Journal, 91(2), 61-67.

Versaci, R. (2008). "Literary Literacy" and the Role of the Comic Book. In N. Frey \& D. Fisher (Eds.), Teaching Visual Literacy: Using Comic Books, Graphic Novels, Anime, Cartoons, and more to Develop Comprehension and Thinking Skills (pp. 91-111). Thousand Oaks: Corwin Press.

Wallin, J., \& Blomgren, A. (2016). Skalmans flygmaskin [Skalman's Flying Machine]. In C. Borelius (Ed.), Bamse för de yngsta [Bamse for the Youngest] (No. 8). Malmö: Egmont Publishing.

Wallner, L. (2017). Speak of the Bubble - Constructing Comic Book Bubbles as Literary Devices in a Primary School Classroom. Journal of Graphic Novels and Comics, 8(2), 173-192. doi:10.1080/ 21504857.2016.1270221

Warnqvist, Å. (2012). Dragonball, LasseMaja och Twilight: Utgivningen av barn- och ungdomslitteratur i Sverige 2001-2010 [Dragonball, LasseMaja and Twilight: The Publication of Children's and Youth Literature in Sweden 2001-2010]. In U. Carlsson \& J. Johannisson (Eds.), Läsarnas marknad, marknadens läsare - en forskningsantologi [The Readers' Market, the Market's Readers - A Research Anthology] (pp. 329-361). Stockholm: Litteraturutredningen.

Wertham, F. (1954). Seduction of the Innocent. New York: Rinehart \& Company.

Westin, B. (1993). Mission impossible - barnlitteraturforskningens dilemma [Mission Impossible - The Dilemma of Research on Children's Literature]. In B. Westin, J. Fornäs, S. Svensson, \& M. 
Nikolajeva (Eds.), Läsebok. En festskrift till Ulf Boëthius [Reading Book. A Miscellany in Honour of Ulf Boëthius] (pp. 15-26). Stockholm/Stenhag: Brutus Östlings Bokförlag Symposion.

Westin, B. (2002). Vad är barnlitteraturforskning? [What is Research on Children's Literature?]. In S. Bergsten (Ed.), Litteraturvetenskap - en inledning [Literary Science - An Introduction] (2 ${ }^{\text {nd }}$ ed., pp. 129-142). Lund: Studentlitteratur.

Wiggins, S. (2017). Discursive Psychology: Theory, Method and Applications. London: Sage.

Wiggins, S., \& Potter, J. (2007). Discursive Psychology. In C. Willig \& W. Stainton-Rogers (Eds.), The SAGE Handbook of Qualitative Research in Psychology (pp. 73-90). Los Angeles: Sage.

Williams, I. C. M. (2012). Graphic Medicine: Comics as Medical Narrative. Medical Humanities, 38(1), 21-27.

Williams, N. (1995). The Comic Book as Course Book: Why and How. Paper presented at the Annual Meeting of the Teachers of English to Speakers of Other Languages, Long Beach, CA. Mar. 26 - Apr. 1.

Wilson, V. (2009). Boys are Reading, but their Choices are not Valued by Teachers and Librarians. Evidence Based Library \& Information Practice, 4(3), 46-48. doi:10.18438/B8H91W

Wittgenstein, L. (1981). Philosophical Investigations (G. E. M. Anscombe, Trans.). Oxford: Basil Blackwell.

Witty, P. (1941a). Children's Interest in Reading the Comics. The Journal of Experimental Education, 10(2), 100-104. doi:10.1080/00220973. 1941.11010239

Witty, P. (1941b). Reading the Comics - A Comparative Study. The Journal of Experimental Education, 10(2), 105-109. doi:10.1080/ 00220973.1941 .11010240

Wolk, D. (2007). Reading Comics - How Graphic Novels Work and What They Mean. Cambridge: Da Capo Press.

Wooffitt, R. (2005). Conversation Analysis and Discourse Analysis: A Comparative and Critical Introduction. London: Sage.

Wright, B. W. (2001). Comic Book Nation: the Transformation of Youth Culture in America. Baltimore: John Hopkins University Press.

Wright, G. (1979). The Comic Strip in the Classroom for the Reluctant Disabled Reader. Reading Improvement, 16(1), 13-17.

Yang, G. L. (2003). Comics in Education. Retrieved from: http://geneyang.com/comicsedu/index.html

Yannicopoulou, A. (2004). Visual Aspects of Written Texts: Preschoolers View Comics. L1 - Educational Studies in Language and Literature, 4, 169-181. 



\section{Publications Included in the Thesis}

Paper I: Kid Friendly? Construction of Comics Literacy in the Classroom

(Wallner, L. Submitted, 2017-09-04)

Paper II: Gutter Talk: Co-constructing Narratives Using Comics in the Classroom

(Wallner, L. Re-submitted after review 2017-09-28).

Paper III: Speak of the Bubble: Constructing Comic Book Bubbles as Literary Devices in the Primary Classroom

Wallner, L. (2017). Journal of Graphic Novels and Comics, 8(2), 173-192. doi:10.1080/21504857.2016.1270221 


\section{Papers}

The papers associated with this thesis have been removed for copyright reasons. For more details about these see:

http:// urn.kb.se/ resolve?urn=urn:nbn:se:liu:diva-142067 


\section{LINKÖPING STUDIES IN PEDAGOGIC PRACTICES}

1. MARKSTRÖM, ANNE-MARIE. Förskolan som normaliseringspraktik. En etnografisk studie. 2005. ISBN 91-85297-70-4.

2. WEDIN ANN-SOFI, Lärares arbete och kunskapsbildning. Utmaningar och inviter i den vardagliga praktiken. 2007. ISBN 978-91-85715-63-3.

3. BRÜDE SUNDIN, JOSEFIN. En riktig rektor. Om ledarskap, genus och skolkulturer. 2007. ISBN 978-91-85715-62-6.

4. HELLBERG, KRISTINA. Elever på ett anpassat individuellt gymnasieprogram: skolvardag och vändpunkter. 2007. ISBN 978-91-85831-92-0.

5. SPARRLÖF, GÖRAN. Vi manliga lärare Folkskolans lärare och lärarinnor i kamp om löner och arbetsvillkor 1920-1963. 2007. ISBN 978-91-85831-38-8.

6. KARLSSON, YVONNE. Att inte vilja vara problem - social organisering och utvärdering av elever i en särskild undervisningsgrupp. 2008. ISBN 978-91-85895-28-1.

7. OLSON, MARIA. Från nationsbyggare till global marknadsnomad. Om medborgarskapet i svensk utbildningspolitik under 1990-talet. 2008. ISBN 978-91-7393-890-7.

8. AYTON, KATARINA. An ordinary school child: Agency and authority in children's schooling. 2008. ISBN 978-91-7393-834-1.

9. BOLANDER, EVA. Risk och bejakande. Sexualitet och genus i sexualupplysning och undervisning i TV. 2009. ISBN 978-91-7393-685-9.

10. JOHNSSON HARRIE, ANNA. Staten och läromedlen. En studie av den svenska statliga förhandsgranskningen av läromedel 1938-1991. 2009. ISBN 978-91-7393-616-3.

11. HÖGBERG, RONNY. Motstånd och konformitet. Om manliga yrkeselevers liv och identitetsskapande i relation till kärnämnena. 2009. ISBN 978-91-7393-543-2.

12. HEGENDER, HENRIK. Mellan akademi och profession. Hur lärarkunskap formuleras och bedöms i verksamhetsförlagd lärarutbildning. 2010. ISBN 978-91-7393-526-5.

13. SEVERINSSON, SUSANNE. Unga i normalitetens gränsland: Undervisning och behandling $\mathrm{i}$ särskilda undervisningsgrupper och hem för vård eller boende. 2010. ISBN 978-91-7393-402-2.

14. WIDÈN, PÄR. Bedömningsmakten. Berättelser om stat, lärare och elev, 1960-1995. 2010. ISBN 978-91-7393-372-8.

15. SANDLUND, MONICA. Lärare med utländsk bakgrund. Sju yrkeslivsberättelser om möten med nya skolsammanhang. 2010. ISBN 978-91-7393-371-1.

16. LILJA, PATRIK. Contextualizing inquiry. Negotiations of tasks, tools and actions in an upper secondary classroom. 2012. ISBN 978-91-7346-735-3

17. FREDRIKSSON, KRISTINA (Licentiatavhandling). Drama som pedagogisk möjlighet. En intervjustudie med lärare i grundskolan. 2013. ISBN 978-91-7519-613-8 
18. BENGTSSON, JENNY. Jag sa att jag älskade han men jag har redan sagt förlåt för det. Ålder, genus och sexualitet i skolans tidigare år. 2013. ISBN 978-91-7519-560-5

19. SÖDERMAN LAGO, LINA. "Mellanklass kan man kalla det": Om tid och meningsskapande vid övergången från förskoleklass till årskurs ett. 2014. ISBN 978-91-7519-349-6

20. STENLIDEN, LINNÉA. Visual Storytelling Interacting in School. 2014. ISBN: 978-91-7519-338-0

21. ELFSTRÖM PETERSSON, KATARINA (Licentiatavhandling). Playing a part in preschool documentation - A study of how participation is enacted preschool documentation practices and how it is affected by material agents. 2014. ISBN: 978-91-7519-339-7

22. DALGREN, SARA (Licentiatavhandling). Förskolans pedagogiska praktik som interaktion. Frågor och svar i vardagliga förskoleaktiviteter. 2014. ISBN: 978-91-7519-262-8

23. HJORT, SIMON (Licentiatavhandling). Kritiskt tänkande i klassrummet. En studie av didaktiska val och manifesterat kritiskt tänkande i samhällskunskaps- och filosofiundervisning. 2014. ISBN: 97891-7519-166-9

24. BOO, SOFIA (Licentiatavhandling). Lärares arbete med individanpassning. Strategier och dilemman i Klassrummet. 2014. ISBN: 978-91-7519-157-7

25. JOHANSSON, MARITHA. Läsa, förstå, analysera. En komparativ studie om svenska och franska gymnasieelevers reception av en narrativ text. 2015. ISBN: 978-91-7685-964-3

26. NORBURG, ULRIKA. Fängelse, skola uppfostringsanstalt eller skyddshem? Åkerbrukskolonien Hall för pojkar år 1876-1940. 2015. ISBN: 978-91-7685980-3

27 ALBINSSON, ANDERS. "De var svinhögt typ 250 kilo". Förskolebarns mätande av längd, volym och tid i legoleken. 2016. ISBN: 978-91-7685-828-8

28 WINZELL, HELEN (Licentiatavhandling). Svensklärares skrivdidaktiska kunskapsbildning: Blivande och tidigt verksamma gymnasielärare i svenska talar om skrivundervisning. 2016. ISBN: 978-91-7685-788-5

29 BODÉN, LINNEA. Present absences. Exploring the posthumanist entanglements of school absenteeism. 2016. ISBN: 978-91-7685-722-9

30 DALGREN, SARA. Att göra pedagogisk praktik tillsammans: Socialt samspel i förskolans vardag. 2017. ISBN: 978-91-7685-593-5

31 ELFSTRÖM PETTERSSON, KATARINA. Productions and Products of Preschool. Documentation. Entanglements of children, things, and templates. 2017. ISBN: 978-91-7685-553-9

32 HARLING, MARTIN. Välja vara. En studie om gymnasieval, mässor och kampen om framtiden. 2017. ISBN: 978-91-7685-549-2

33 MARTÍN-BYLUND, ANNA. Towards a minor bilingualism: Exploring variations of language and literacy with early childhood education. 2017. ISBN: 978-91-7685-478-5 


\section{Skrifter utgivna av Svenska barnboksinstitutet}

Studies published by the Swedish Institute for Children's Books ISSN 0347-5387

Tidigare titlar, se www.sbi.kb.se

116 Paulin, Lotta: Den didaktiska fiktionen. Konstruktion av förebilder ur ett barn- och ungdomslitterärt perspektiv 1400-1750. Stockholm: Acta Universitatis Stockholmiensis, 2012. Diss. Stockholm.

117 Till en evakuerad igelkott. Festskrift till Maria Nikolajeva. Red. Maria Lassén-Seger \& Mia Österlund. Göteborg \& Stockholm: Makadam, 2012.

118 Bengtsson, Lars: Bildbibliografi över Astrid Lindgrens skrifter 1921-2010. Lidingö: Salikon förlag, 2012.

119 Barnlitteraturens värden och värderingar. Red. Sara Kärrholm \& Paul Tenngart. Lund: Studentlitteratur, 2012.

120 Pålsson, Yvonne: I Skinnstrumpas spår. Svenska barn- och ungdomsböcker om indianer, 1860- 2008. Umeå: Institutionen för kultur- och medievetenskaper, Umeå universitet. Diss. Umeå, 2013.

121 Lindskog, Gerda Helena: Norrbarn. Norrland i 1900-talets svenskspråkiga barn- och ungdomslitteratur. Umeå: h:ström - Text \& Kultur, 2013.

122 En fanfar för bilderboken! Red. Lena Eriksson, Ulla Rhedin \& Oscar K. Stockholm: Alfabeta/Nordiska akvarellmuseet, 2013.

123 Flicktion. Perspektiv på flickan i fiktionen. Red. Bodil Formark, Eva Söderberg \& Mia Österlund. Malmö: Universus Academic Press, 2013.

124 Druker, Elina: Eva Billow. Bilderbokskonstnär och författare. Göteborg \& Stockholm: Makadam, 2014.

125 Emanuelsson, Lars \& Ekman, Oskar: Gustaf Tenggren - en biografi. Stockholm: Kartago, 2014.

126 Andersen, Jens: Denna dagen, ett liv. En biografi över Astrid Lindgren. Stockholm: Norstedts, 2014.

127 Kalejdoskopiska läsningar. Vänbok till Janina Orlov. Red. Maria Andersson, Elina Druker, Maria Lassén-Seger \& Mia Österlund. Åbo: Juvenes Print, 2015.

128 Axell, Cecilia, Barnlitteraturens tekniklandskap. En didaktisk vandring från Nils Holgersson till Pettson och Findus. Linköping: Linköpings universitet, 2015. Diss. Norrköping.

129 Widhe, Olle: Dö din hund! Krig, lek och läsning $i$ svensk barnboksutgivning under 200 år, Lund: ellerströms, 2015.

130 Törnqvist, Lena: Man tar vanliga ord. Att läsa om Astrid Lindgren. Lidingö: Salikon, 2015. 
131 Boglind, Ann \& Nordenstam, Anna: Från fabler till manga 1. Litteraturhistoriska och didaktiska perspektiv på barnlitteratur. Malmö: Gleerups, 2015.

132 Boglind, Ann \& Nordenstam, Anna: Från fabler till manga 2. Litteraturhistoriska och didaktiska perspektiv på ungdomslitteratur. Malmö: Gleerups, 2016.

133 Kulla-Gulla och alla de andra. Martha Sandwall-Bergström 100 år. Red. Helene Ehriander \& Eva Söderberg. Växjö: Linnaeus University Press, 2015.

134 Nya läsningar av Astrid Lindgrens författarskap. Red. Helene Ehriander \& Martin Hellström. Stockholm: Liber, 2015.

135 Hellström, Martin: Pippi på scen. Astrid Lindgren och teatern. Göteborg \& Stockholm: Makadam, 2015.

136 Räder, Andréa: Bröderna Grimm. En biografi. Göteborg: Tvilling, 2016.

137 Alkestrand, Malin: Magiska möjligheter. Harry Potter, Artemis Fowl och Cirkeln $i$ skolans värdegrundsarbete. Göteborg \& Stockholm: Makadam, 2016. Diss. Stockholm.

138 Mångkulturell barn- och ungdomslitteratur. Analyser. Red. Maria Andersson \& Elina Druker. Lund: Studentlitteratur, 2017.

139 Öhrn, Magnus: Pojklandet. Pojken i svensk barn- och ungdomslitteratur, Stockholm: CKM Förlag, 2017.

140 Samtida svensk ungdomslitteratur. Analyser. Red. Åsa Warnqvist. Lund: Studentlitteratur, 2017.

141 Wistisen, Lydia: Gångtunneln. Urbana erfarenheter i svensk ungdomslitteratur 18902010. Lund: ellerströms, 2017. Diss. Stockholm.

142 Choi, Sun-Kyoung: Kraften att älska, makten att tjäna. Religion, emancipation och den kvinnliga skapande kraften i Jeanna Oterdahls sagor 1908-1927. Umeå: Två Förläggare Bokförlag, 2017. Diss. Umeå.

143 Theander, Birgitta: Till arbetet! Yrkesdrömmar och arbetsliv i flickboken 1920-65. Göteborg \& Stockholm: Makadam, 2017.

144 Wallner, Lars: Framing Education: Doing Comics Literacy in the Classroom. Linköping: Linköpings universitet, 2017. Diss. Linköping. 